\title{
Bioactive Flavonoids and Triterpenes from Terminalia fagifolia (Combretaceae)
}

\author{
Fernanda R. Garcez, ${ }^{*, a}$ Walmir S. Garcez, ${ }^{a}$ Andréa L. B. D. Santana, ${ }^{a}$ Milene M. Alves, ${ }^{a}$ \\ Maria de Fátima C. Matos ${ }^{b}$ and Anne de M. Scaliante ${ }^{a}$ \\ ${ }^{a}$ Departamento de Química and ${ }^{b}$ Departamento de Farmácia-Bioquímica, Universidade Federal de \\ Mato Grosso do Sul, 79070-900 Campo Grande-MS, Brazil
}

\begin{abstract}
Da madeira e das cascas do caule de Terminalia fagifolia foram isolados dois 1,3-diarilpropanos, 1-(4'-hidróxi-2'-metóxifenil)-3-(3"'-metóxi-4"'-hidróxifenil)-propano e 1-(2'-hidróxi-4',6'dimetóxifenil)-3-(3"'-metóxi-4"'-hidróxifenil)-propano, sete flavanonas, naringenina, 5-hidróxi-4',7dimetóxiflavanona, sakuranetina, isosakuranetina, 7,4'-dimetóxiflavanona, 7-hidróxi-4'metóxiflavanona, 7-metóxi-4'-hidróxiflavanona, duas chalconas, 2',4'-diidroxi-4-metóxichalcona e 2'-4-diidroxi-4'-metóxichalcona, uma flavana, 7,4'-diidróxi-3'-metóxiflavana e nove triterpenos pentacíclicos, ácido arjúnico, arjunetina, arjungenina, arjunglucosídeo I, ácido arjunólico, arjunglucosídeo II, 23-galoilarjunglucosídeo (isolado como seus derivados mono-, di- e trimetilados após metilação com diazometano), ácido betulínico e acetato do ácido ursólico, além de ácido gálico e sitosterol. Os diarilpropanos representam os primeiros membros desta classe em Combretaceae e as flavanonas e chalconas estão sendo descritas pela primeira vez na família. As

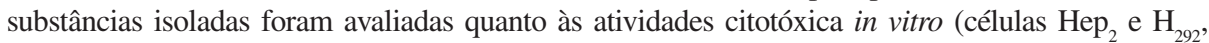
carcinomas de laringe e mucoepidermóide de pulmão humanos, respectivamente) e antioxidante. As chalconas, o diarilpropano 1-(2'-hidróxi-4',6'-dimetóxifenil)-3-(3"--metóxi-4"-hidróxifenil)propano e os derivados di- e tri-metilados de 23-galoilarjunglucosídeo foram os mais ativos quanto à atividade citotóxica.
\end{abstract}

Two 1,3-diarylpropanes, 1-(4'-hydroxy-2'-methoxyphenyl)-3-(3"'-methoxy-4"'hydroxyphenyl)-propane and 1-(2'-hydroxy-4',6'-dimethoxyphenyl)-3-(3'--methoxy-4"'hydroxyphenyl)-propane, seven flavanones, naringenin, naringenin-4',7-dimethyl-ether, sakuranetin, isosakuranetin, liquiritigenin-4',7-dimethyl-ether, liquiritigenin-7-methyl-ether and liquiritigenin-4'-methyl-ether, two chalcones, isoliquiritigenin-4-methyl-ether and isoliquiritigenin-4'-methyl-ether, one flavan, 7,4'-dihydroxy-3'-methoxyflavan, nine triterpenes, arjunic acid, arjunetin, arjungenin, arjunglucoside I, arjunolic acid, arjunglucoside II, 23galloylarjunglucoside II (isolated as its mono-, di- and tri- $O$-methyl derivatives after methylation with diazomethane), betulinic acid and ursolic acid acetate, along with gallic acid and sitosterol were isolated from the heartwood and trunk bark of of Terminalia fagifolia. The flavanones and chalcones obtained in the present work are new in the Combretaceae and this is the first report of the occurrence of 1,3-diarylpropanes in this family. The isolated compounds were evaluated for their in vitro cytotoxic activity against two human cancer cell lines (Hep larynx carcinoma and $\mathrm{H}_{292}$ lung mucoepidermoid carcinoma) and antioxidant properties. Isoliquiritigenin-4-methylether, isoliquiritigenin-4' -methyl-ether, 1-(2'-hydroxy-4',6'-dimethoxyphenyl)-3-(3''-methoxy4 "'-hydroxyphenyl)-propane and the di- and tri- $O$-methyl derivatives of 23 -galloylarjunglucoside II were the most active in the cytotoxic assay.

Keywords: Terminalia fagifolia, Combretaceae, diarylpropanes, cytotoxic activity, antioxidant activity

\section{Introduction}

Terminalia fagifolia Mart. \& Zucc. (Combretaceae), popularly known as "cachaporra do gentio" and

*e-mail: frgarcez@nin.ufms.br "capitão do seco", is a tree found in the "cerrado" of Mato Grosso do Sul, Brazil and in the Brazilian folk medicine the trunk bark is used for the treatment of tumors and aphthas. ${ }^{1}$ To date, no phytochemical or biological studies on this species have been reported. 
In a continuation of our study on constituents of plants of the Terminalia genus which occur in the central-western region of Brazil, ${ }^{2,3}$ we have examined the composition of the ethanol extracts from the heartwood and the trunk bark of $T$. fagifolia. Herein we describe the isolation and structural identification of twelve flavonoids, comprising seven flavanones (1-7), one flavan (8), two chalcones (9 and 10), two diarylpropanes (11 and 12) and nine pentacyclic triterpenes (13-21), in addition to gallic acid and sitosterol. The flavanones and chalcones are new in the Combretaceae. To date, diarylpropanes were mostly reported in members of the Myristicaceae and this is the first report for their occurrence in the Combretaceae family.

The structural elucidation of these isolates was established on the basis of 1D and 2D NMR spectroscopic techniques.

The evaluation of the in vitro cytotoxic activities of sixteen compounds against two human cancer cell lines $\left(\mathrm{Hep}_{2}\right.$ and $\left.\mathrm{H}_{292}\right)$, as well as the antioxidative properties of eighteen isolated compounds are also reported.

\section{Results and Discussion}

After a series of partition procedures and a combination of column chromatography separations of the ethanol extracts from the heartwood and trunk bark, twelve flavonoids (1-12) and nine triterpenoids (13-21) were isolated, together with gallic acid (22) and sitosterol (23).

Compounds 1-7 are known flavanones and identified as naringenin-4',7-dimethyl-ether, ${ }^{4}$ isosakuranetin (naringenin-4'-methyl-ether), ${ }^{5}$ naringenin, ${ }^{6}$ liquiritigenin4',7-dimethyl-ether (7,4'-dimethoxyflavanone), ${ }^{7,8}$ liquiritigenin-4'-methyl-ether, ${ }^{9}$ liquiritigenin-7-methylether ${ }^{8,9}$ and sakuranetin, ${ }^{10}$ respectively, which have not been described in the Combretaceae yet. Since the ${ }^{13} \mathrm{C}$ NMR data of $\mathbf{5}$ have not been reported, the carbon signals of this compound were assigned and are listed in Table 1.

Compound 8, identified as 7,4'-dihydroxy-3' methoxyflavan, was previously isolated from T. argentea. ${ }^{3}$ Beyond 8, only two flavans have been obtained from members of this genus. ${ }^{11}$

The isomeric chalcones $\mathbf{9}$ and $\mathbf{1 0}$ differed only by the hydroxyl or methoxyl groups at C-4 and C-4' and were identified as 2',4'-dihydroxy-4-methoxychalcone (isoliquiritigenin-4-methyl-ether) ${ }^{9}$ and 2',4-dihydroxy-4'methoxychalcone (isoliquiritigenin-4'-methyl-ether), ${ }^{8,12}$ respectively, which had not been previously isolated from any member of the Combretaceae. The occurrence of flavanones and chalcones in a Terminalia species is of particular interest since to date only four flavanones and one chalcone have been isolated from Terminalia species. ${ }^{13}$
Compounds $\mathbf{1 1}$ and $\mathbf{1 2}$ were identified as the diarylpropanes 1-(4'-hydroxy-2'-methoxyphenyl)-3-(3"'methoxy-4"-hydroxyphenyl)-propane, also known as virolane (11) and 1-(2'-hydroxy-4',6'-dimethoxyphenyl)3-(3"-methoxy-4"-hydroxyphenyl)-propane (12). ${ }^{14}$ Although the presence of diarylpropanes is, with very few exceptions, restricted to members of the Myristicaceae family, this is the first report of the occurrence of this class of compounds in the Combretaceae. With regard to the spectroscopic NMR properties of $\mathbf{1 1}$ and $\mathbf{1 2}$ only ${ }^{1} \mathrm{H}$ data have been reported and to date no ${ }^{13} \mathrm{C}$ NMR values are available for these compounds. In the present study, several $1 \mathrm{D}$ and $2 \mathrm{D}$ NMR data, including those from ${ }^{1} \mathrm{H}$ ${ }^{1} \mathrm{H}$ COSY, NOESY, HMQC and HMBC experiments, were assigned accordingly for all carbon resonances of $\mathbf{1 1}$ and 12 (Table 1).

Table 1. ${ }^{13} \mathrm{C}(75 \mathrm{MHz}) \mathrm{NMR}$ spectral data for $\mathbf{5 , 1 1}$ and $\mathbf{1 2}\left(\delta, \mathrm{CDCl}_{3}\right)$

\begin{tabular}{lccc}
\hline $\mathbf{C}$ & 5 & 11 & 12 \\
\hline 1 & - & 134.7 & 134.6 \\
2 & 79.9 & 111.0 & 110.9 \\
3 & 44.1 & 146.2 & 146.3 \\
4 & 191.0 & 143.4 & 143.5 \\
5 & 129.4 & 114.0 & 114.1 \\
6 & 110.5 & 120.9 & 120.9 \\
7 & 164.0 & - & - \\
8 & 103.4 & - & - \\
9 & 162.5 & - & - \\
10 & 115.1 & - & - \\
$1{ }^{\prime}$ & 130.7 & 123.0 & 108.9 \\
2 & 127.7 & 158.5 & 154.7 \\
3, & 114.2 & 98.8 & 93.3 \\
4 & 160.0 & 154.8 & 159.0 \\
5 & 114.2 & 106.3 & 91.3 \\
6 & 127.7 & 130.1 & 159.2 \\
$\alpha$ & - & 31.8 & 30.9 \\
$\beta$ & - & 35.3 & 35.3 \\
$\beta$ & - & 29.2 & 22.2 \\
OMe-2' & - & 55.3 & \\
OMe-4' & 55.4 & - & 55.6 \\
OMe-6' & - & - & 55.3 \\
OMe-3 & - & 55.9 & 55.8 \\
\hline Ass & - & &
\end{tabular}

Assignments confirmed by HMQC, HMBC and NOESY experiments.

Compounds 13-18 and 20, known pentacyclic triterpenes whose occurrence is not uncommon in the genus Terminalia, were identified as arjunic acid, arjunetin, arjungenin, arjunglucoside I, arjunolic acid, arjunglucoside II and betulinic acid, respectively, and their corresponding NMR spectral data were in full agreement with those reported in the literature. ${ }^{15,16} 23$-Galloylarjunglucoside II (19) has been formerly obtained solely from $T$. macroptera $^{17}$ and in the present work it was isolated and characterized after methylation with diazomethane as its mono-, di- and tri- $O$-methyl derivatives 23-(4"- $O$-methyl)-galloylarjunglucoside II (19a), 23-(3",4"'-di-O-methyl)-galloylarjun- 
glucoside II (19b) and 23-(3",4",5"-tri- $O$-methyl)galloylarjunglucoside II (19c). The carbon signals of 19a$19 \mathrm{c}$ were very similar to those of $\mathbf{1 9}$, except for the signals attributable to the galloyl moiety, which were consistent with the presence of methoxy groups at C-4" in 19a, C-3" and C-4" in 19b and C-3", C-4" and C-5" in 19c, as shown in Table 2. Compound $\mathbf{2 1}$ was identified as ursolic acid acetate $^{15}$ and in spite of the wide distribution of this

Table $2 .{ }^{13} \mathrm{C}(75 \mathrm{MHz}) \mathrm{NMR}$ spectral data for 19, 19a, 19b and 19c $(\delta$, Py- $d_{5}$ )

\begin{tabular}{|c|c|c|c|c|}
\hline C & $19^{17}$ & $19 a^{*}$ & $19 b^{*}$ & $19 \mathrm{c} *$ \\
\hline 1 & 47.8 & 47.6 & 47.7 & 48.0 \\
\hline 2 & 68.3 & 68.2 & 68.2 & 68.3 \\
\hline 3 & 77.6 & 77.5 & 77.3 & 77.3 \\
\hline 4 & 43.2 & 43.1 & 43.0 & 43.1 \\
\hline 5 & 48.9 & 48.8 & 48.7 & 48.7 \\
\hline 6 & 18.8 & 18.6 & 18.5 & 18.5 \\
\hline 7 & 32.9 & 32.7 & 32.7 & 32.9 \\
\hline 8 & 39.9 & 39.8 & 39.8 & 39.9 \\
\hline 9 & 48.5 & 48.4 & 48.4 & 48.5 \\
\hline 10 & 38.2 & 38.1 & 38.1 & 38.2 \\
\hline 11 & 23.9 & 23.8 & 23.7 & 23.8 \\
\hline 12 & 122.2 & 122.4 & 122.4 & 122.6 \\
\hline 13 & 144.2 & 144.0 & 143.9 & 144.0 \\
\hline 14 & 42.1 & 42.0 & 41.9 & 41.9 \\
\hline 15 & 28.0 & 27.9 & 27.8 & 27.9 \\
\hline 16 & 23.4 & 23.2 & 23.1 & 23.1 \\
\hline 17 & 47.0 & 46.9 & 46.8 & 46.8 \\
\hline 18 & 41.8 & 41.7 & 41.5 & 41.5 \\
\hline 19 & 46.2 & 46.0 & 45.9 & 46.0 \\
\hline 20 & 30.7 & 30.6 & 30.5 & 30.6 \\
\hline 21 & 34.0 & 33.8 & 33.7 & 33.7 \\
\hline 22 & 32.5 & 32.3 & 32.2 & 32.3 \\
\hline 23 & 67.0 & 67.2 & 67.6 & 66.9 \\
\hline 24 & 14.0 & 13.8 & 13.7 & 13.8 \\
\hline 25 & 17.3 & $17.4^{\mathrm{a}}$ & $17.3^{\mathrm{b}}$ & $17.3^{\mathrm{c}}$ \\
\hline 26 & 17.6 & $17.1^{\mathrm{a}}$ & $17.1^{\mathrm{b}}$ & $17.2^{\mathrm{c}}$ \\
\hline 27 & 25.9 & 25.7 & 25.7 & 25.6 \\
\hline 28 & 176.5 & 176.4 & 176.4 & 176.4 \\
\hline 29 & 33.1 & 32.9 & 32.8 & 32.9 \\
\hline 30 & 23.6 & 23.5 & 23.4 & 23.5 \\
\hline \multicolumn{5}{|c|}{ Glucose moiety } \\
\hline 1 ' & 95.7 & 95.6 & 95.5 & 95.5 \\
\hline $2^{\prime}$ & 74.0 & 73.9 & 73.8 & 73.9 \\
\hline 3' & 78.8 & 78.7 & 78.6 & 78.7 \\
\hline $4^{\prime}$ & 71.0 & 70.9 & 70.9 & 70.9 \\
\hline 5 , & 79.3 & 79.2 & 79.1 & 79.1 \\
\hline 6 & 62.2 & 62.1 & 62.0 & 62.0 \\
\hline \multicolumn{5}{|c|}{ Galloyl moiety } \\
\hline $1 ”$ & 121.5 & 122.6 & 126.3 & 125.9 \\
\hline $2 "$ & 110.0 & 109.8 & 104.9 & 107.1 \\
\hline $3 "$ & 147.5 & 152.3 & 153.6 & 153.5 \\
\hline $4 "$ & 140.7 & 141.3 & 141.7 & 142.8 \\
\hline $5 "$ & 147.5 & 152.3 & 152.0 & 153.5 \\
\hline $6 "$ & 110.0 & 109.8 & 111.9 & 107.1 \\
\hline 7” & 167.1 & 166.6 & 166.2 & 165.9 \\
\hline OMe-3" & - & - & 55.7 & 55.9 \\
\hline OMe-4" & - & 60.1 & 60.3 & 60.5 \\
\hline OMe-5" & - & - & - & 55.9 \\
\hline
\end{tabular}

"Assignments confirmed by HMQC and HMBC experiments. a, b,c Interchangeable signals. triterpene in other plant genera, no record is available for its presence in Terminalia.

Compounds 2, 3, 6, 8-16, 19a-19c and 22 were assayed in vitro against the $\mathrm{Hep}_{2}$ (larynx carcinoma) and $\mathrm{H}_{292}$ (lung mucoepidermoid carcinoma) human cell lines. As depicted in Table 3, compounds 9, 10, 12, 19b and 19c displayed significant cytotoxic activity on both cell lines $\left(\mathrm{IC}_{50}\right.$ values in the range of 9.7-23.2 $\mu \mathrm{g} \mathrm{mL}^{-1}$ ), while $\mathbf{1 1}$ and $\mathbf{1 3}$ exhibited weak cytotoxicity in this assay $\left(\mathrm{IC}_{50}\right.$ values in the range of $\left.30.7-41.4 \mu \mathrm{g} \mathrm{mL}^{-1}\right)$. The cytotoxic antitumor drug cisplatin was taken as positive control $\left(\mathrm{IC}_{50}\right.$ 5.1 and $\left.7.8 \mu \mathrm{g} \mathrm{mL}^{-1}\right)$. The detection of cytotoxic compounds in Terminalia fagifolia associated to its use in the Brazilian folk medicine for the treatment of tumors requires further investigations.

Table 3. Cytotoxicity of compounds $2-3,6,8-16,19 a-19 c$ and 22 against $\mathrm{Hep}_{2}$ and $\mathrm{H}_{292}$ cell lines

\begin{tabular}{lcc}
\hline Compound & \multicolumn{2}{c}{$\mathrm{IC}_{50} /\left(\mu \mathrm{g} \mathrm{mL}^{-1}\right)$} \\
\cline { 2 - 3 } $\mathbf{2}$ & $\mathrm{Hep}_{2}$ & $\mathrm{H}_{292}$ \\
$\mathbf{3}$ & $>50$ & $>50$ \\
$\mathbf{6}$ & $>50$ & $>50$ \\
$\mathbf{8}$ & $>50$ & $>50$ \\
$\mathbf{9}$ & $>50$ & $>50$ \\
$\mathbf{1 0}$ & 19.81 & 20.70 \\
$\mathbf{1 1}$ & 22.62 & 18.42 \\
$\mathbf{1 2}$ & 32.41 & 30.66 \\
$\mathbf{1 3}$ & 22.02 & 23.19 \\
$\mathbf{1 4}$ & 41.36 & 38.07 \\
$\mathbf{1 5}$ & $>50$ & $>50$ \\
$\mathbf{1 6}$ & $>50$ & $>50$ \\
$\mathbf{1 9 a}$ & $>50$ & $>50$ \\
$\mathbf{1 9 b}$ & $>50$ & $>50$ \\
$\mathbf{1 9 c}$ & 15.81 & 16.23 \\
$\mathbf{2 2}$ & 16.93 & 9.70 \\
Cisplatin* & $>50$ & $>50$ \\
\hline
\end{tabular}

*positive control.

In the antioxidant assay, compounds $\mathbf{8 , 1 1 - 1 3}$ and 19a19c strongly inhibited bleaching of $\beta$-carotene on TLC plates, while 14-16 and 22 showed moderate activity. On the other hand, compounds 2-6 and 9-10 were inactive. Although the antioxidative properties of a number of ortho-dioxygenated flavonoid derivatives are well known and several oxygenated pentacyclic triterpenes have also been reported as antioxidant compounds, ${ }^{18,19}$ there is no report for the antioxidant activity of diarylpropanes $\mathbf{1 1}$ and 12 and triterpenes 19a-19c. Recently arjungenin (15) and its glucoside (16) were found to show a moderate free radical scavenging activity in the DPPH model, while arjunic acid (13) and arjunetin (14) exhibited no significant activity in the same assay. ${ }^{19}$ However, in the present work $\mathbf{1 3}$ and $\mathbf{1 4}$ showed strong and moderate activities, respectively, in the autography assay towards $\beta$-carotene. 
Although a large number of cytotoxic constituents from different flavonoid classes has been described, to the best of our knowledge this is the first report on the cytotoxicity of 1,3-diarylpropanes. In addition, the isolation of this class of compounds from a member of the Combretaceae adds new phytochemical data, which might have chemotaxonomical importance.

\section{Experimental}

\section{General experimental procedures}

IR spectra were recorded as $\mathrm{KBr}$ pellets on a BomemHartmann \& Braun FT IR spectrometer. ${ }^{1} \mathrm{H}$ and ${ }^{13} \mathrm{C}$ 1D and 2D NMR spectra were recorded at $300 \mathrm{MHz}\left({ }^{1} \mathrm{H}\right)$ and $75 \mathrm{MHz}\left({ }^{13} \mathrm{C}\right)$ on a Bruker DPX-300 spectrometer. Standard pulse sequences were used for homo - and heteronuclear correlation experiments. Column chromatography procedures were performed on silica gel 70-230 mesh and 230-400 mesh, RP-18 silica gel 230400 mesh, and Sephadex LH-20. Preparative TLC was carried out on silica gel $\mathrm{PF}_{254}$ plates. Reversed phase semipreparative HPLC separations were performed with a Shimadzu LC-6AD pump, using a RP-18, $25 \times 250 \mathrm{~mm}$, $5 \mu \mathrm{m}$ particle size, Shim-Pack PREP-ODS(H) column, with a flow rate of $10 \mathrm{~mL}$ or $14 \mathrm{~mL} \mathrm{m^{-1 }}$ and monitoring at 254 or $280 \mathrm{~nm}$.

\section{Plant material}

Heartwood and trunk bark of Terminalia fagifolia Mart. were collected in Aquidauana, Mato Grosso do Sul, Brazil, in June 2002. The plant material was identified by MSc. Ubirazilda M. Resende, CGMS Herbarium, Universidade Federal de Mato Grosso do Sul, Brazil, where a voucher specimen (No. 0938) was deposited.

\section{Extraction and isolation of chemical constituents}

Air-dried and powdered heartwood (2684 g) was extracted at room temperature with EtOH. After concentration in vacuo, the residue was partitioned between hexane/ $\mathrm{CH}_{3} \mathrm{CN} / \mathrm{CHCl}_{3} / \mathrm{H}_{2} \mathrm{O}$ (20:34:10:10). The $\mathrm{CH}_{3} \mathrm{CN} / \mathrm{CHCl}_{3}$ phase $(21.4 \mathrm{~g})$ was applied to a silica gel CC (70-230 mesh) eluted with hexane/EtOAc and EtOAc/ $\mathrm{MeOH}$ gradient systems. The fractions showing similar spots by TLC were combined to give nineteen fractions (I $\rightarrow$ XIX). Fraction III (hexane/EtOAc 9:1, 282.0 mg) was further separated by CC over Sephadex LH-20 (hexane/ $\mathrm{CH}_{2} \mathrm{Cl}_{2}$ 1:4). Compound $\mathbf{1}$ was identified as the major component of fractions $10-13(50.0 \mathrm{mg})$ whereas $\mathbf{2 3}$ (30.0 $\mathrm{mg}$ ) was obtained from fractions 17-18. Fraction V (hexane/EtOAc 1:1, 259.0 mg) was chromatographed on a Sephadex LH-20 column using hexane $/ \mathrm{CH}_{2} \mathrm{Cl}_{2}$ (1:4) followed by $\mathrm{CH}_{2} \mathrm{Cl}_{2}$ /acetone (3:2) as solvents. Fractions 13-16 (hexane/ $\mathrm{CH}_{2} \mathrm{Cl}_{2} 1$ :4) from this column provided 4 $(3.0 \mathrm{mg})$ while fractions $53-56\left(\mathrm{CH}_{2} \mathrm{Cl}_{2} /\right.$ acetone $\left.3: 2\right)$ yielded $2(7.2 \mathrm{mg})$ and $\mathbf{1 0}(6.2 \mathrm{mg})$, after semi-preparative HPLC $\left(\mathrm{MeOH} / \mathrm{H}_{2} \mathrm{O} \quad 17: 3\right.$ and $\mathrm{MeOH} / \mathrm{H}_{2} \mathrm{O}$ 8:2, respectively). Fractions 57-69 $\left(\mathrm{CH}_{2} \mathrm{Cl}_{2} /\right.$ acetone $\left.3: 2\right)$ contained a mixture of $\mathbf{2}, \mathbf{5}$ and $\mathbf{9}$ and were again separated by $\mathrm{CC}$ on Sephadex $\mathrm{LH}-20\left(\mathrm{CHCl}_{3} / \mathrm{MeOH} 3: 2\right)$ to give $\mathbf{5}$ $(4.0 \mathrm{mg})$ and an unresolved mixture of $\mathbf{2}$ and $\mathbf{9}$ which was further separated by semi-preparative $\mathrm{HPLC}\left(\mathrm{MeOH} / \mathrm{H}_{2} \mathrm{O}\right.$ $8: 2)$ to yield $2(3.6 \mathrm{mg})$ and $\mathbf{9}(2.3 \mathrm{mg})$. Separation of fraction VI (hexane/EtOAc 1:1, 311.8 mg) by repeated $\mathrm{CC}$ on Sephadex $\mathrm{LH}-20\left(\mathrm{CHCl}_{3} / \mathrm{MeOH} 3: 2\right)$ gave two main fractions. The former furnished $\mathbf{6}(5.9 \mathrm{mg})$ and $\mathbf{1 2}$ $(7.5 \mathrm{mg})$ while the latter gave $\mathbf{1 1}(3.8 \mathrm{mg})$ and further amounts of 12 (10.5 mg), after semi-preparative HPLC $\left(\mathrm{MeOH} / \mathrm{H}_{2} \mathrm{O}\right.$ 7:3 and $\mathrm{CH}_{3} \mathrm{CN} / \mathrm{H}_{2} \mathrm{O}$ 11:9, respectively). Fraction VII (hexane/EtOAc 1:1, $202.0 \mathrm{mg}$ ) was subjected to $\mathrm{CC}$ on Sephadex $\mathrm{LH}-20\left(\mathrm{CHCl}_{3} / \mathrm{MeOH} 3: 2\right)$. Fractions 12-19 from this column yielded 7 (12.4 mg), after semipreparative HPLC $\left(\mathrm{MeOH} / \mathrm{H}_{2} \mathrm{O}\right.$ 7:3) while fractions 2325 consisted of $\mathbf{3}(12.8 \mathrm{mg})$. Fraction IX (EtOAc, $2.88 \mathrm{~g}$ ) afforded $\mathbf{1 3}(12.1 \mathrm{mg})$ and $22(34.6 \mathrm{mg})$, fraction XII (EtOAc/MeOH 9.5:0.5, $1.30 \mathrm{~g})$ yielded $15(186.0 \mathrm{mg})$ and $\mathbf{1 7}(6.0 \mathrm{mg}$ ) and fraction XIV (EtOAc/MeOH 9:1, $504.6 \mathrm{mg}$ ) gave $\mathbf{1 4}(13.6 \mathrm{mg})$, after a series of CC on Sephadex $\mathrm{LH}-20(\mathrm{MeOH})$, followed by $\mathrm{CC}$ on silica gel 230-400 mesh $\left(\mathrm{CHCl}_{3} / \mathrm{MeOH}\right.$ 97:3 and $\mathrm{CHCl}_{3} / \mathrm{MeOH}$ 9:1). Fraction XV (EtOAc/MeOH 9:1, $1.28 \mathrm{~g}$ ) was subjected to CC on Sephadex LH-20 (MeOH). Fraction 9 from this column provided $\mathbf{1 8}(4.0 \mathrm{mg})$, while fractions $11-12(171.0 \mathrm{mg})$ consisted of a complex mixture which was treated with an ethereal solution of diazomethane to give, after successive CC separations on Sephadex LH$20(\mathrm{MeOH})$ and silica gel $230-400$ mesh $\left(\mathrm{CHCl}_{3} / \mathrm{MeOH}\right.$ 95:5), the corresponding three $O$-methyl derivatives of compound 19: 19a (7.9 mg), 19b (8.0 mg) and 19c (12.4 $\mathrm{mg})$. Compound $16(29.1 \mathrm{mg})$ was isolated from fraction XVII (EtOAc/MeOH 9:1, $1.49 \mathrm{~g}$ ) after CC on Sephadex LH-20 (MeOH) followed by CC on silica gel 230-400 mesh $\left(\mathrm{CHCl}_{3} / \mathrm{MeOH}\right.$ 9:1).

Air-dried and powdered trunk bark (1500 g) was extracted at room temperature with EtOH. The residue obtained from the EtOH extract was subsequently partitioned between $\mathrm{MeOH} / \mathrm{H}_{2} \mathrm{O}(9: 1)$ and hexane; and $\mathrm{MeOH} / \mathrm{H}_{2} \mathrm{O}(1: 1)$ and $\mathrm{CH}_{2} \mathrm{Cl}_{2}$. The $\mathrm{CH}_{2} \mathrm{Cl}_{2}$ phase $(22.2 \mathrm{~g}$ ) was subjected to $\mathrm{CC}$ on silica gel (70-230 mesh) eluted with hexane, $\mathrm{CH}_{2} \mathrm{Cl}_{2}$, EtOAc and EtOAc/MeOH $20 \%$ to 
<smiles>[R20]c1ccc([C@H]2CC(=O)c3c([R])cc([R2])cc3O2)cc1</smiles><smiles>COc1cc([C@H]2CCc3ccc(O)cc3O2)ccc1O</smiles><smiles>[R20]c1ccc(/C=C/C(=O)c2ccc([R2])cc2O)cc1</smiles>

$\begin{array}{ll}1 \mathrm{R}^{1}=\mathrm{OH}, \mathrm{R}^{2}=\mathrm{R}^{3}=\mathrm{CH}_{3} \\ 2 \mathrm{R}^{1}=\mathrm{OH}, \mathrm{R}^{2}=\mathrm{H}^{3}, \mathrm{R}^{3}=\mathrm{CH}_{3} \\ 3 \mathrm{R}^{1}=\mathrm{OH}, \mathrm{R}^{2}=\mathrm{R}^{3}=\mathrm{H} \\ 4 & \mathrm{R}^{1}=\mathrm{H}, \mathrm{R}^{2}=\mathrm{R}^{3}=\mathrm{CH}_{3} \\ 5 & \mathrm{R}^{1}=\mathrm{R}^{2}=\mathrm{H}, \mathrm{R}^{3}=\mathrm{CH}_{3} \\ 6 & \mathrm{R}^{1}=\mathrm{R}^{3}=\mathrm{H}, \mathrm{R}^{2}=\mathrm{CH}_{3} \\ 7 & \mathrm{R}^{1}=\mathrm{OH}, \mathrm{R}^{2}=\mathrm{CH}_{3}, \mathrm{R}^{3}=\mathrm{H}\end{array}$

$$
\begin{array}{ll}
9 & \mathrm{R}^{1}=\mathrm{H}, \mathrm{R}^{2}=\mathrm{CH}_{3} \\
10 & \mathrm{R}^{1}=\mathrm{CH}_{3}, \mathrm{R}^{2}=\mathrm{H}
\end{array}
$$<smiles>[R20]c1cc([R])c(CCCc2ccc(O)c(OC)c2)c(O)c1</smiles>

$11 \mathrm{R}^{1}=\mathrm{CH}_{3}, \mathrm{R}^{2}=\mathrm{R}^{3}=\mathrm{H}$

$12 \mathrm{R}^{1}=\mathrm{H}, \mathrm{R}^{2}=\mathrm{CH}_{3}, \mathrm{R}^{3}=\mathrm{OCH}_{3}$

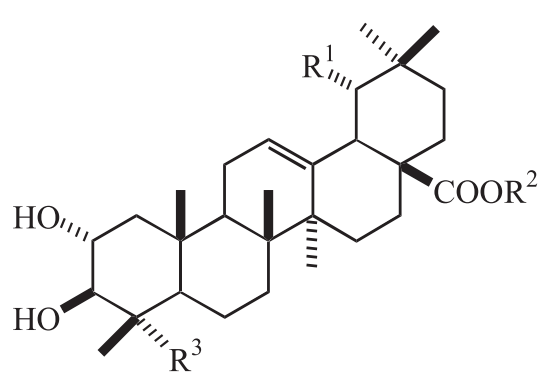

$13 \mathrm{R}^{1}=\mathrm{OH}, \mathrm{R}^{2}=\mathrm{H}, \mathrm{R}^{3}=\mathrm{CH}_{3}$

$14 \mathrm{R}^{1}=\mathrm{OH}, \mathrm{R}^{2}=\beta$-D-Glc, $\mathrm{R}^{3}=\mathrm{CH}_{3}$

$15 \mathrm{R}^{1}=\mathrm{OH}, \mathrm{R}^{2}=\mathrm{H}, \mathrm{R}^{3}=\mathrm{CH}_{2} \mathrm{OH}$

$16 \mathrm{R}^{1}=\mathrm{OH}, \mathrm{R}^{2}=\beta$-D-Glc, $\mathrm{R}^{3}=\mathrm{CH}_{2} \mathrm{OH}$

$17 \mathrm{R}^{1}=\mathrm{R}^{2}=\mathrm{H}, \mathrm{R}^{3}=\mathrm{CH}_{2} \mathrm{OH}$

$18 \mathrm{R}^{1}=\mathrm{H}, \mathrm{R}^{2}=\beta$-D-Glc, $\mathrm{R}^{3}=\mathrm{CH}_{2} \mathrm{OH}$

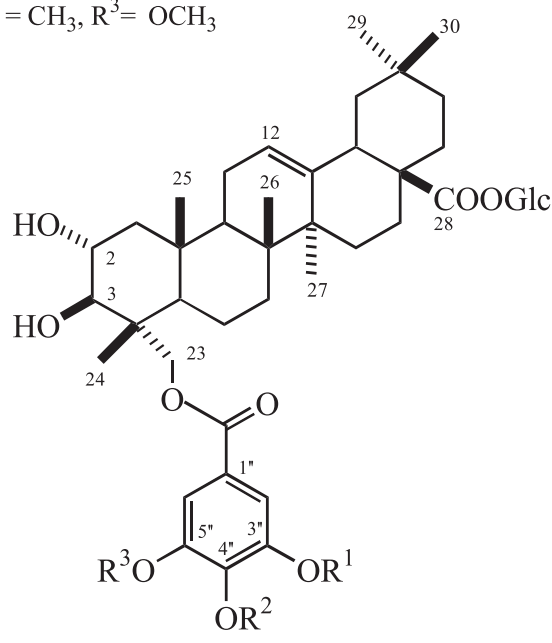

Figure 1. Chemical constituents from T. fagifolia.

yield twelve combined fractions $(\mathrm{I} \rightarrow \mathrm{XII}$ ). Fraction $\mathrm{V}$ $\left(\mathrm{CH}_{2} \mathrm{Cl}_{2} 306.5 \mathrm{mg}\right)$ was chromatographed on a Sephadex LH-20 column $\left(\mathrm{CHCl}_{3} / \mathrm{MeOH} 3: 2\right)$. Fractions 12-13 from this column were again subjected to $\mathrm{CC}$ on silica gel 230400 mesh developed with hexane/acetone $(9: 1)$ followed by hexane/acetone (8.5:1.5) to give $\mathbf{2 1}(4.7 \mathrm{mg})$. Fraction VI $\left(\mathrm{CH}_{2} \mathrm{Cl}_{2}, 1.16 \mathrm{~g}\right)$ was separated on a Sephadex LH-20 column eluted with $\mathrm{CHCl}_{3} / \mathrm{MeOH}$ (3:2). The major constituent of fractions 7-8 $(130.0 \mathrm{mg})$ was found to be 20, which was not further purified. Fractions 15-19 (36.2 $\mathrm{mg}$ ) yielded a mixture of $\mathbf{2}$ and $\mathbf{7}(6.0 \mathrm{mg})$ and of $\mathbf{9}$ and $\mathbf{1 0}$ $(5.0 \mathrm{mg})$, after separation on Sephadex $\mathrm{LH}-20\left(\mathrm{CHCl}_{3} /\right.$ $\mathrm{MeOH} 3: 2$ ) followed by preparative TLC (hexane/acetone/ acetic acid 3.5:1.5:0.1). Fraction IX (EtOAc, $101.0 \mathrm{mg}$ ) yielded $\mathbf{1 3}(6.0 \mathrm{mg})$ after CC on RP-18 silica gel, eluted with $\mathrm{MeOH} / \mathrm{H}_{2} \mathrm{O}$ (6:4 to pure $\mathrm{MeOH}$ ). Fraction XI (EtOAc, $3.88 \mathrm{~g})$ afforded $\mathbf{1 4}(27.3 \mathrm{mg}), \mathbf{1 5}(8.0 \mathrm{mg})$ and $\mathbf{1 6}(95.5$ $\mathrm{mg}$ ) after a series of CC procedures on Sephadex LH-20 $(\mathrm{MeOH})$ and on silica gel 230-400 mesh eluted with $\mathrm{CHCl}_{3} / \mathrm{MeOH}$ (9.5:0.5). 
In vitro cytotoxic assay

In vitro cytotoxic activities were measured against $\mathrm{Hep}_{2}$, a human larynx carcinoma cell line and $\mathrm{H}_{292}$, a human lung mucoepidermoid carcinoma cell line, obtained from Instituto Adolfo Lutz (São Paulo, SP, Brazil). Cells were cultivated in DMEM medium supplemented with $10 \%$ foetal calf serum, $100 \mu \mathrm{g} \mathrm{mL} \mathrm{m}^{-1}$ streptomycin, $100 \mathrm{U} \mathrm{mL}^{-1}$ penicillin and $0.25 \mu \mathrm{g} \mathrm{mL}^{-1}$ anfotericin $\mathrm{B}$, at $37^{\circ} \mathrm{C}$ in a humidified incubator with $5 \%$ $\mathrm{CO}_{2}$. Cellular viability was assessed by formazan production from methylthiazolyldiphenyltetrazolium bromide (MTT colorimetric assay) as described previously. ${ }^{20}$

\section{Bleaching experiments on $\beta$-carotene}

The test was carried out on TLC plates, using a solution of $\beta$-carotene as a spraying reagent and $\alpha$-tocopherol as the reference compound. ${ }^{21}$ Sample solutions of 2-6, 8-16, 19a-19c and 22 at similar concentrations were applied on TLC plates. After developing and drying, the plates were sprayed with a $0.02 \%$ solution of $\beta$-carotene in $\mathrm{CH}_{2} \mathrm{Cl}_{2}$ and subsequently placed under natural light until discoloration of the background.

\section{Acknowledgments}

The authors are grateful to FUNDECT-MS, CPqPROPP-UFMS and PROAP-CAPES for their financial support and to CAPES and CNPq for the scholarships awarded. Thanks are also given to the Department of Morphophysiology (CCBS-UFMS) and Agência Estadual de Defesa Sanitária Animal e Vegetal (IAGRO, MS) for providing the laboratory facilities.

\section{Supplementary Information}

Supplementary Information is avaliable free of charge at http://jbcs.sbq.org.br, as PDF file.

\section{References}

1. Almeida, S. P; Proença, C. E. B.; Sano, S. M.; Ribeiro, J. F.; Cerrado - Espécies Vegetais Úteis, Empresa Brasileira de Pesquisa Agropecuária: Planaltina, 1998.

2. Garcez, F. R.; Garcez, W. S.; Miguel, D. L. S.; Serea, A. A. T.; Prado, F. C.; J. Braz. Chem. Soc. 2003, 14, 461.

3. Garcez, F. R.; Garcez, W. S.; Martins, M.; Lopes, F. A.; Biochem. Syst. Ecol. 2003, 31, 229.
4. Rossi M. H.; Yoshida, M.; Maia, J. G. S.; Phytochemistry 1997, $45,1263$.

5. Vasconcelos, J. M. J.; Silva, A. M. S.; Cavaleiro, J. A. S.; Phytochemistry 1998, 49, 1421.

6. Niwa, M.; Otsuji, S.; Tatematsu, H.; Liu, G. Q.; Chen, X. F.; Hirata, Y.; Chem. Pharm. Bull. 1986, 34, 3249.

7. Gottlieb, O. R.; Maia, J. G. S.; Ribeiro, M. N.; Phytochemistry 1976, 15, 773.

8. Pelter, A.; Ward, R. S.; Gray, T. I.; J. Chem. Soc., Perkin Trans. I 1976, 2475.

9. Achenbach, H.; Stocker, M.; Constenla, M. A.; Phytochemistry 1988, 27, 1835.

10. Agrawal, P. K.; Thakur, R. S.; Bansal, M. C. In Carbon-13 NMR of Flavonoids; Agrawal, P. K., ed.; Elsevier: Amsterdam, 1989, ch. 3.

11. Valsaraj, R.; Pushpangadan, P.; Smitt, U. W.; Adsersen, A.; Christensen, S. B.; Sittie, A.; Nyman, U.; Nielsen, C.; Olsen, C. E.; J. Nat. Prod. 1997, 60, 739.

12. Veitch, N. C.; Sutton, P. S. E.; Kite, G. C.; Ireland, H. E.; J. Nat. Prod. 2003, 66, 210.

13. Srivastava, S. K.; Srivastava, S. D.; Indian J. Chem. 2004, 43B, 2731; Srivastava, S. K.; Srivastava, S. D.; Chouksey, B. K.; Fitoterapia 2001, 72, 106; Srivastava, S. K.; Srivastava, S. D.; Chouksey, B. K.; Proc. Phytochem. Soc. Eur. 2000, 45, 107; Nagar, A.; Gujral, V. K.; Gupta, S. R.; Planta Med. 1979, 37, 183; Srivastava, S. K.; Srivastava, S. D.; Chouksey, B. K.; Fitoterapia 1999, 70, 390.

14. De Lima, R. A.; Franca, N. C.; Diaz, P. P.; Gottlieb, O. R.; Phytochemistry 1975, 14, 1831; Diaz, P. P.; Diaz, A. M. P.; Phytochemistry 1986, 25, 2395.

15. Ahmad, V. U.; Rahman A.; Handbook of Natural Products Data. Volume 2. Pentacyclic Triterpenoids, Elsevier: Amsterdam, 1994.

16. Zhou, X.; Kasai, R.; Ohtani, K.; Tanaka, O.; Nie, R. L.; Yang, C. R.; Zhou, J.; Yamasaki, K.; Phytochemistry 1992, 31, 3642; Nandy, A. K.; Podder, G.; Sahu, N. P.; Mahato, S. B.; Phytochemistry 1989, 28, 2769; Romussi, G.; De Tommasi, N.; Pharmazie 1992, 47, 877.

17. Conrad, J.; Vogler, B.; Klaiber, I.; Roos, G.; Walter, U.; Kraus, W.; Phytochemistry 1998, 48, 647.

18. Gulcin, I.; Mshvildadze, V.; Gepdiremen, A.; Elias, R.; Phytother. Res. 2006, 20, 130; D’Abrosca, B.; Fiorentino, A.; Monaco, P.; Oriano, P.; Pacifico, S.; Food Chem. 2006, 98, 285; Montilla, M. P.; Agil, A.; Navarro, C.; Jimenez, M. I.; Garcia-Granados, A.; Parra, A.; Cabo, M. M.; Planta Med. 2003, 69, 472.

19. Pawar, R. S.; Bhutani, K. K.; Phytomedicine 2005, 12, 391.

20. Mosmann, T.; J. Immunol. Methods 1983, 65, 55.

21. Pratt, D. E.; Miller, E. E.; J. Am. Oil Chem. Soc. 1984, 61, 1064.

Received: March 20, 2006

Published on the web: August 1, 2006 
Bioactive Flavonoids and Triterpenes from Terminalia fagifolia (Combretaceae)

Fernanda R. Garcez, ${ }^{*, a}$ Walmir S. Garcez, ${ }^{a}$ Andréa L. B. D. Santana, ${ }^{a}$ Milene M. Alves, ${ }^{a}$ Maria de Fátima C. Matos ${ }^{b}$ and Anne de M. Scaliante ${ }^{a}$

${ }^{a}$ Departamento de Química and ${ }^{b}$ Departamento de Farmácia-Bioquímica, Universidade Federal de Mato Grosso do Sul, 79070-900 Campo Grande-MS, Brazil

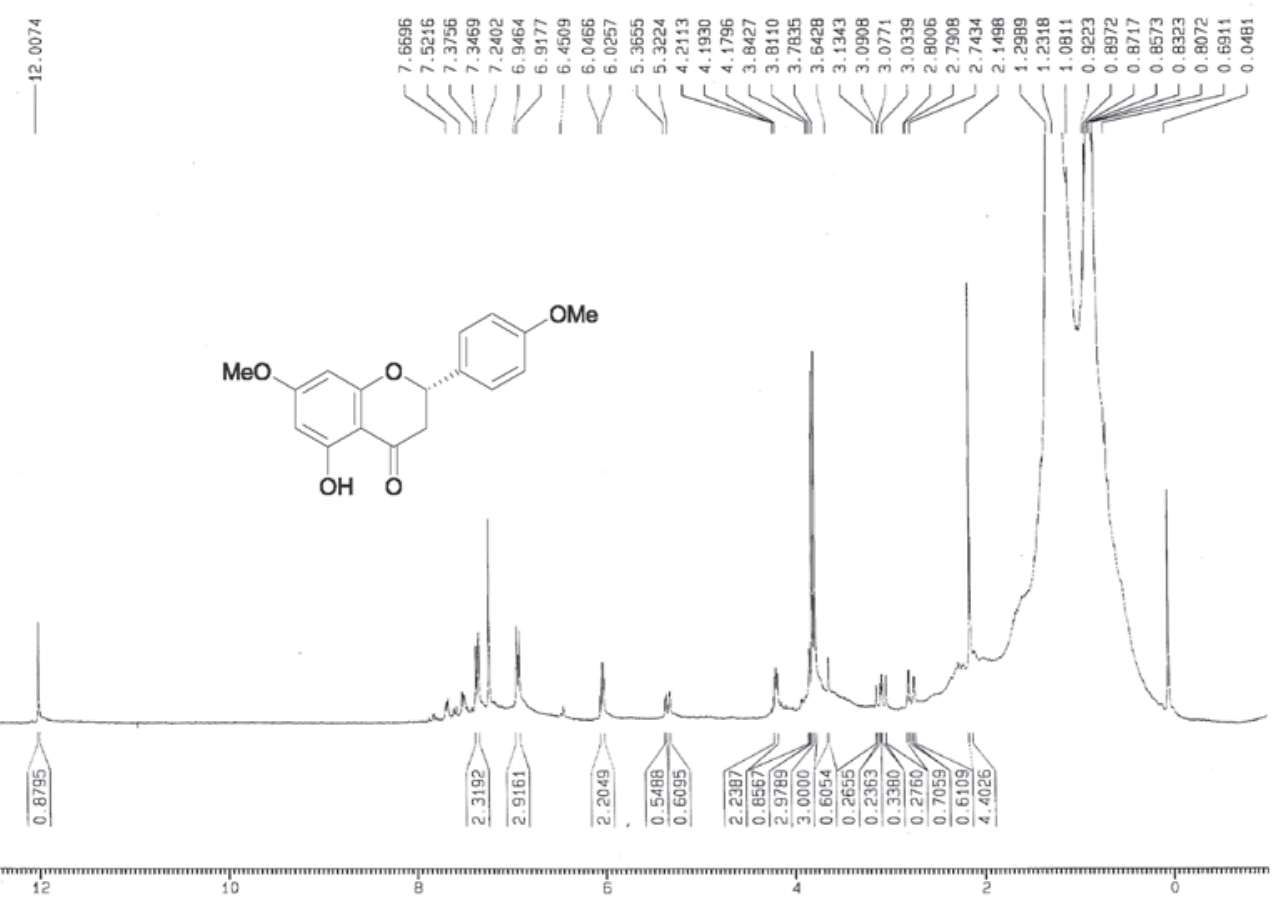

Figure S1. ${ }^{1} \mathrm{H}$ NMR spectrum of compound $1\left(300 \mathrm{MHz}, \mathrm{CDCl}_{3}\right)$. 


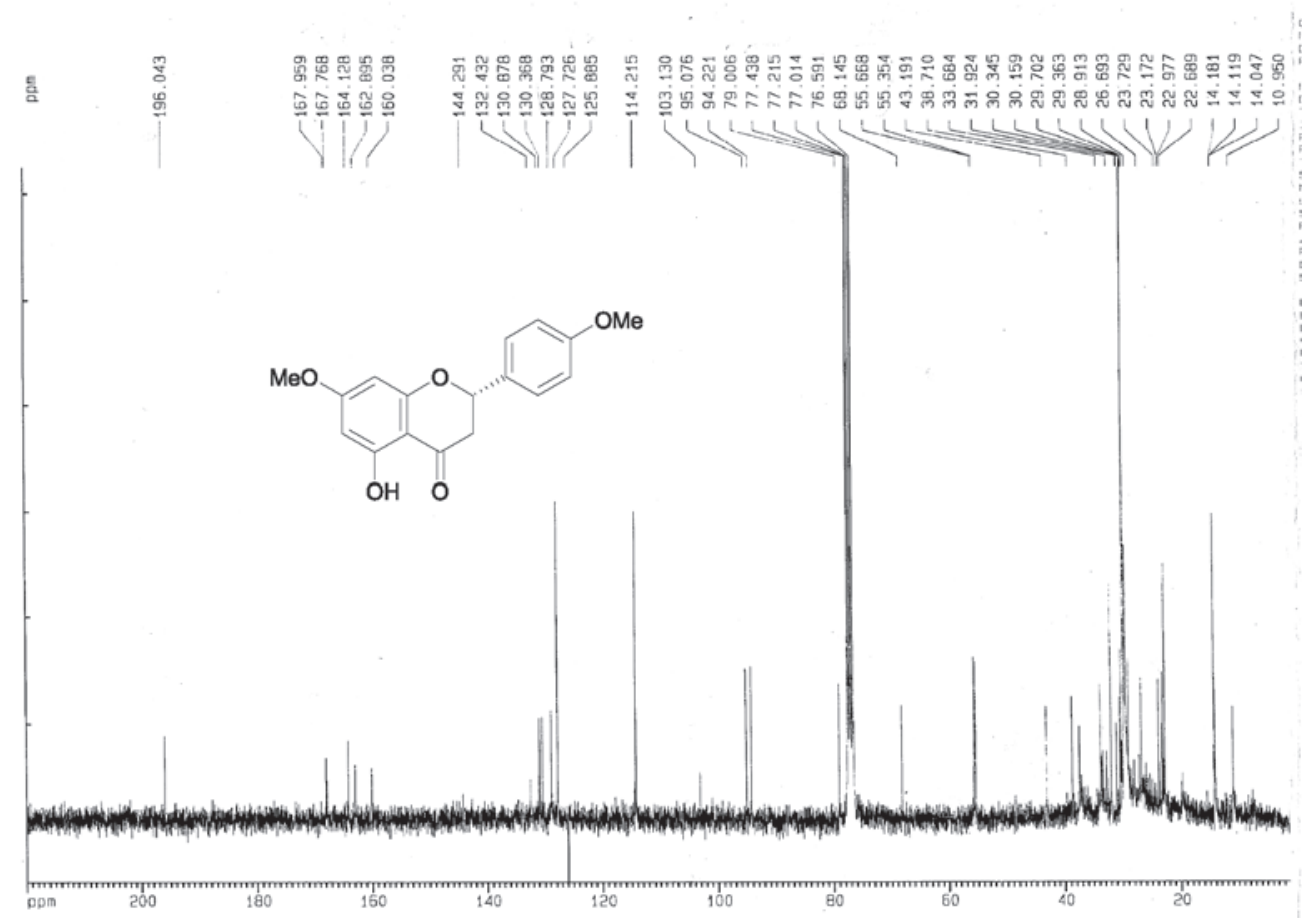

Figure S2. ${ }^{13} \mathrm{C}$ NMR spectrum of compound $1\left(75 \mathrm{MHz}, \mathrm{CDCl}_{3}\right)$.

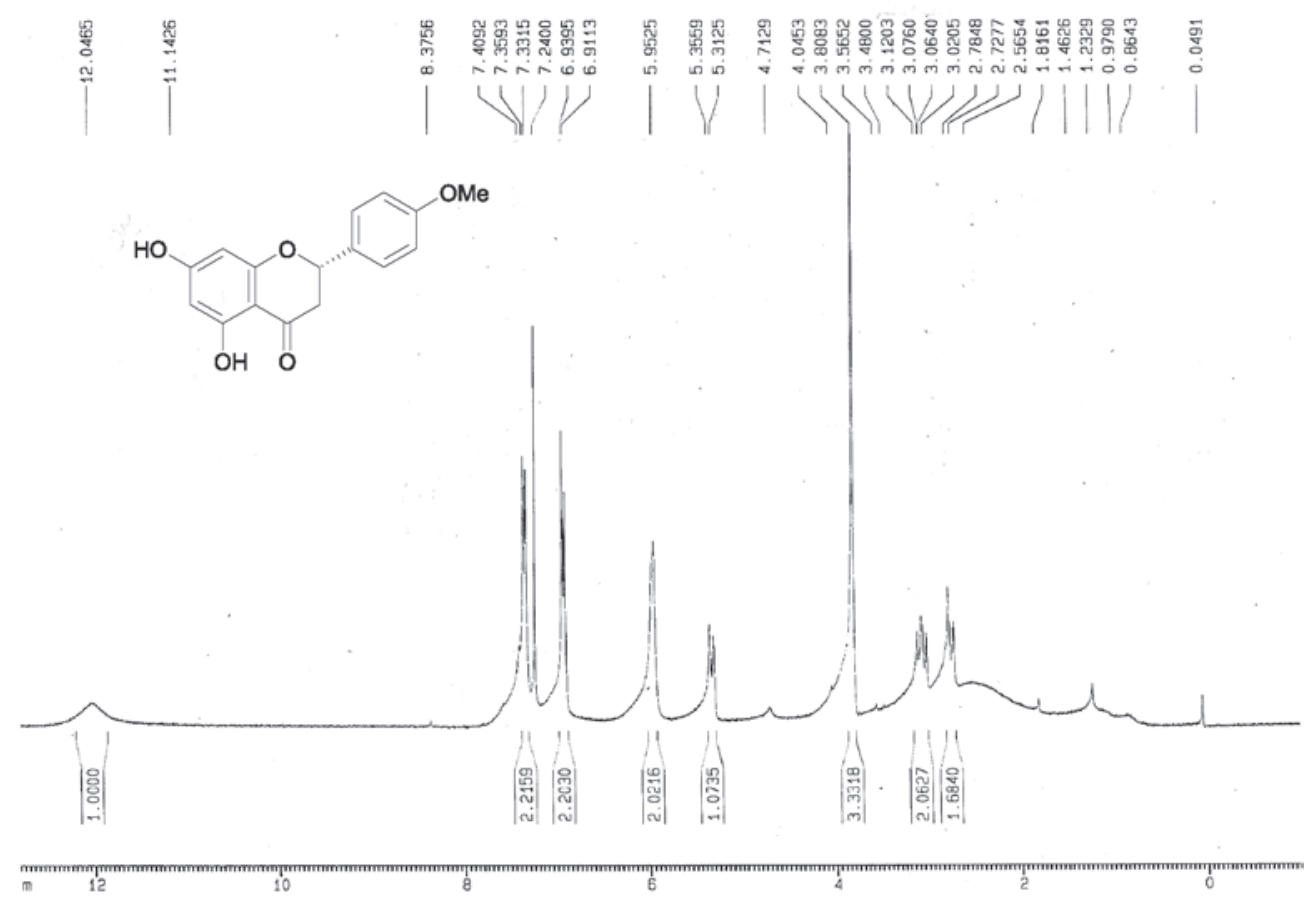

Figure S3. ${ }^{1} \mathrm{H}$ NMR spectrum of compound $2\left(300 \mathrm{MHz}, \mathrm{CDCl}_{3}\right)$. 


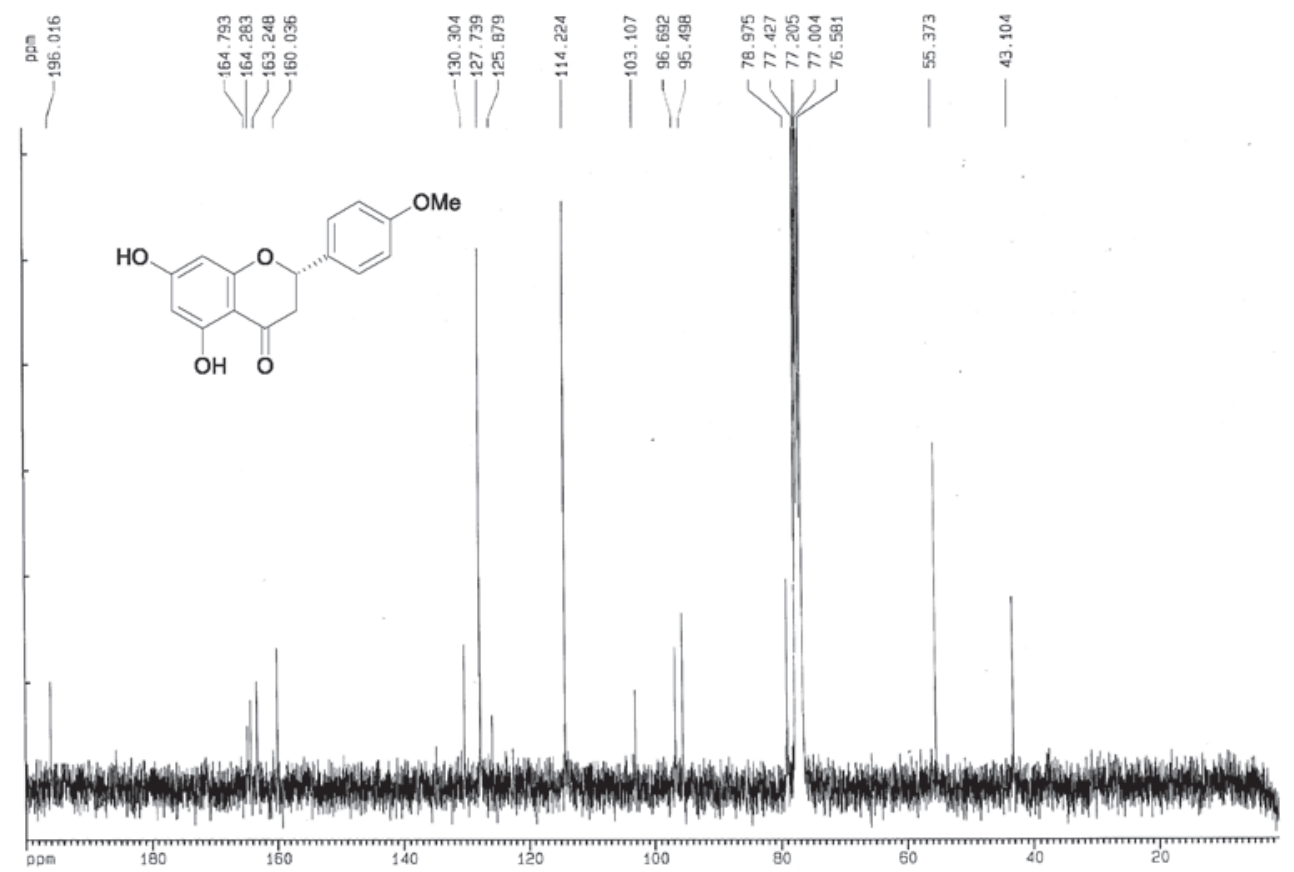

Figure S4. ${ }^{13} \mathrm{C}$ NMR spectrum of compound $2\left(75 \mathrm{MHz}, \mathrm{CDCl}_{3}\right)$.

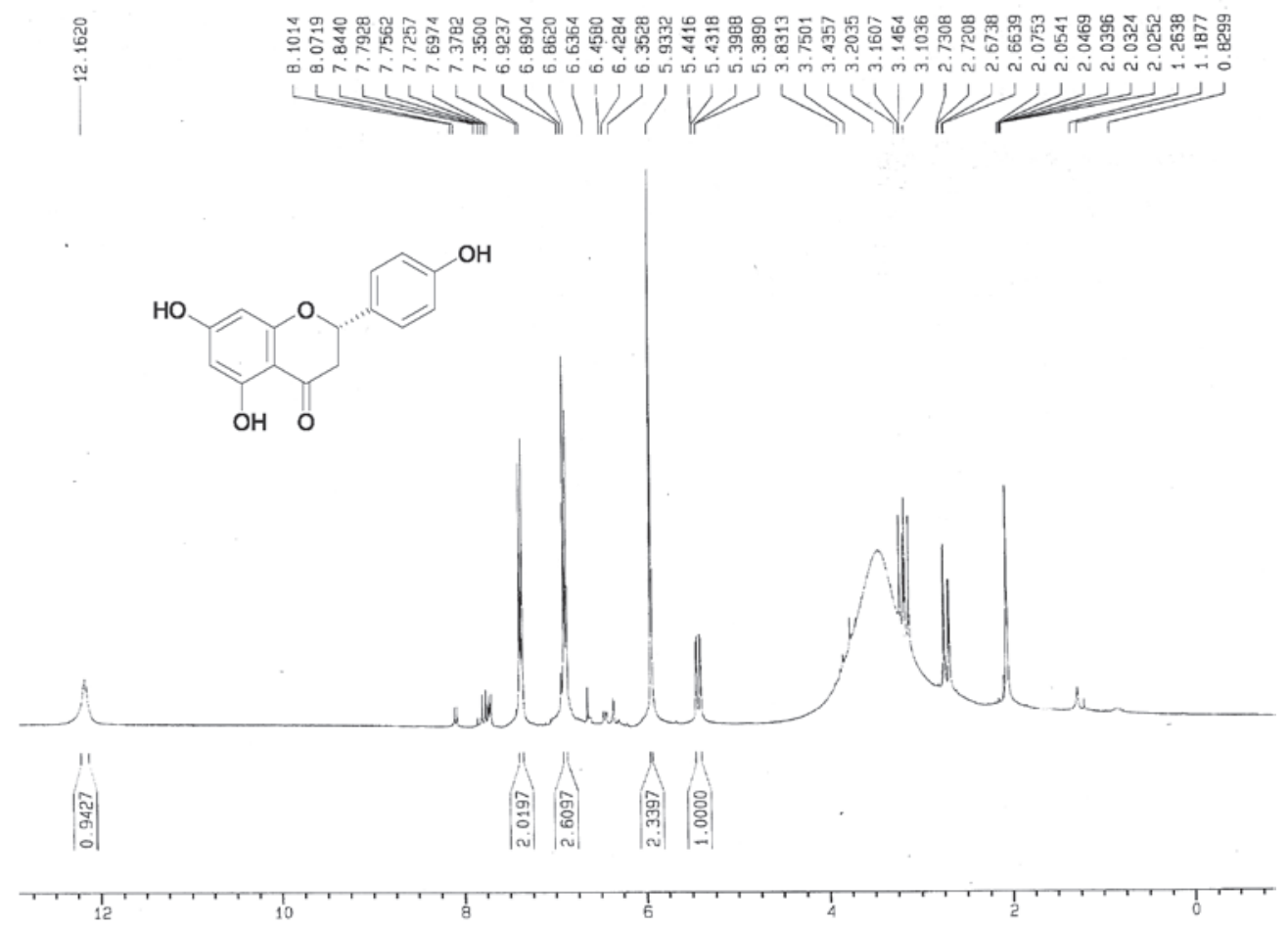

Figure S5. ${ }^{1} \mathrm{H}$ NMR spectrum of compound 3 (300 MHz, acetone- $d_{6}$ ). 


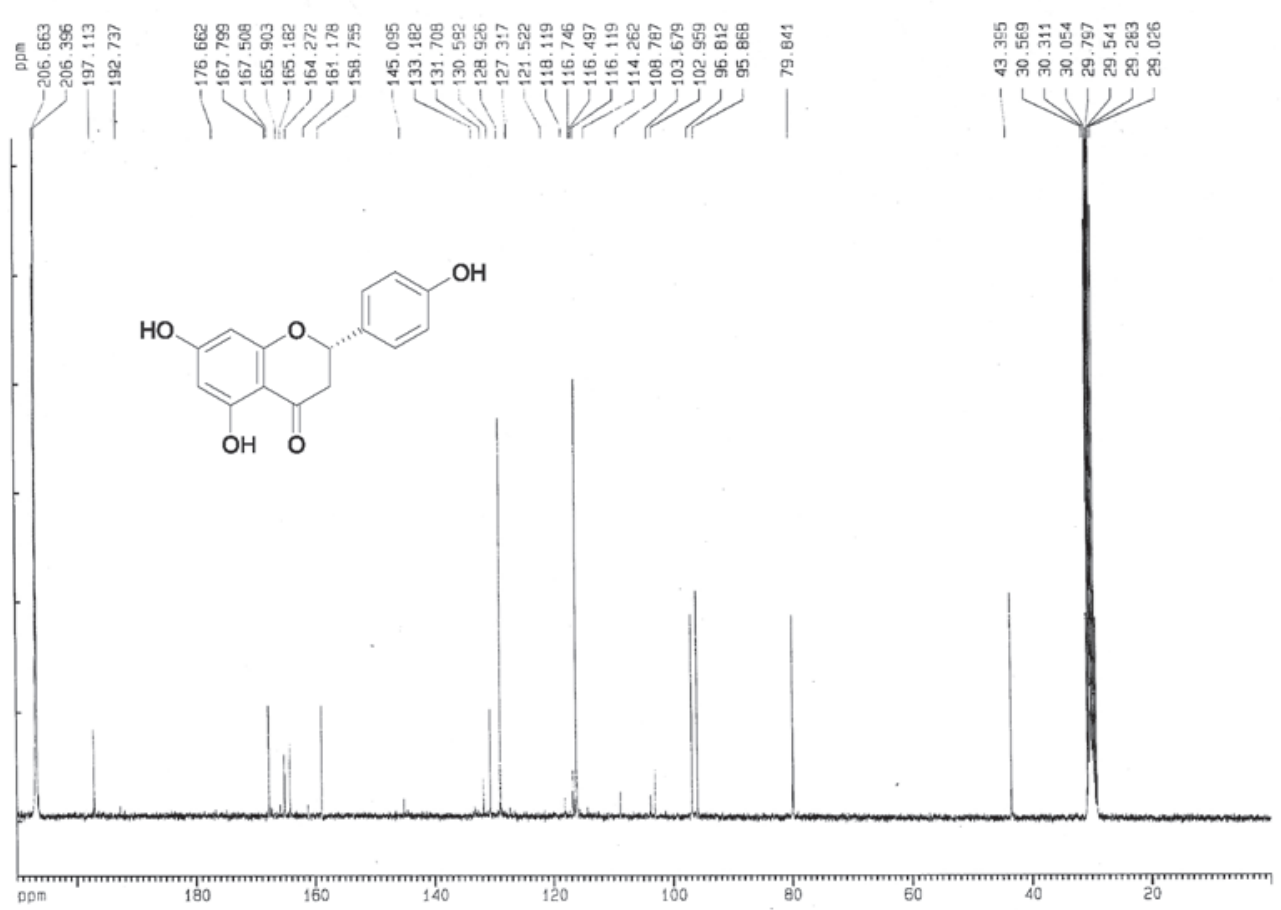

Figure S6. ${ }^{13} \mathrm{C}$ NMR spectrum of compound $3\left(75 \mathrm{MHz}\right.$, acetone- $\left.d_{6}\right)$.
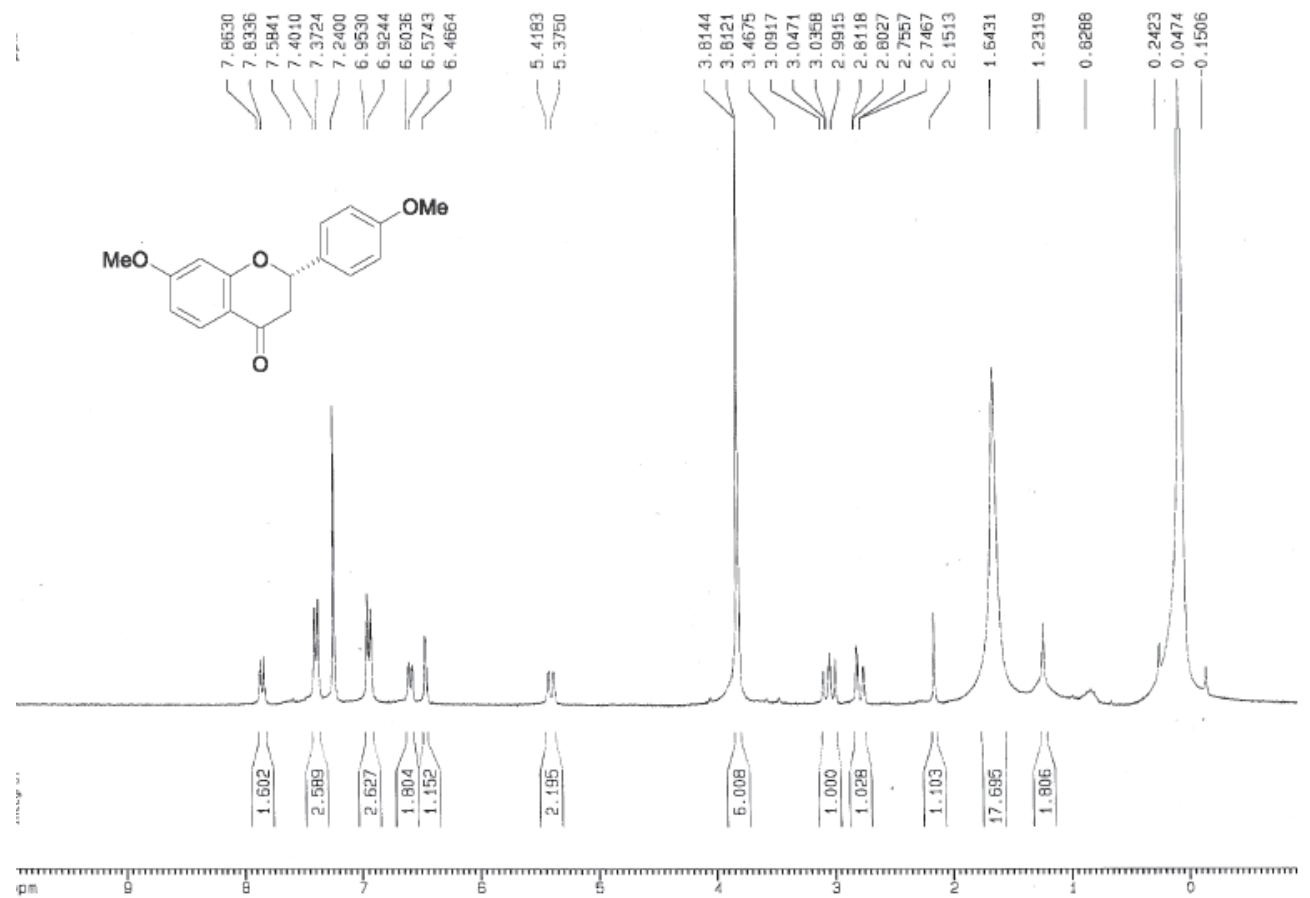

Figure S7. ${ }^{1} \mathrm{H}$ NMR spectrum of compound $4\left(300 \mathrm{MHz}, \mathrm{CDCl}_{3}\right)$. 


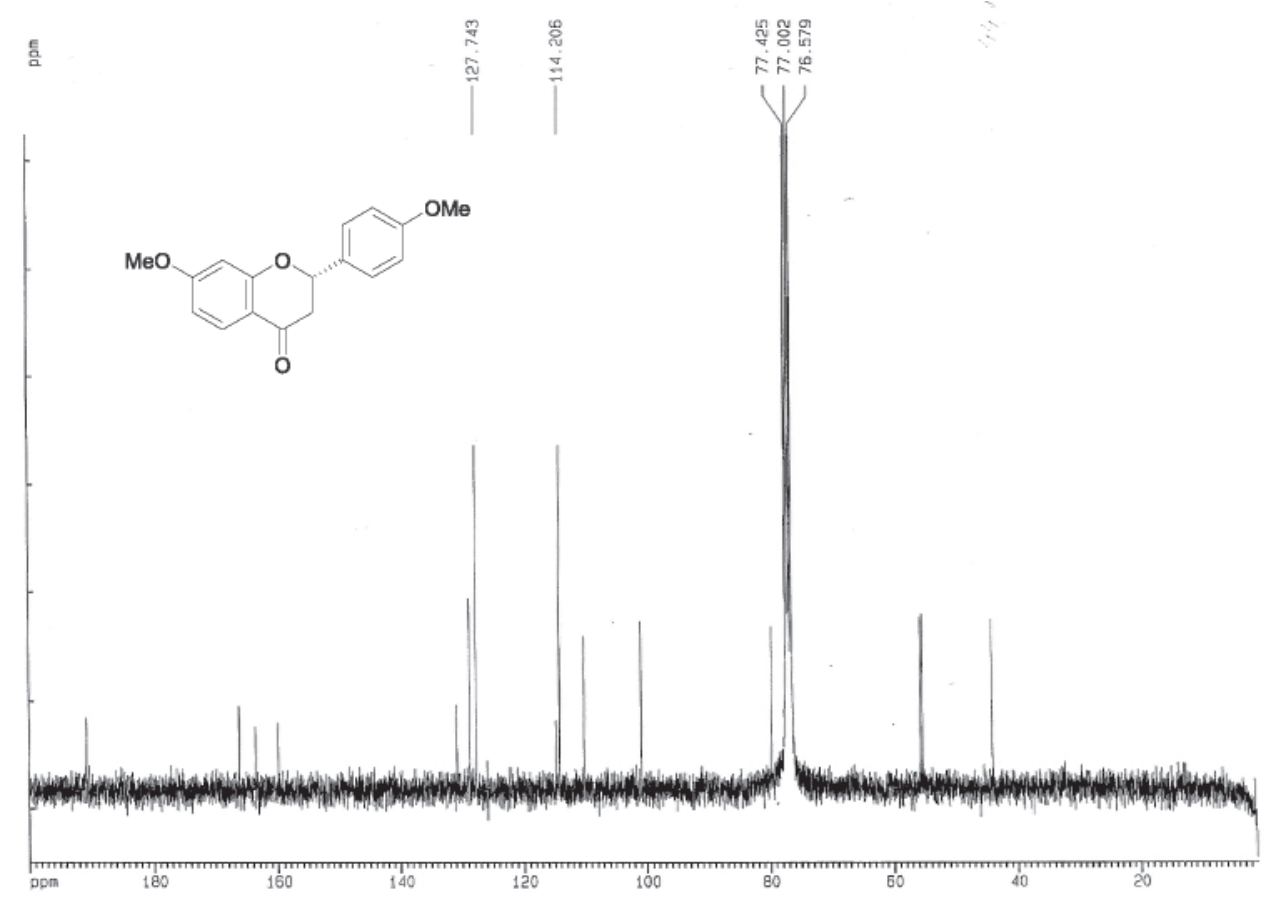

Figure S8. ${ }^{13} \mathrm{C}$ NMRspectrum of compound $4\left(75 \mathrm{MHz}, \mathrm{CDCl}_{3}\right)$.

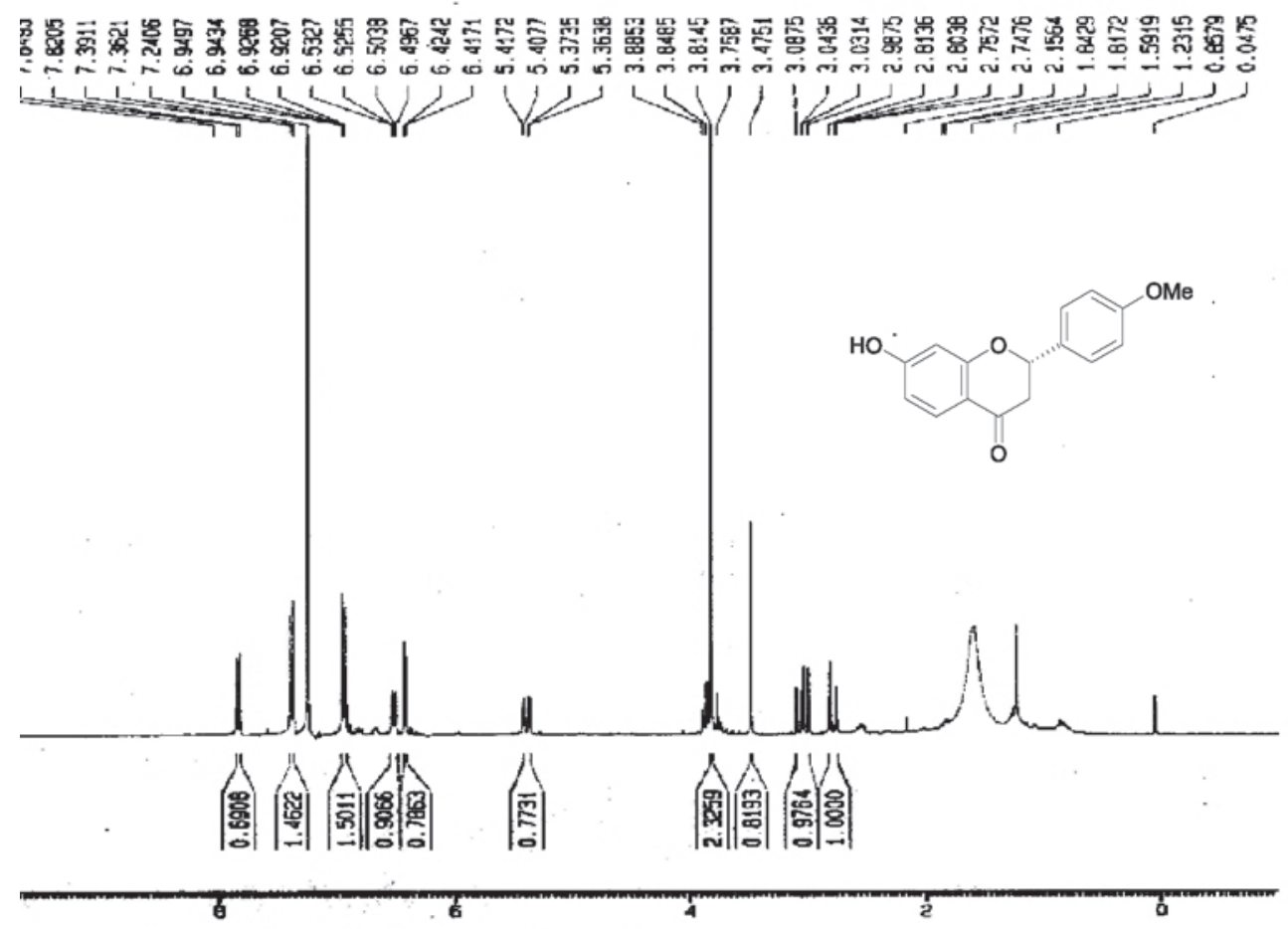

Figure S9. ${ }^{1} \mathrm{H}$ NMR spectrum of compound $5\left(300 \mathrm{MHz}, \mathrm{CDCl}_{3}\right.$ ). 


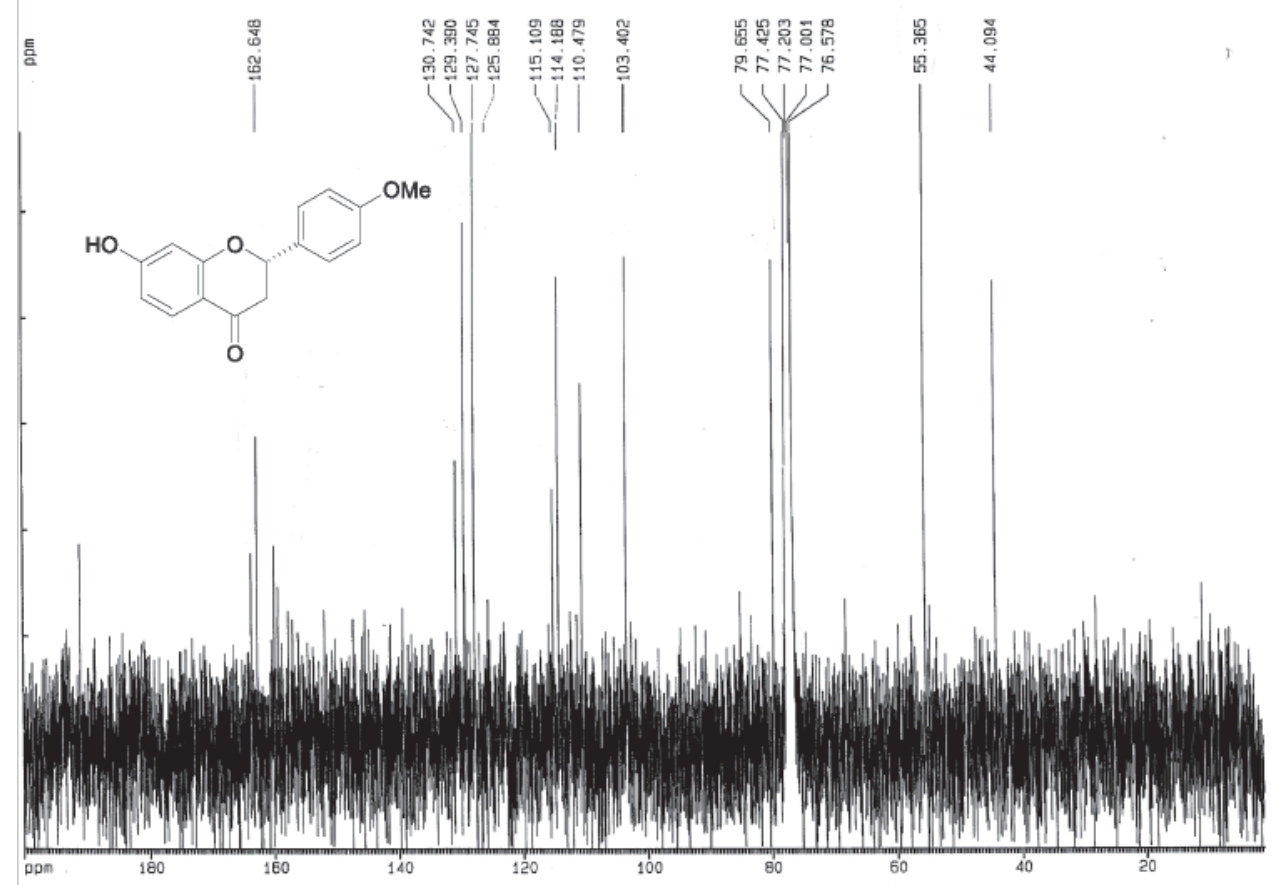

Figure S10. ${ }^{13} \mathrm{C}$ NMR spectrum of compound $5\left(75 \mathrm{MHz}, \mathrm{CDCl}_{3}\right)$.

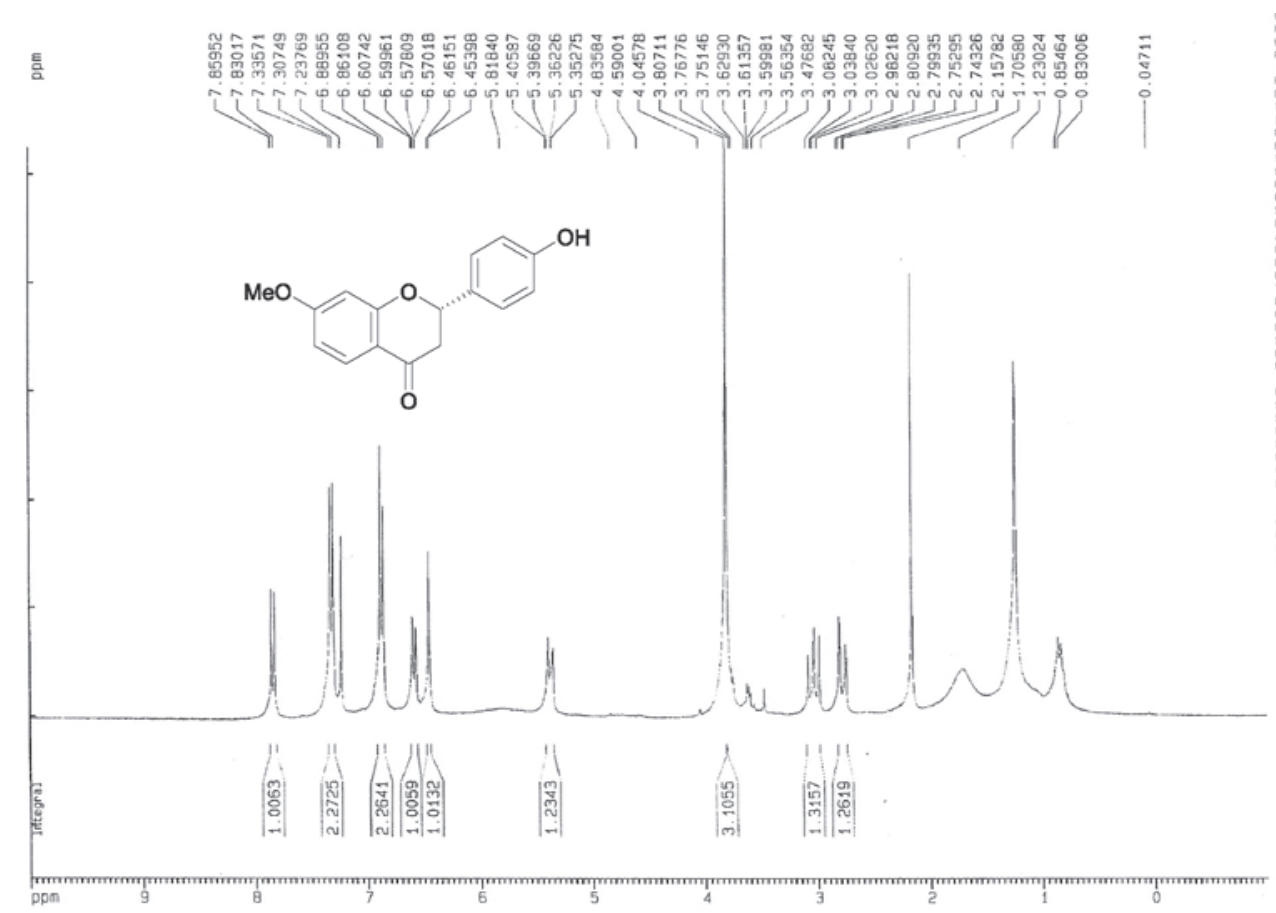

Figure S11. ${ }^{1} \mathrm{H}$ NMR spectrum of compound $6\left(300 \mathrm{MHz}, \mathrm{CDCl}_{3}\right)$. 


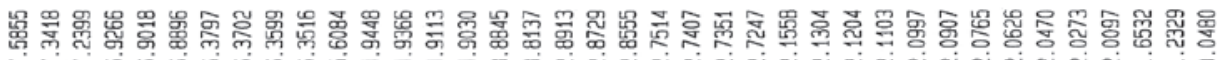
م $\sim$ ம

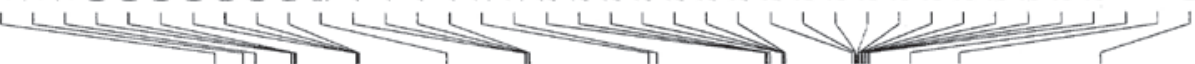
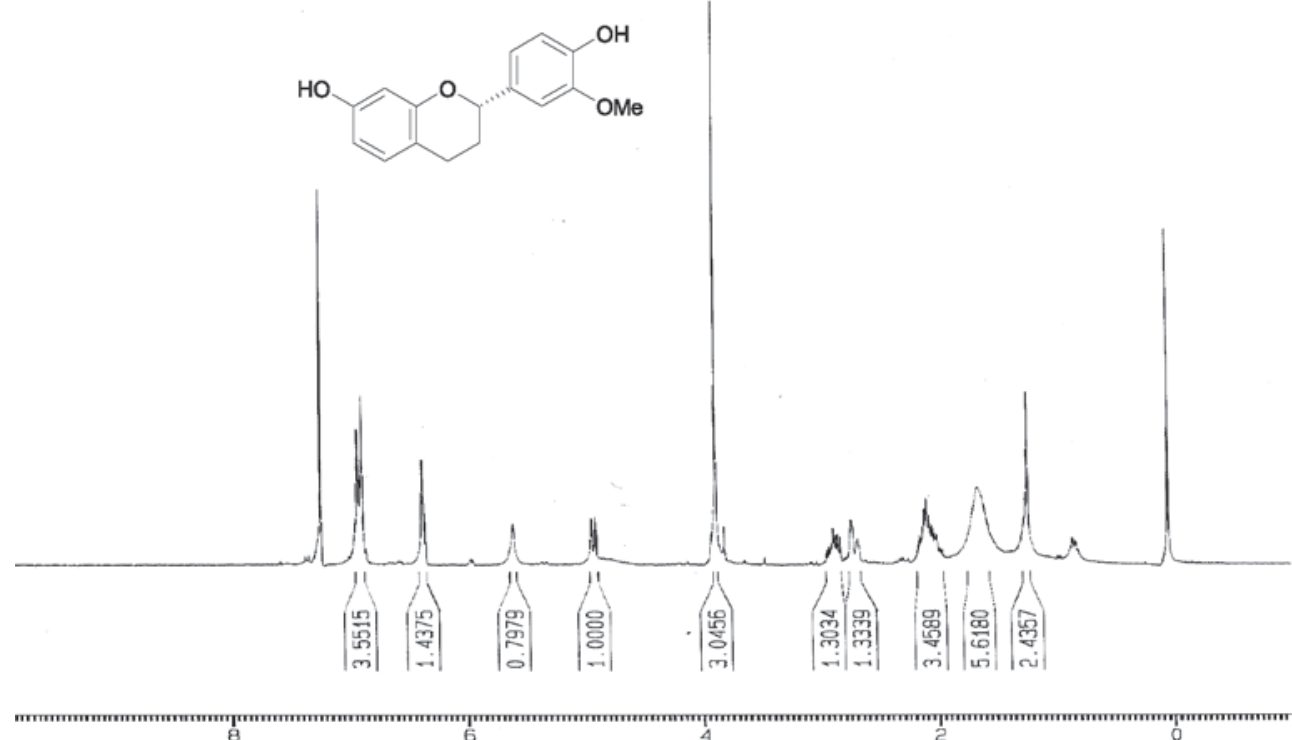

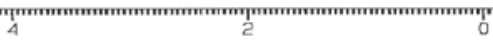

Figure S12. ${ }^{13} \mathrm{C}$ NMR spectrum of compound $6\left(75 \mathrm{MHz}, \mathrm{CDCl}_{3}\right)$.

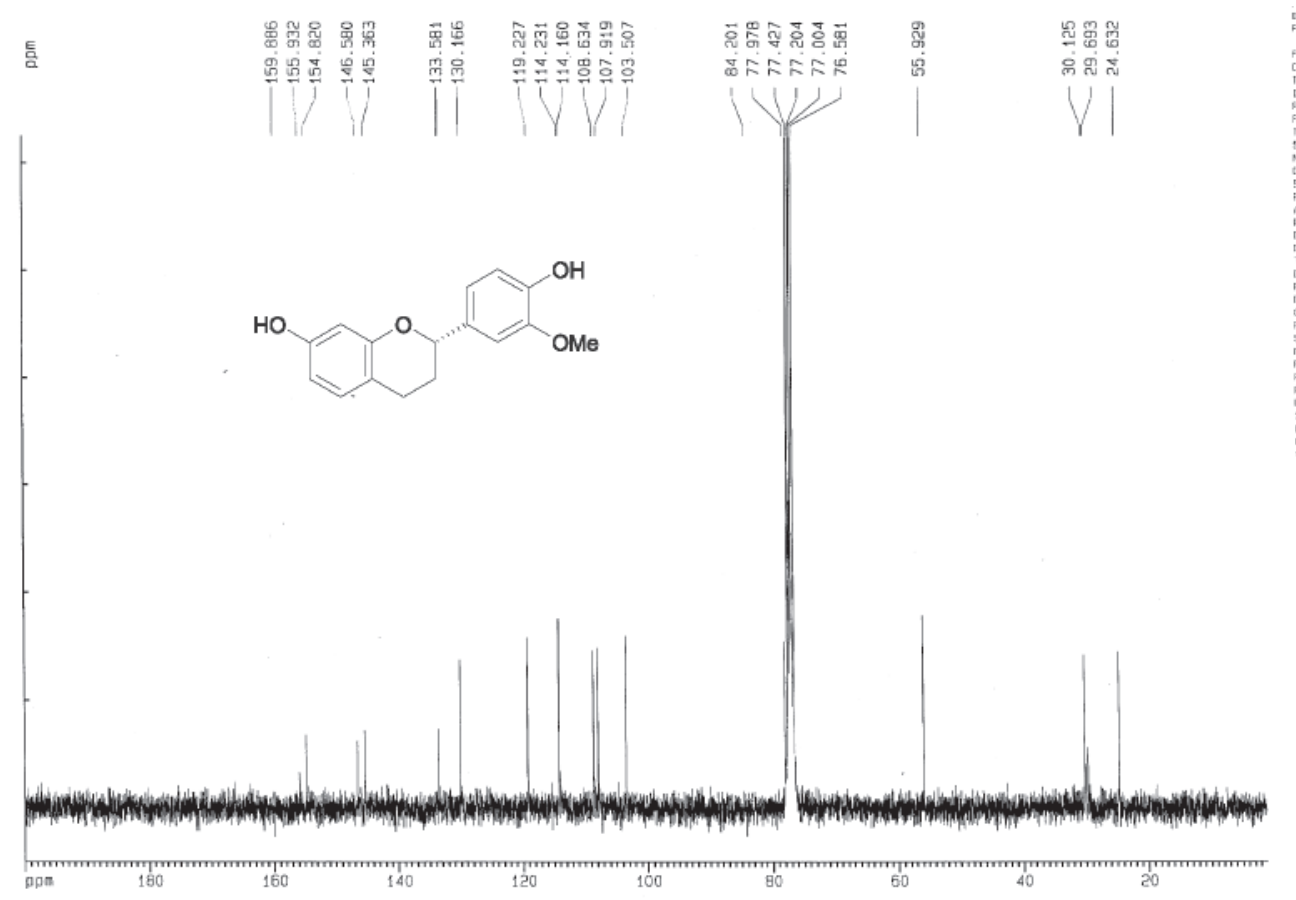

Figure S13. ${ }^{1} \mathrm{H}$ NMR spectrum of compound $8\left(300 \mathrm{MHz}, \mathrm{CDCl}_{3}\right)$. 


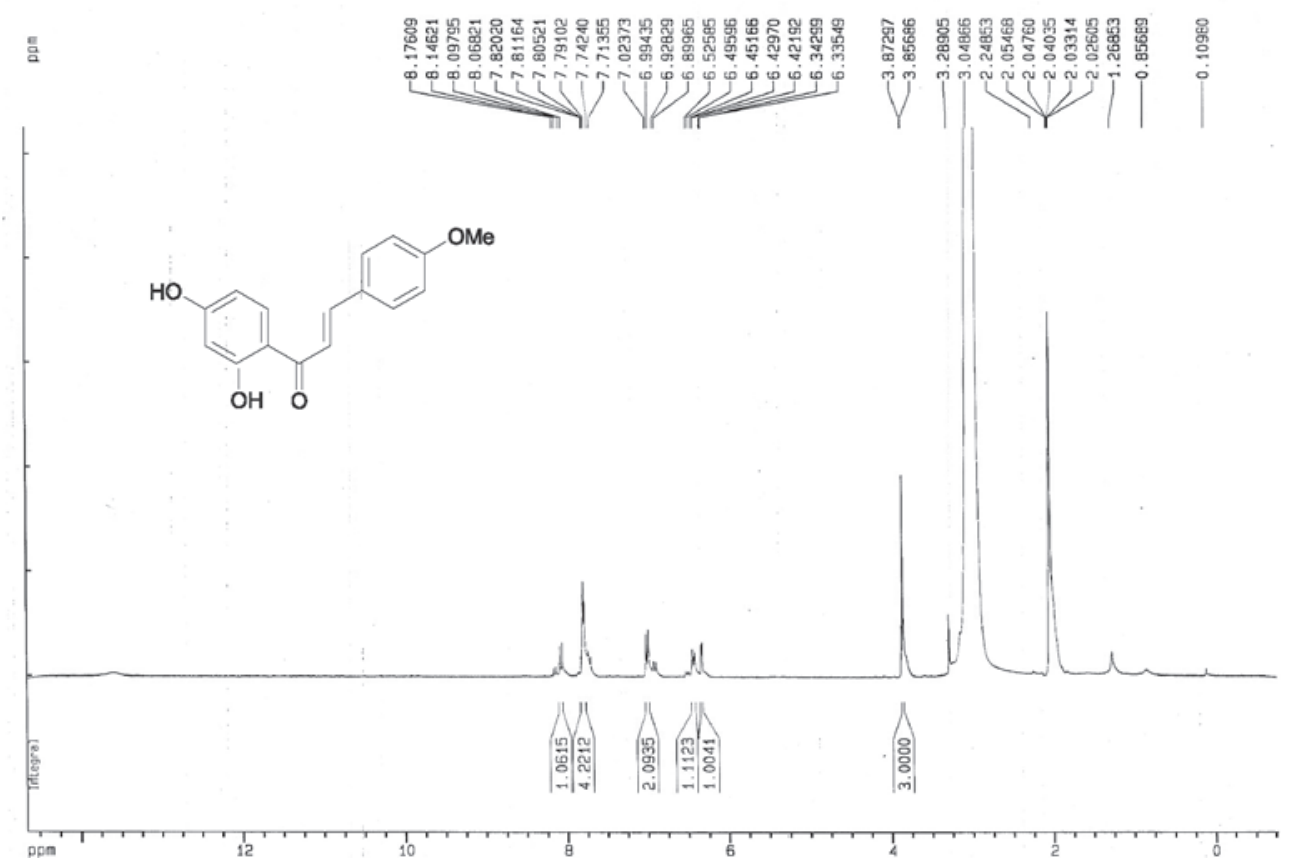

Figure S14. ${ }^{13} \mathrm{C}$ NMR spectrum of compound $8\left(75 \mathrm{MHz}, \mathrm{CDCl}_{3}\right)$.

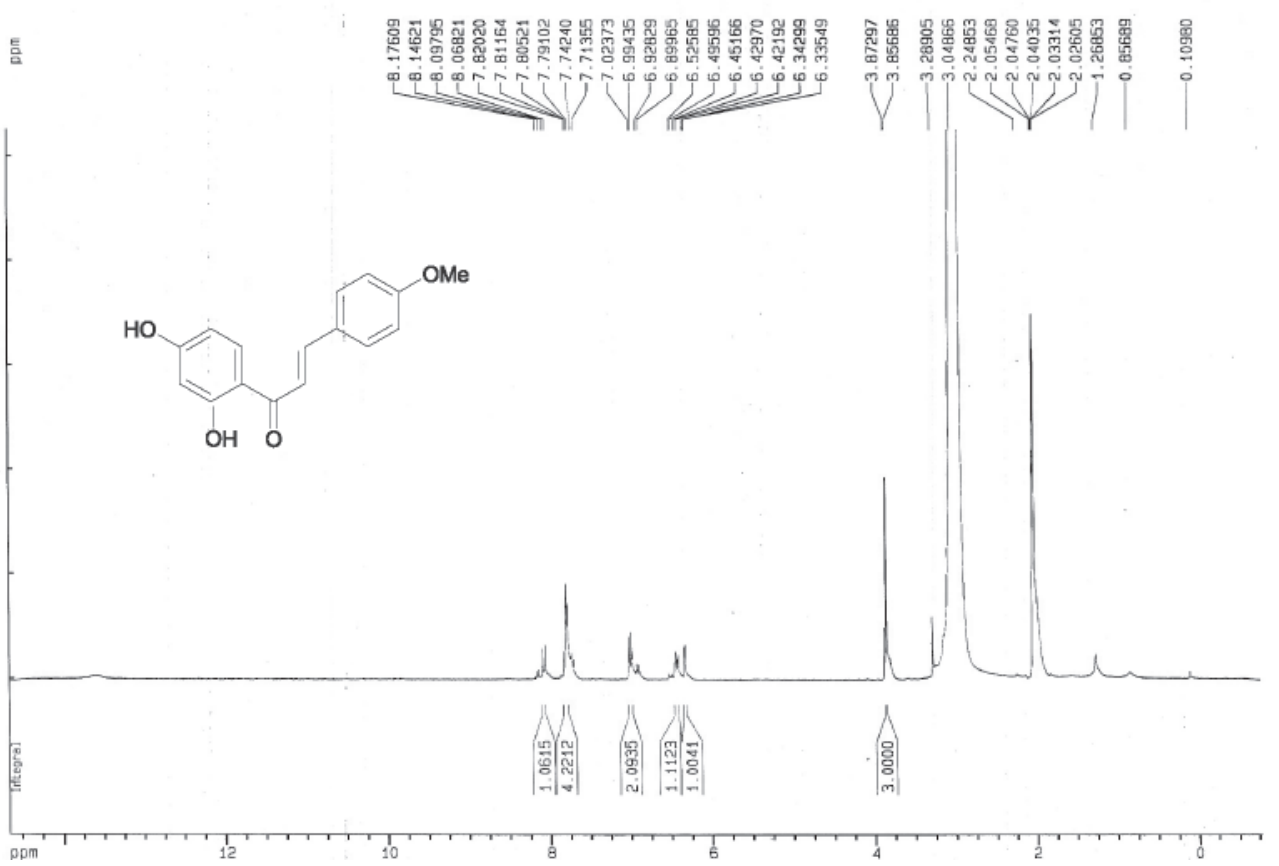

Figure S15. ${ }^{1} \mathrm{H}$ NMR spectrum of compound 9 (300 MHz, acetone- $\left.d_{6}\right)$. 


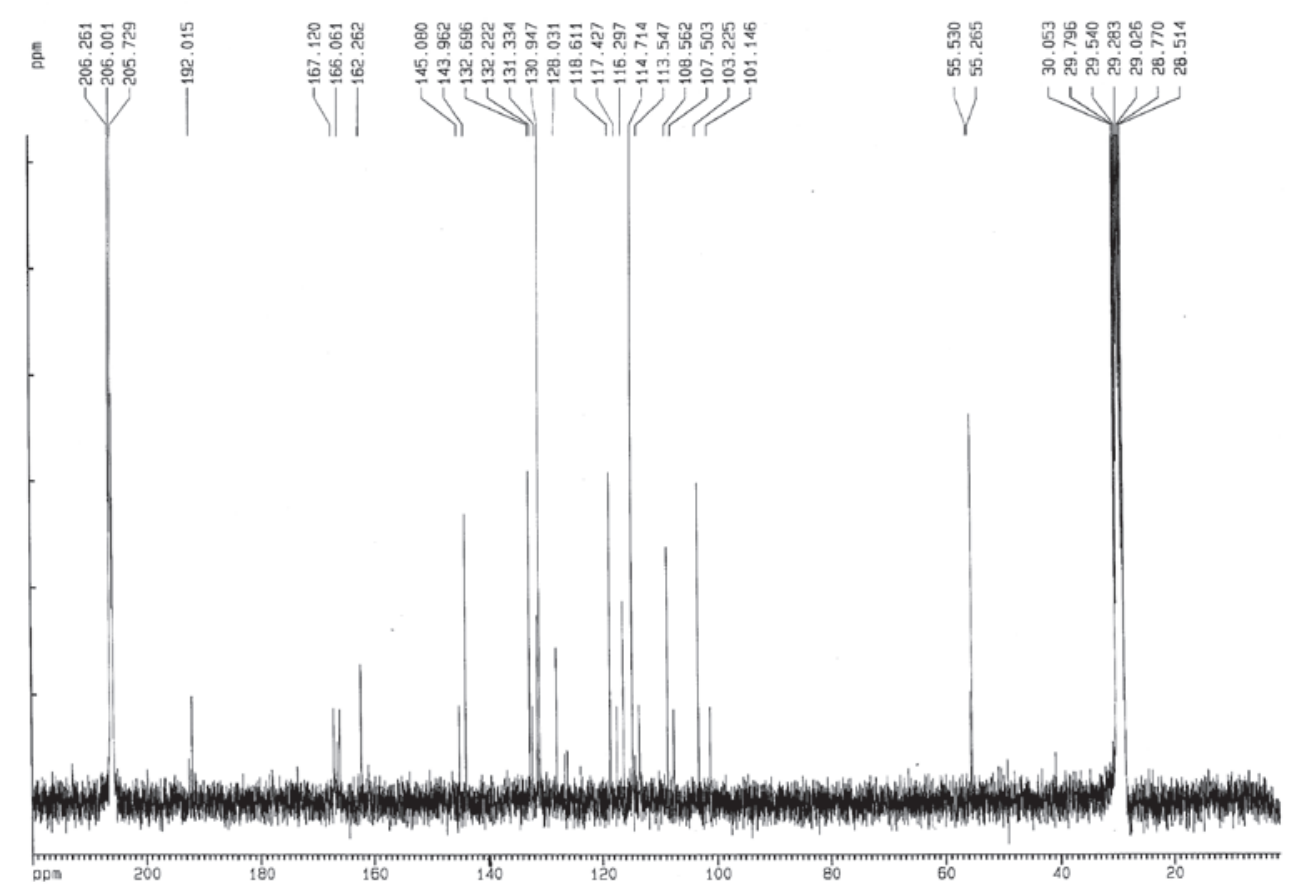

Figure S16. ${ }^{13} \mathrm{C}$ NMR spectrum of compound $9\left(75 \mathrm{MHz}\right.$, acetone- $\left.d_{6}\right)$.

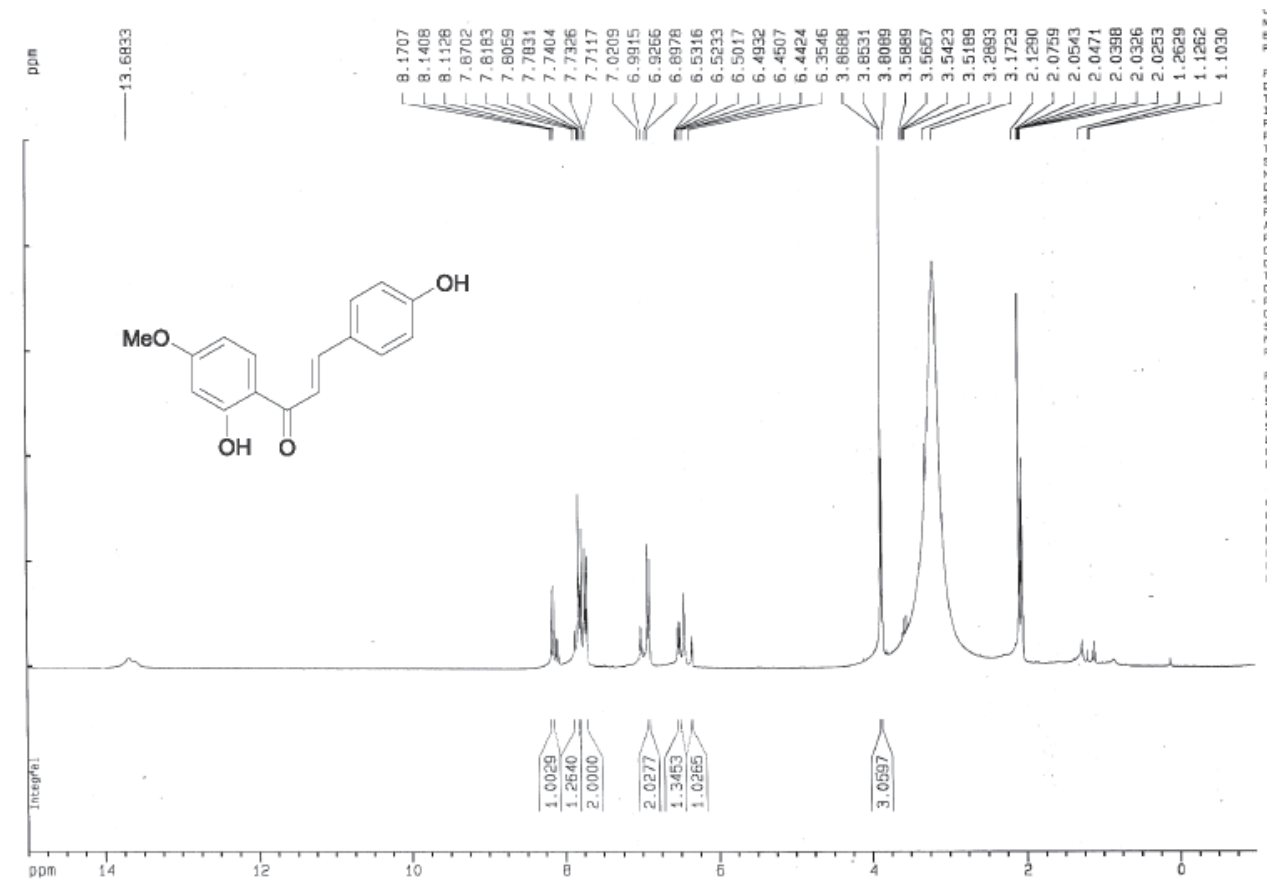

Figure S17. ${ }^{1} \mathrm{H}$ NMR spectrum of compound $10\left(300 \mathrm{MHz}\right.$, acetone- $\left.d_{6}\right)$. 


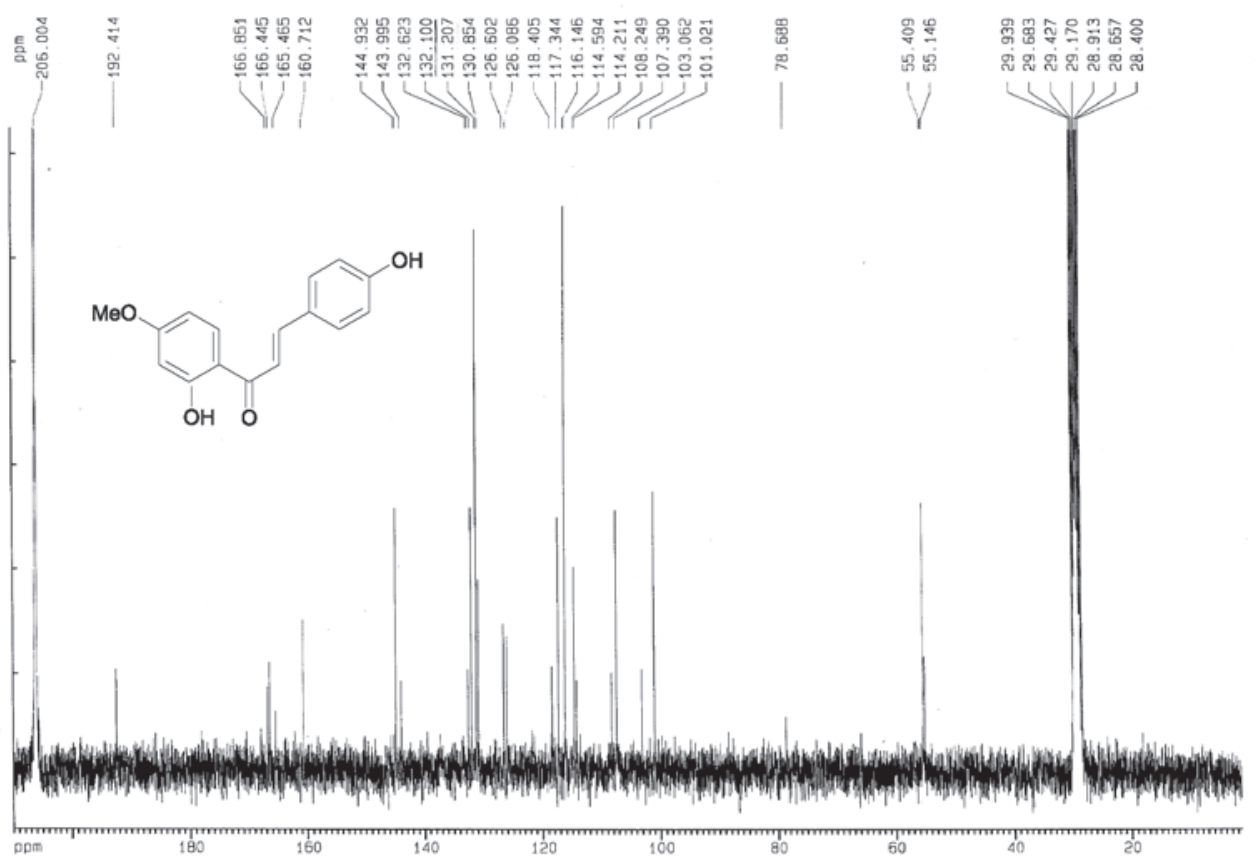

Figure S18. ${ }^{13} \mathrm{C}$ NMR spectrum of compound $10\left(75 \mathrm{MHz}\right.$, acetone- $\left.d_{6}\right)$.

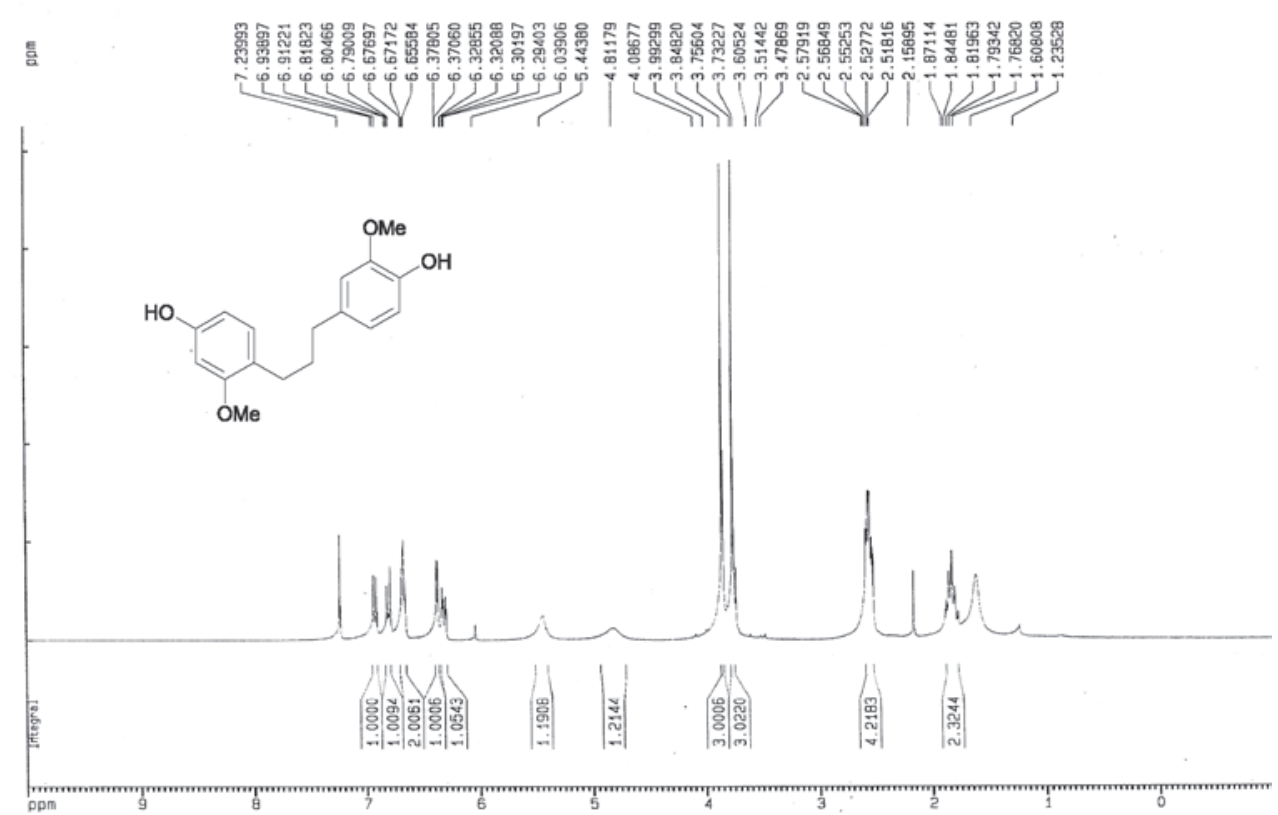

Figure S19. ${ }^{1} \mathrm{H}$ NMR spectrum of compound $11\left(300 \mathrm{MHz}, \mathrm{CDCl}_{3}\right)$. 


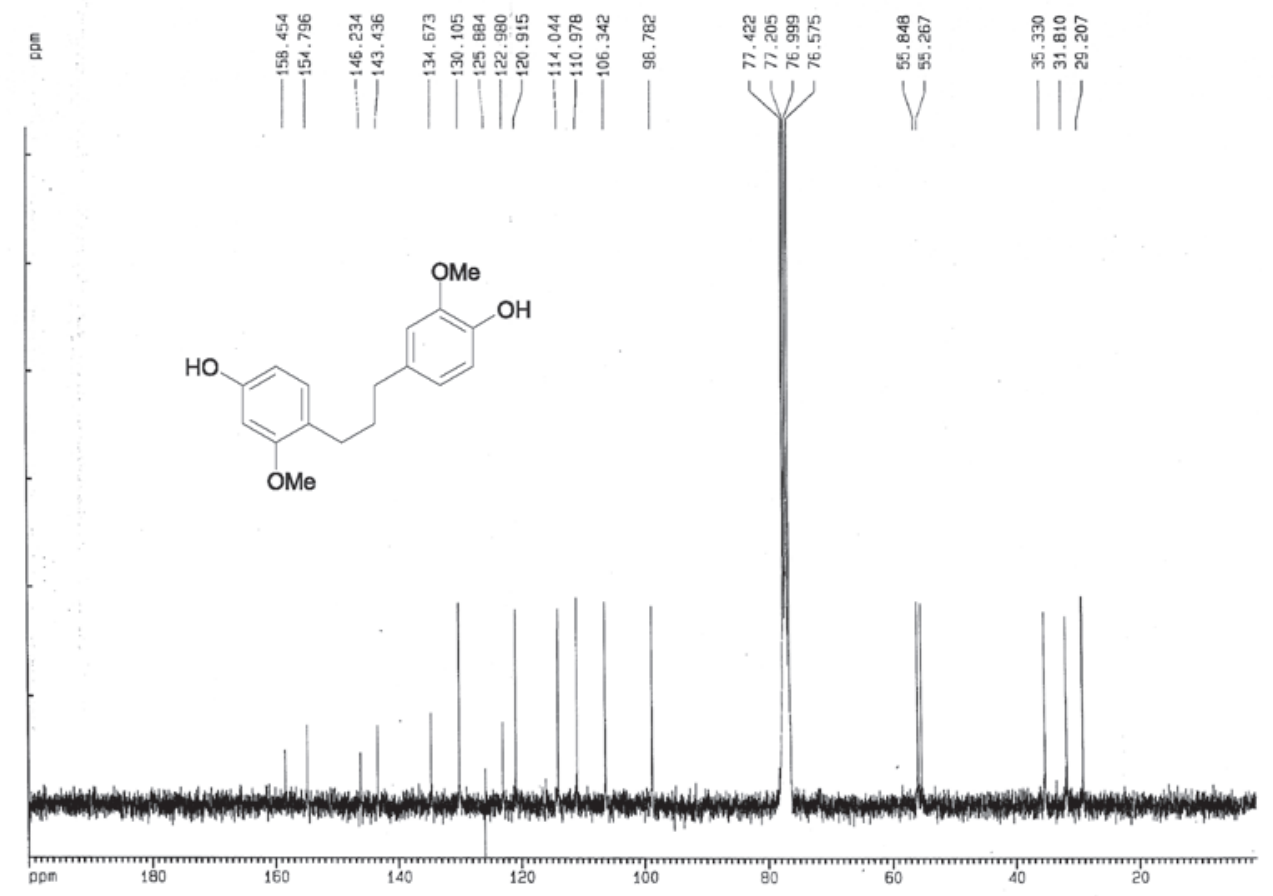

Figure S20. ${ }^{13} \mathrm{C}$ NMR spectrum of compound $11\left(75 \mathrm{MHz}, \mathrm{CDCl}_{3}\right)$.

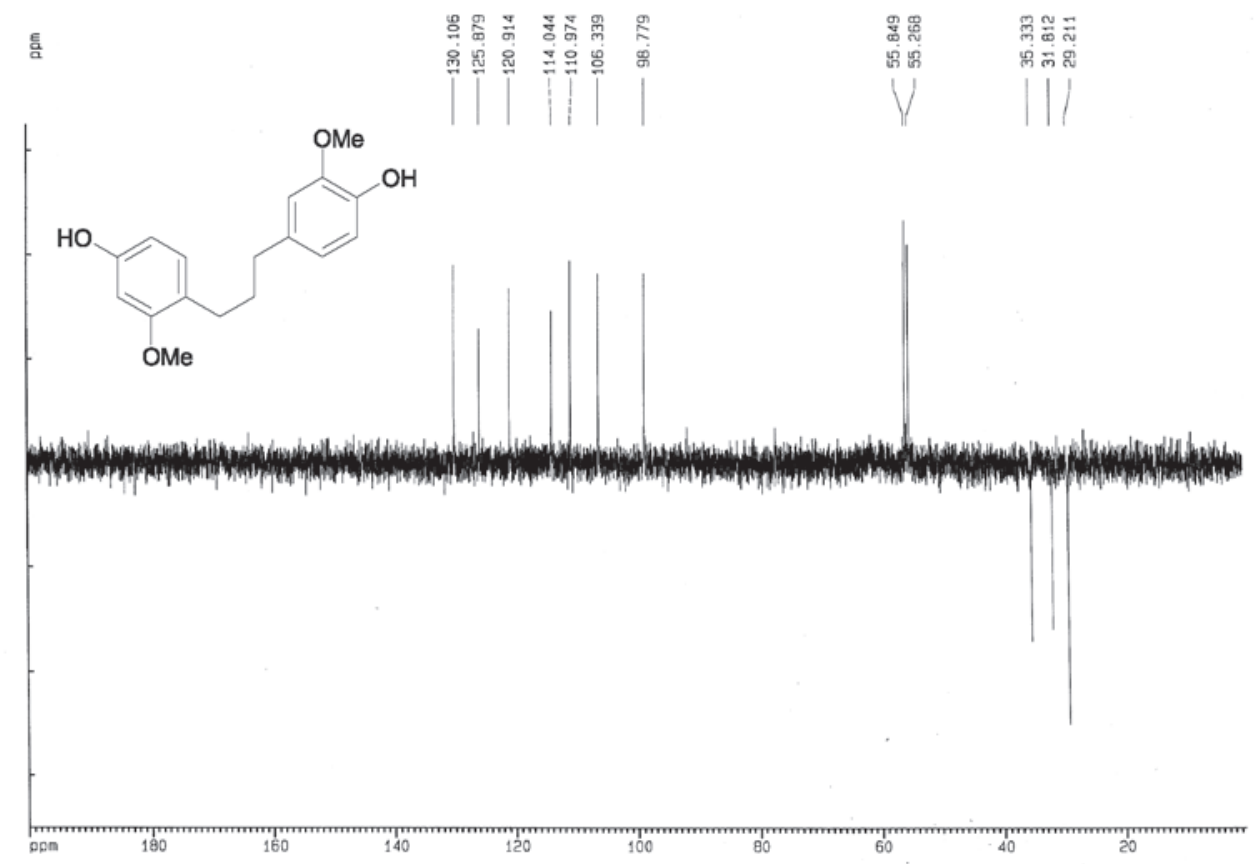

Figure S21. DEPT- $135^{\circ}$ spectrum of compound $11\left(75 \mathrm{MHz}, \mathrm{CDCl}_{3}\right)$. 


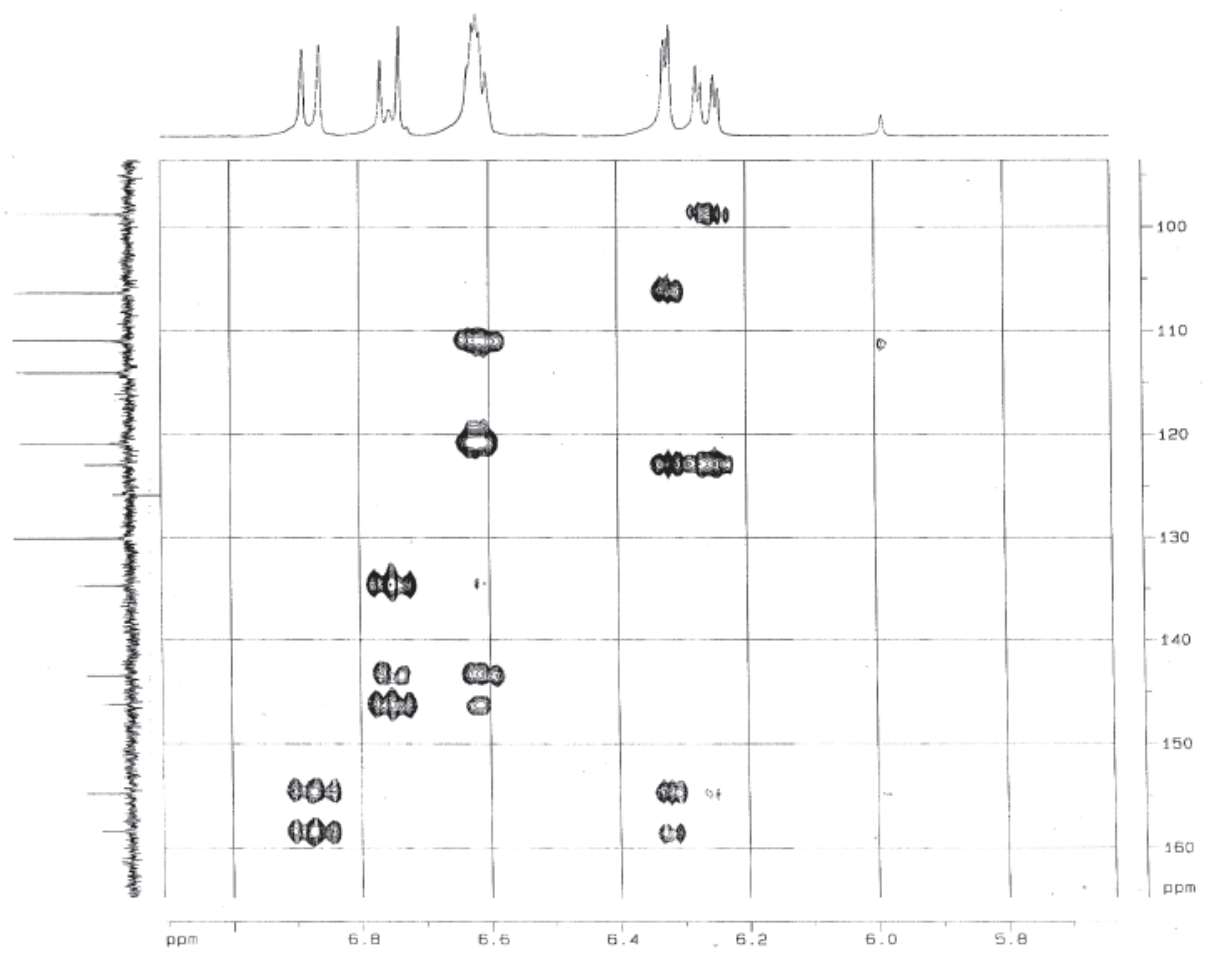

Figure S22. HMBC experiment of compound $\mathbf{1 1 .}$

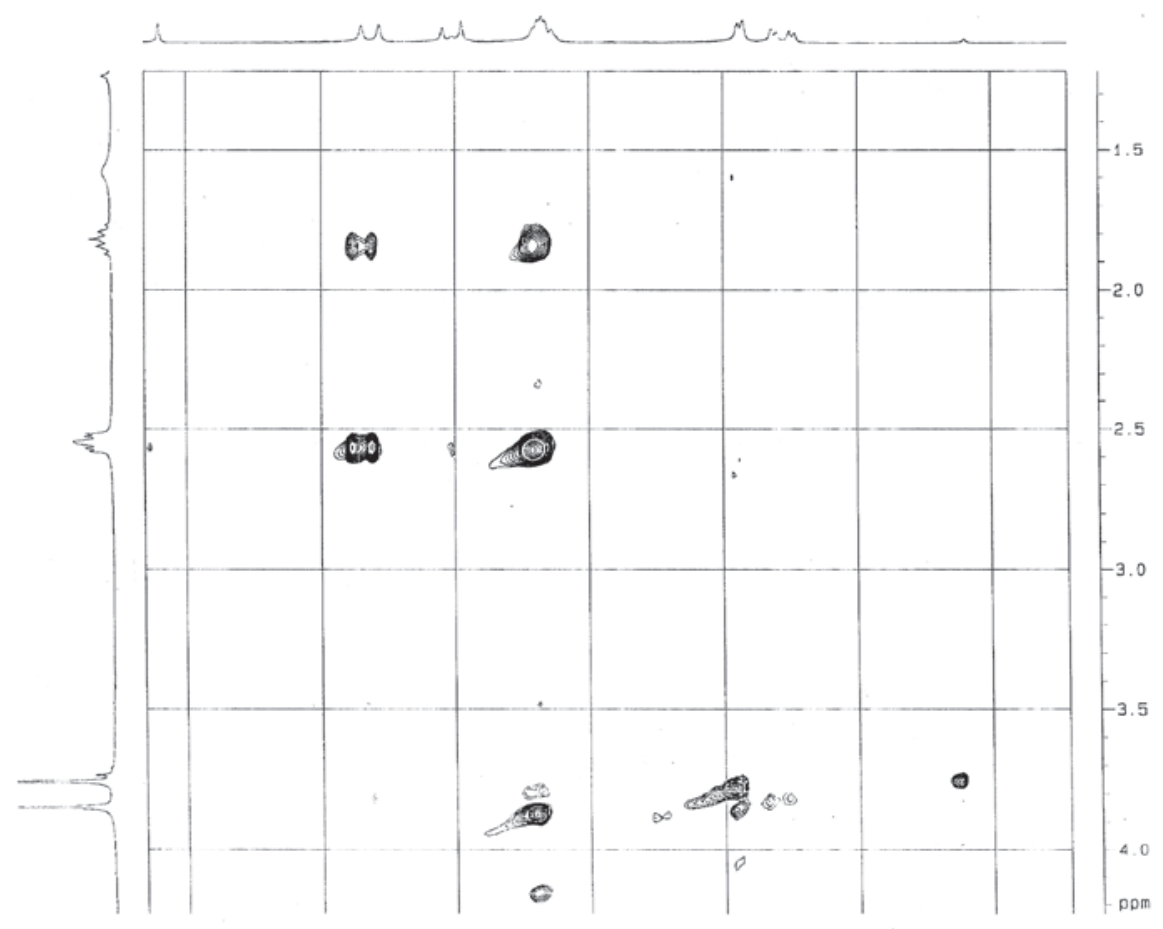

Figure S23. NOESY experiment of compound 11. 


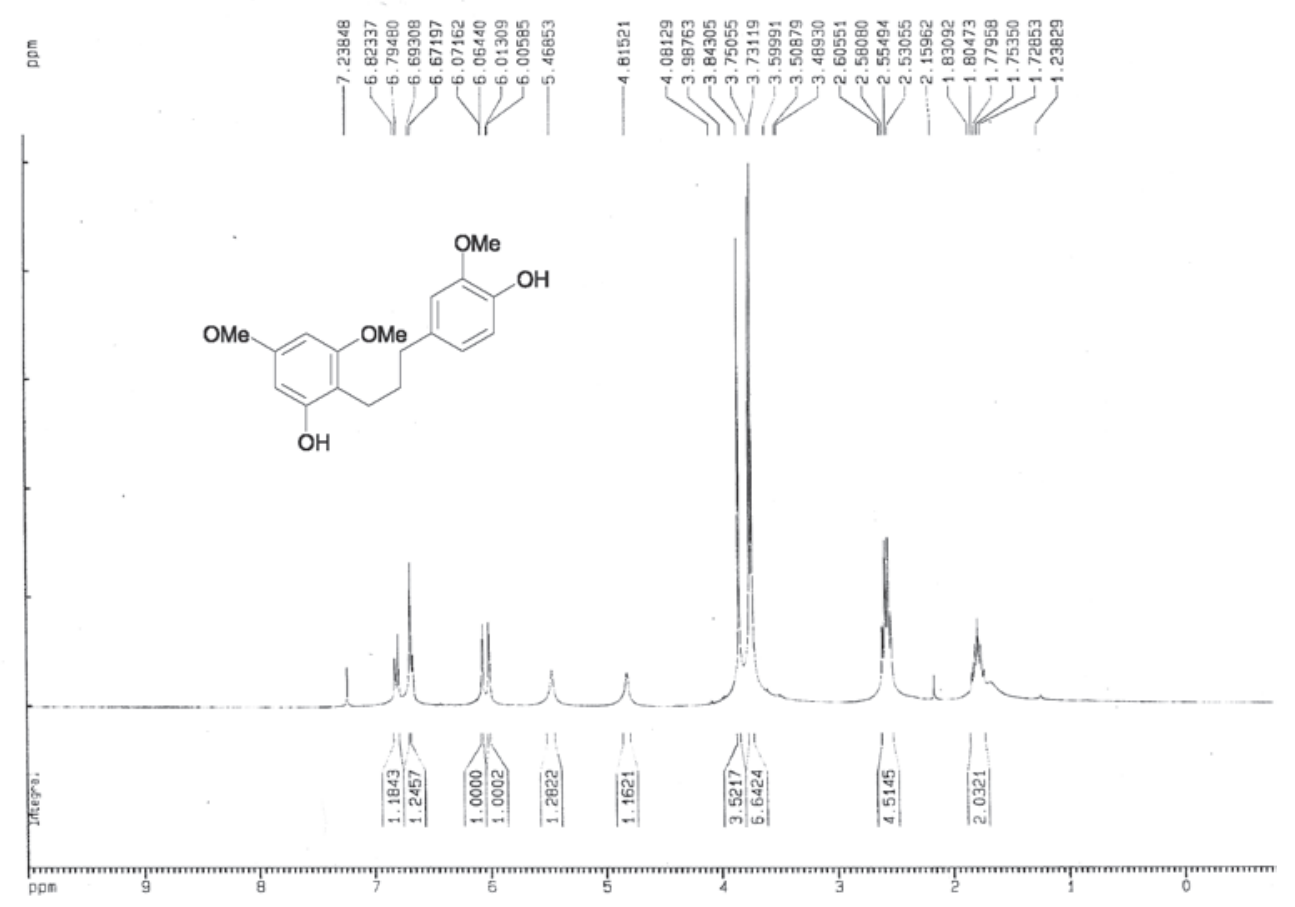

Figure S24. ${ }^{1} \mathrm{H}$ NMR spectrum of compound $12\left(300 \mathrm{MHz}, \mathrm{CDCl}_{3}\right)$.

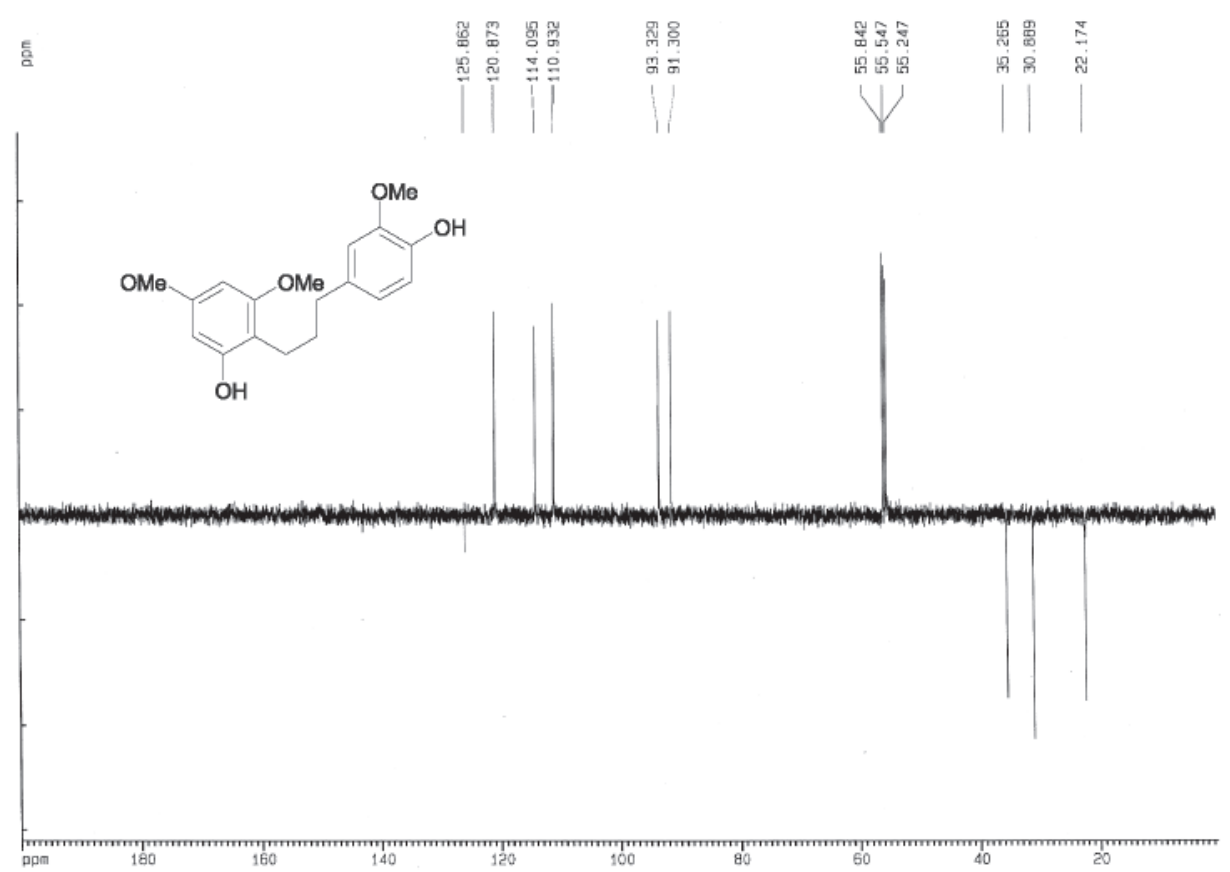

Figure S25. ${ }^{13} \mathrm{C}$ NMR spectrum of compound $12\left(75 \mathrm{MHz}, \mathrm{CDCl}_{3}\right)$. 


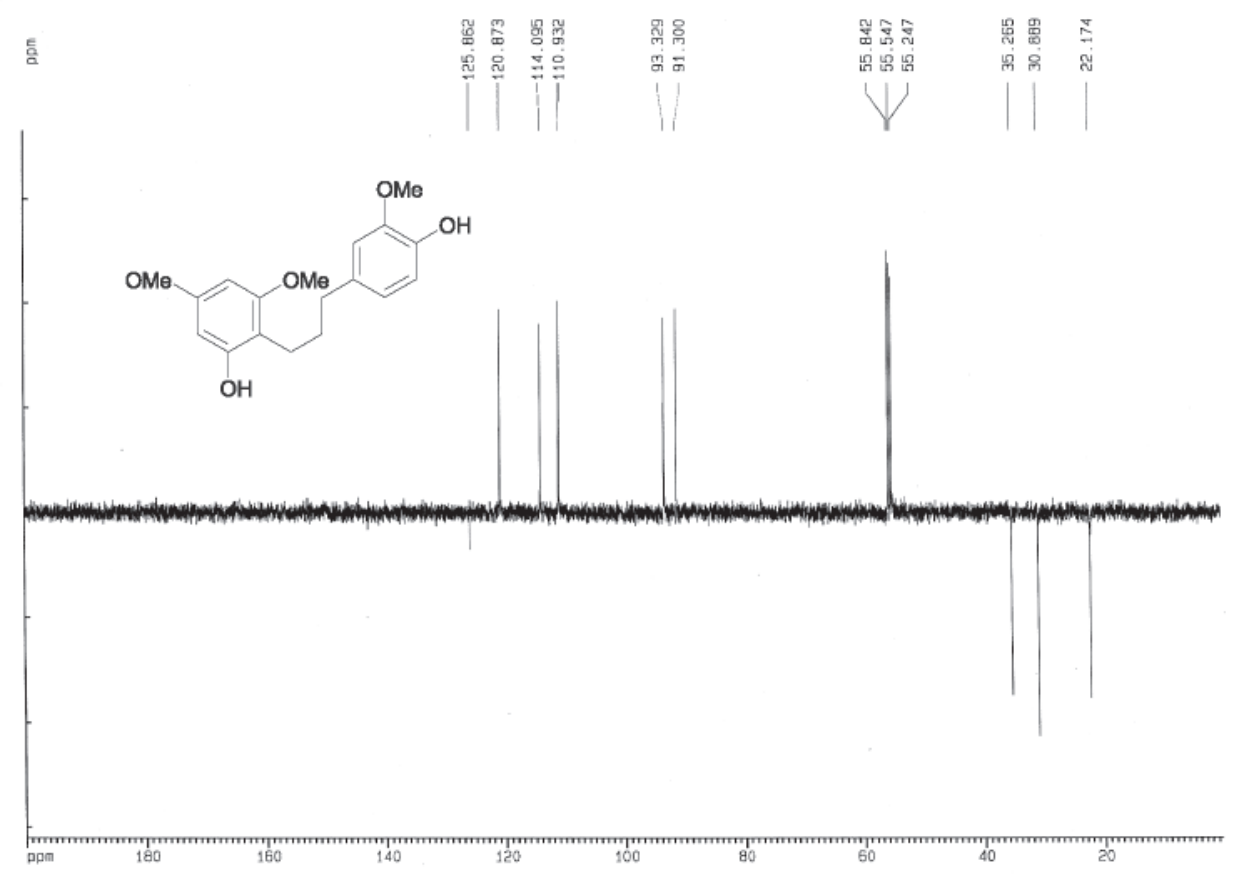

Figure S26. DEPT- $135^{\circ}$ spectrum of compound $12\left(75 \mathrm{MHz}, \mathrm{CDCl}_{3}\right)$.

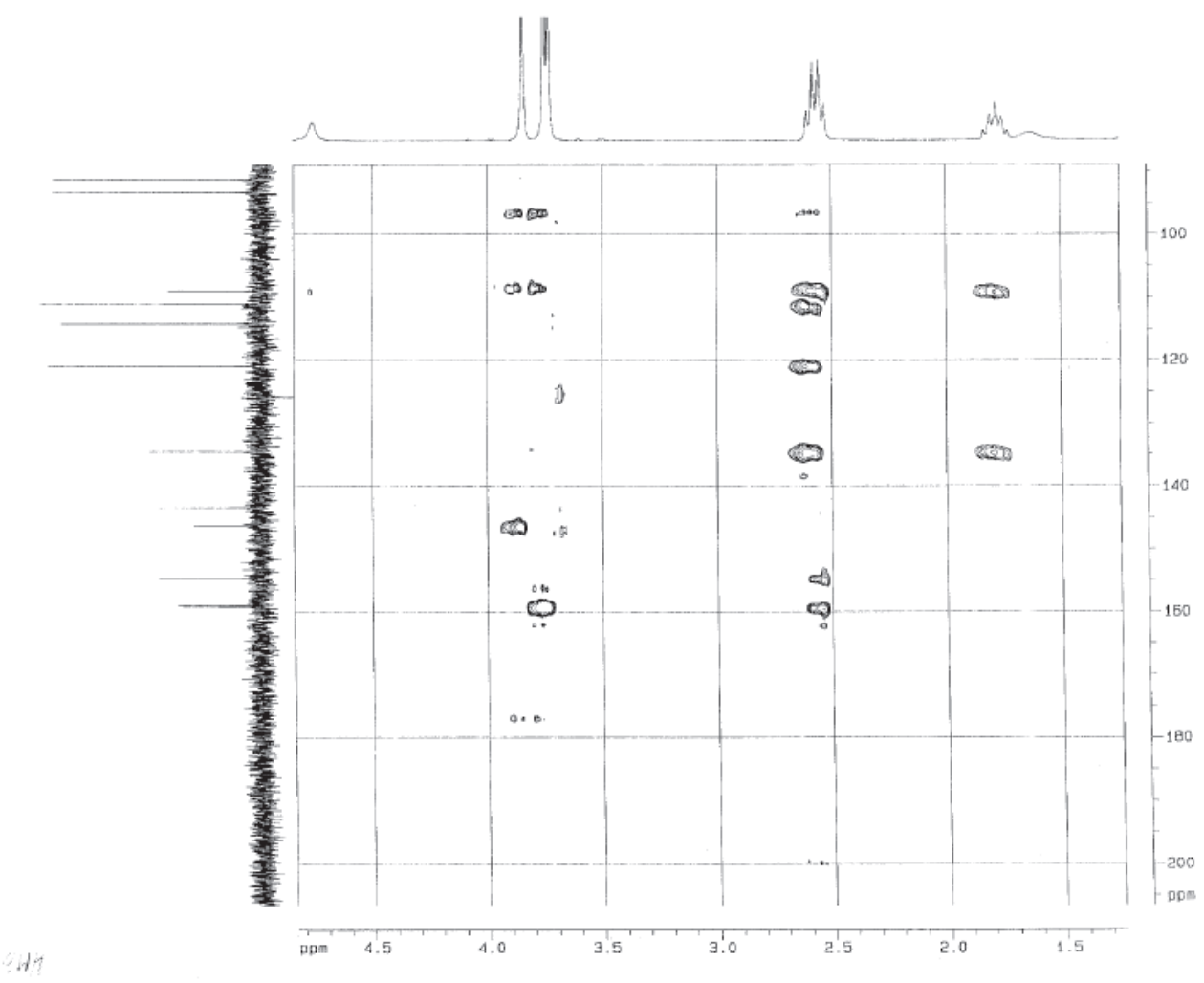

Figure S27. HMBC experiment of compound 12. 


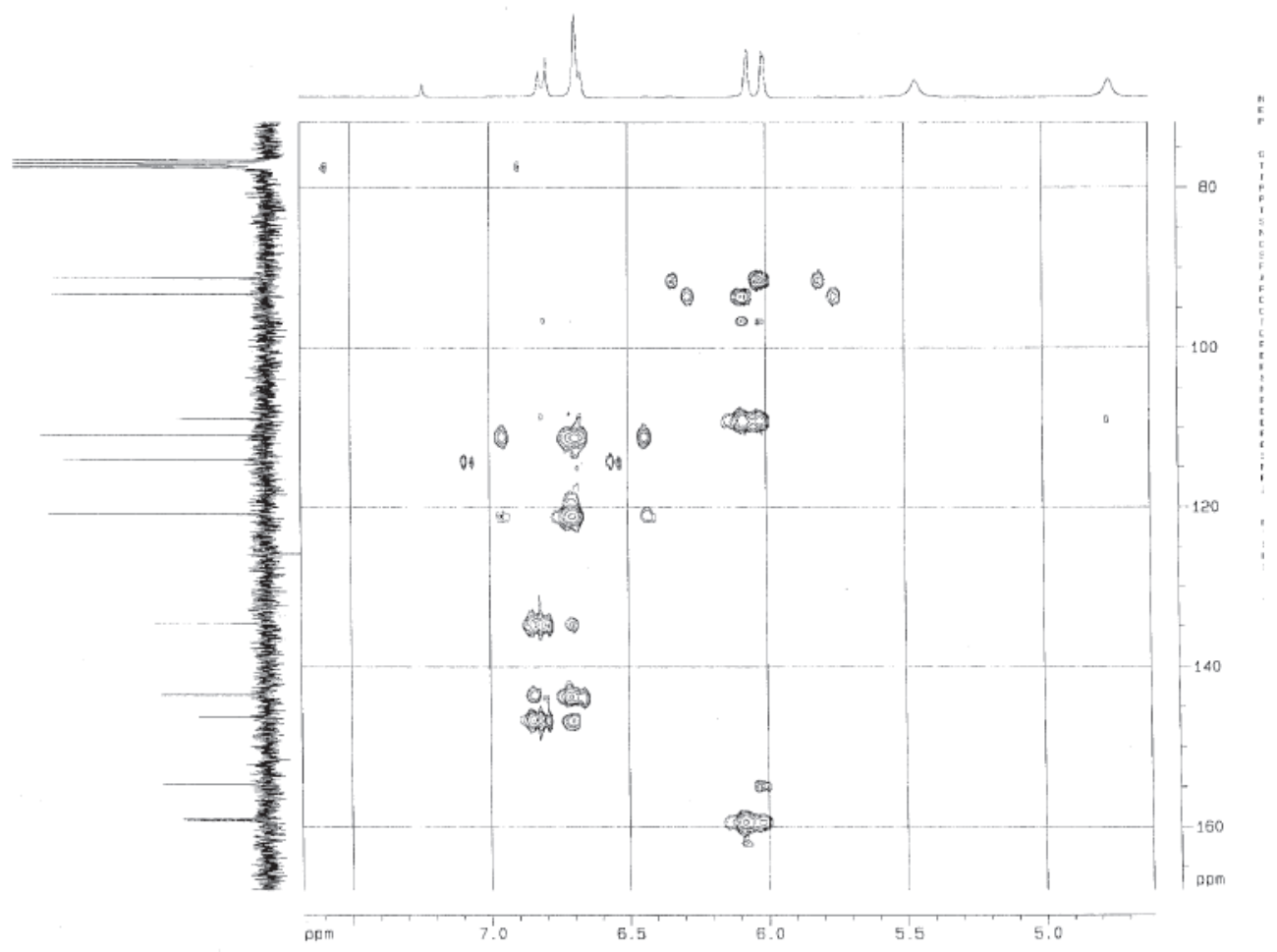

Figure S28. HMBC experiment of compound $\mathbf{1 2}$.

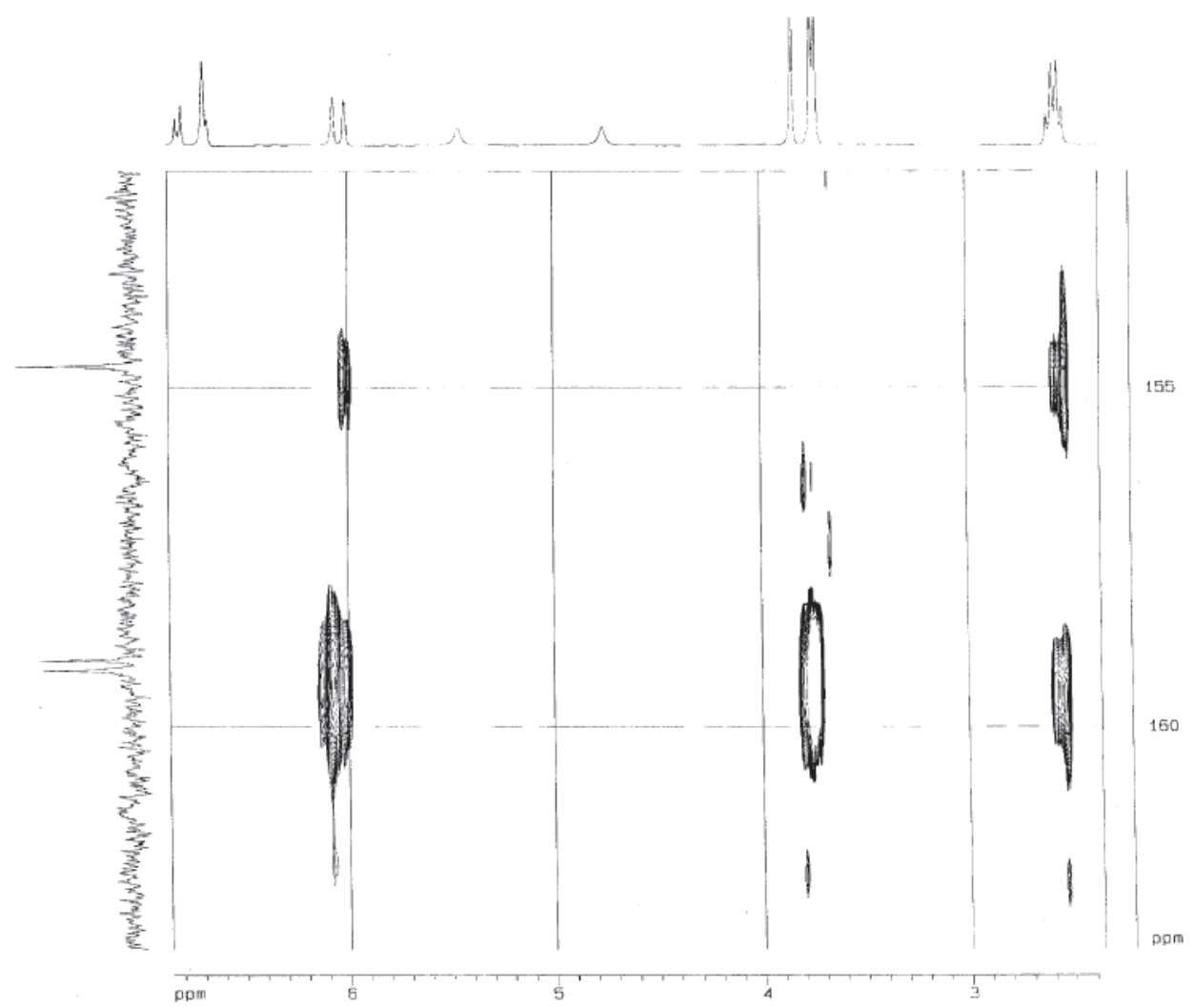

Figure S29. HMBC experiment of compound 12. 


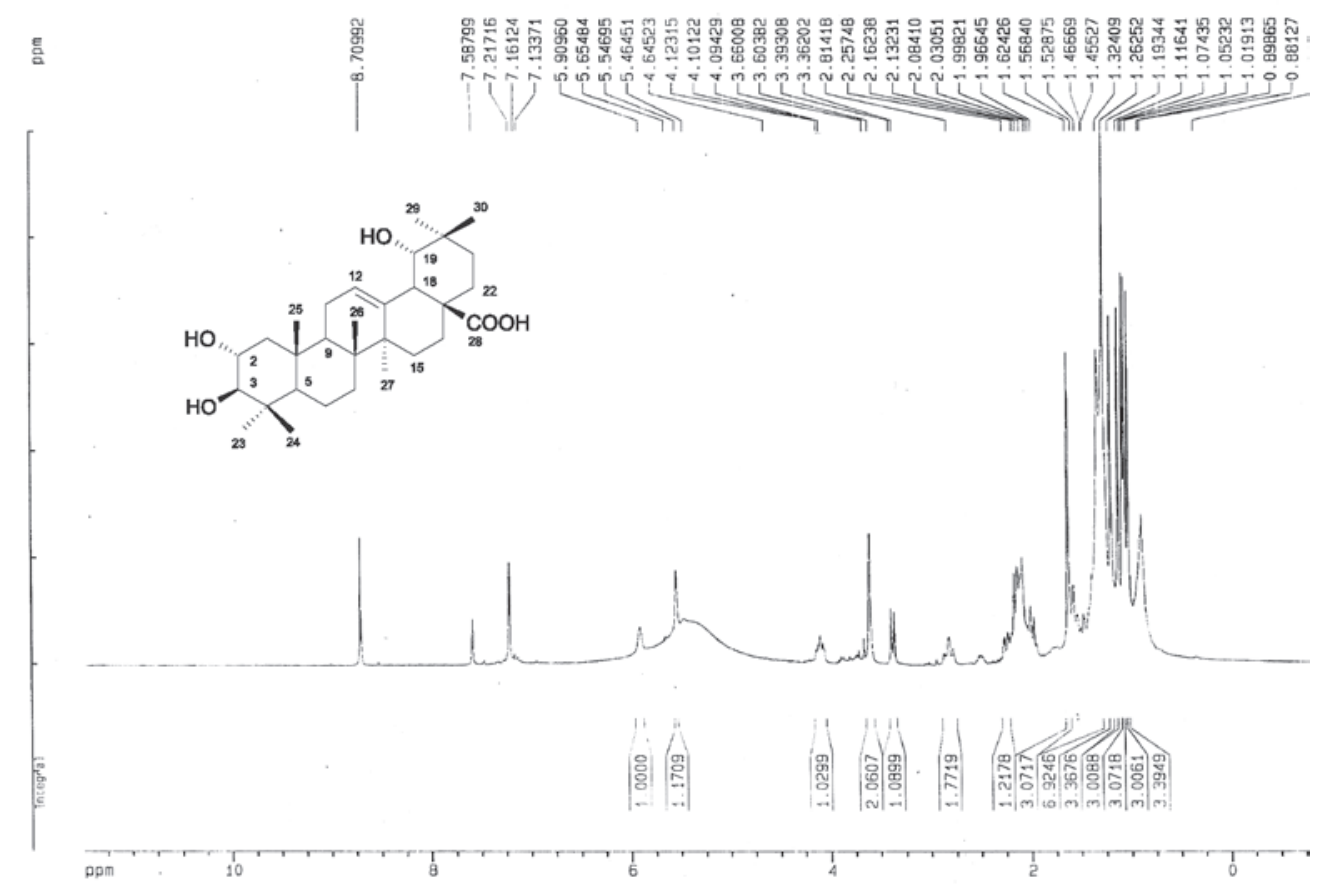

Figure S30. ${ }^{1} \mathrm{H}$ NMR spectrum of compound $13\left(300 \mathrm{MHz}\right.$, Py- $\left.d_{5}\right)$.

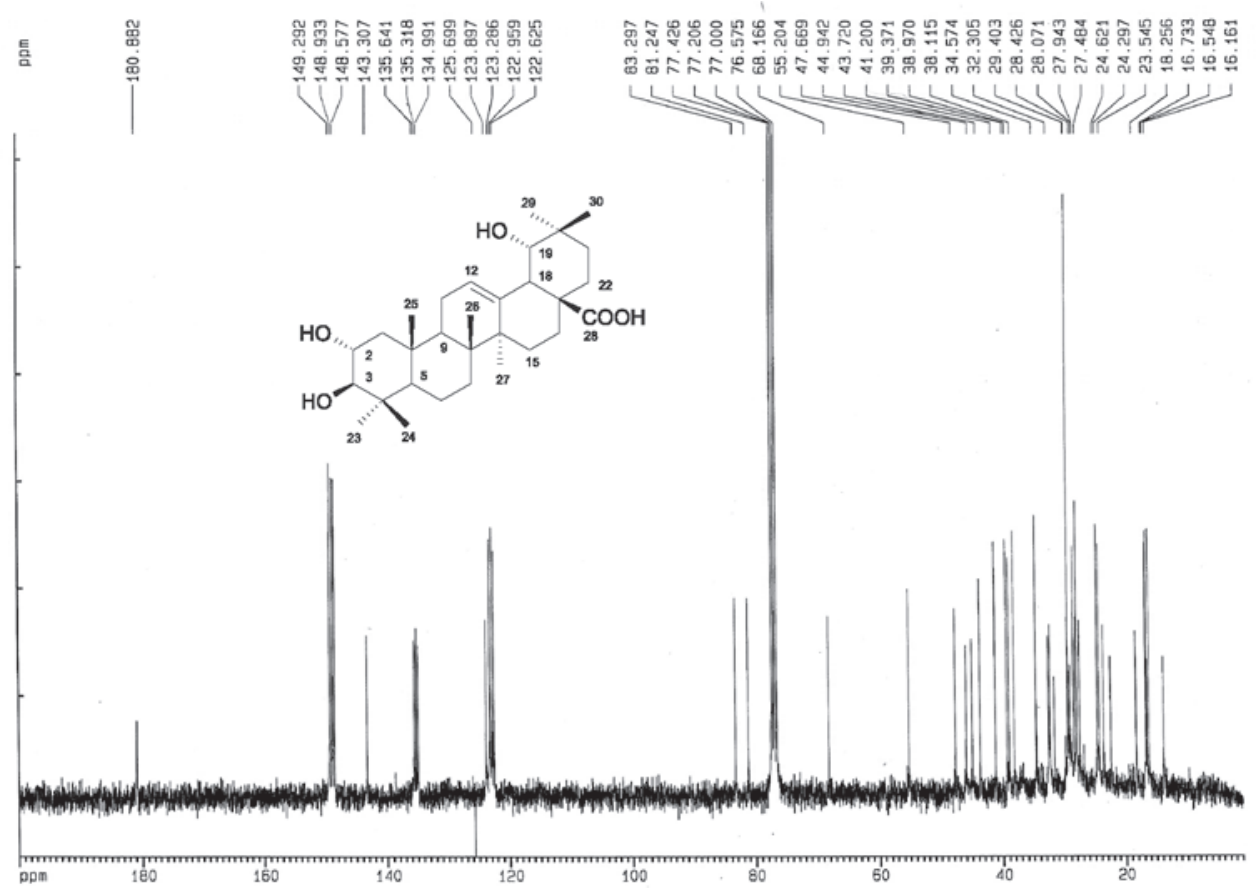

Figure S31. ${ }^{13} \mathrm{C}$ NMR spectrum of compound $13\left(75 \mathrm{MHz}, \mathrm{CDCl}_{3}+\mathrm{Py} d_{5}\right)$. 


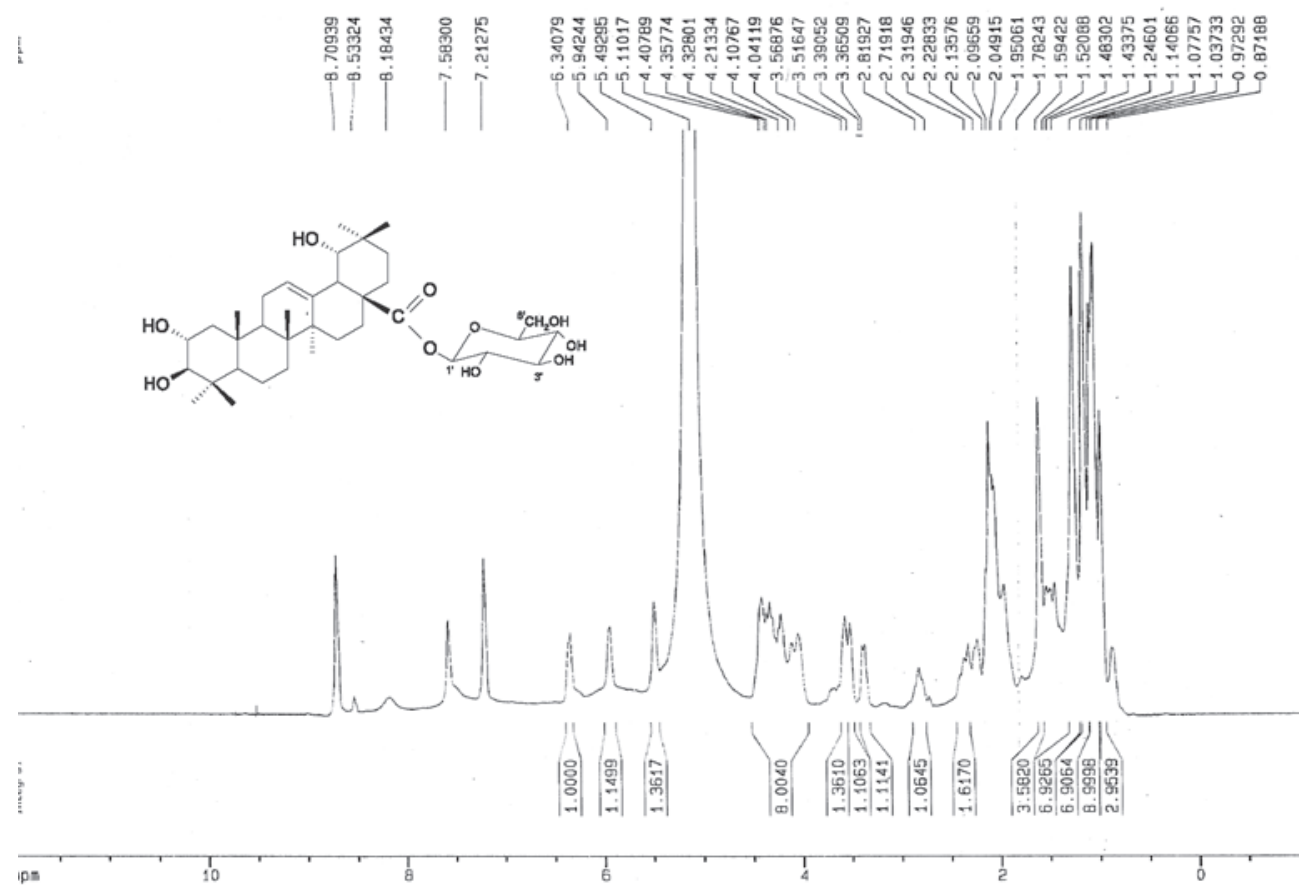

Figure S32. ${ }^{1} \mathrm{H}$ NMR spectrum of compound $14\left(300 \mathrm{MHz}, \mathrm{Py}-d_{5}\right)$.

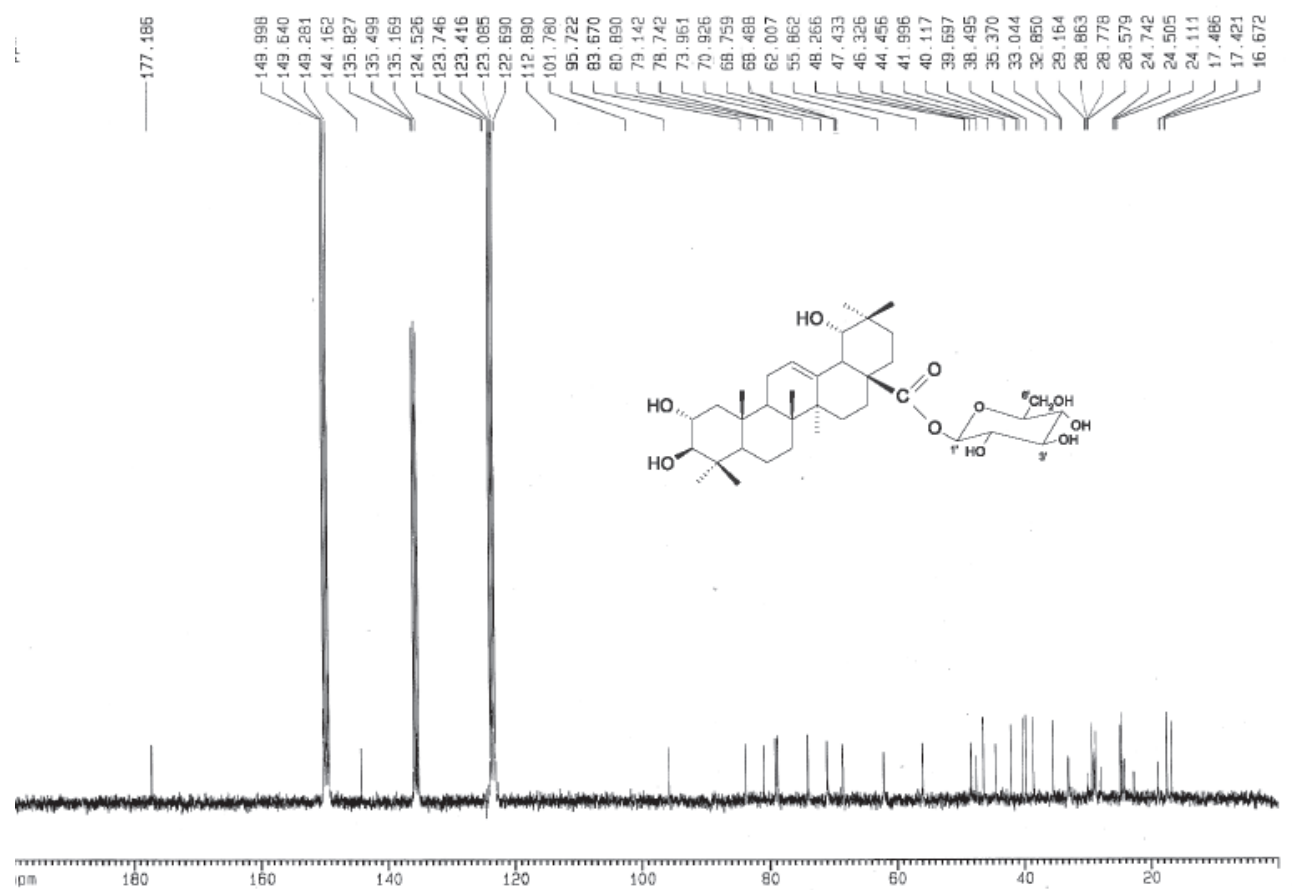

Figure S33. ${ }^{13} \mathrm{C}$ NMR spectrum of compound $14\left(75 \mathrm{MHz}\right.$, Py- $\left.d_{5}\right)$. 

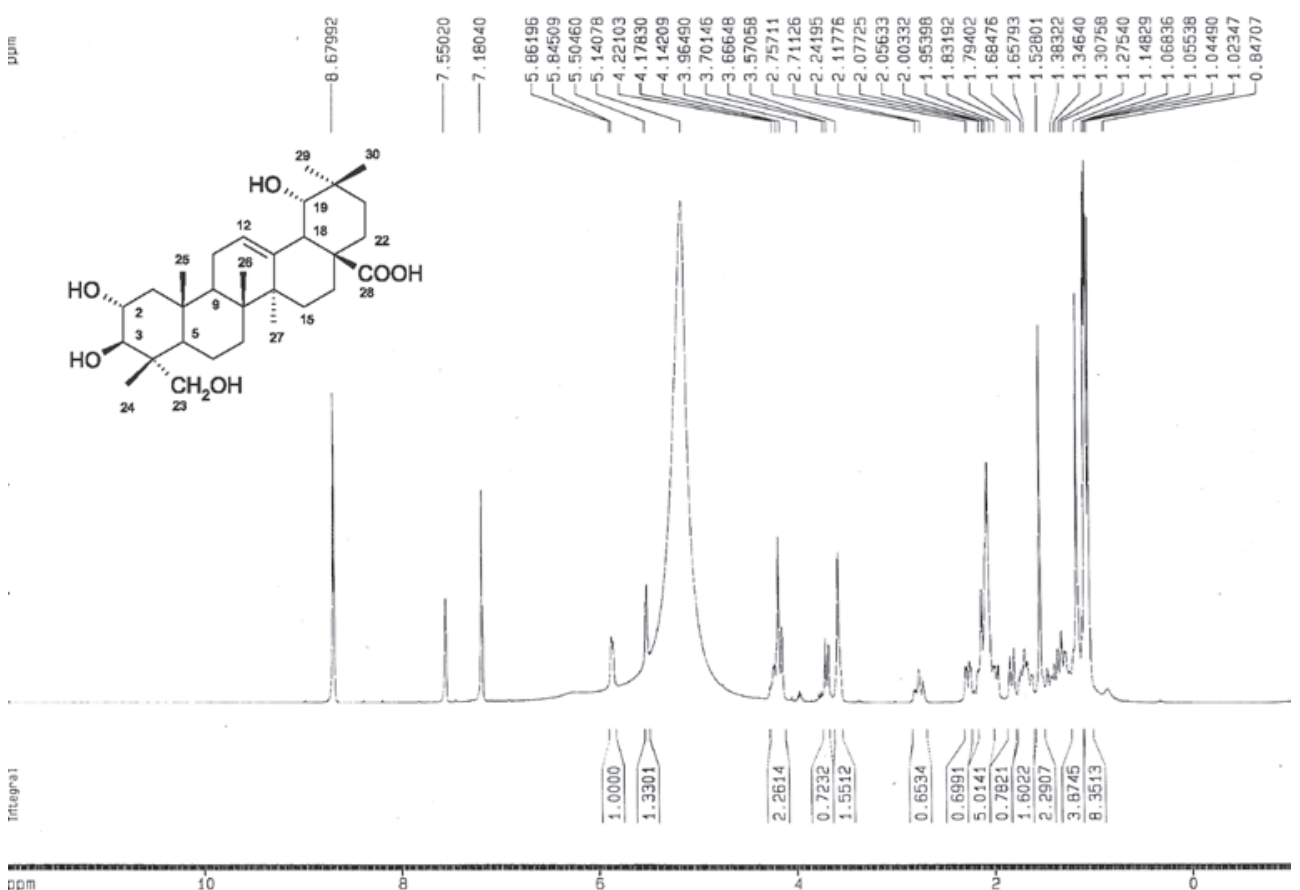

Figure S34. ${ }^{1} \mathrm{H}$ NMR spectrum of compound $15\left(300 \mathrm{MHz}, \mathrm{Py}-d_{5}\right)$.

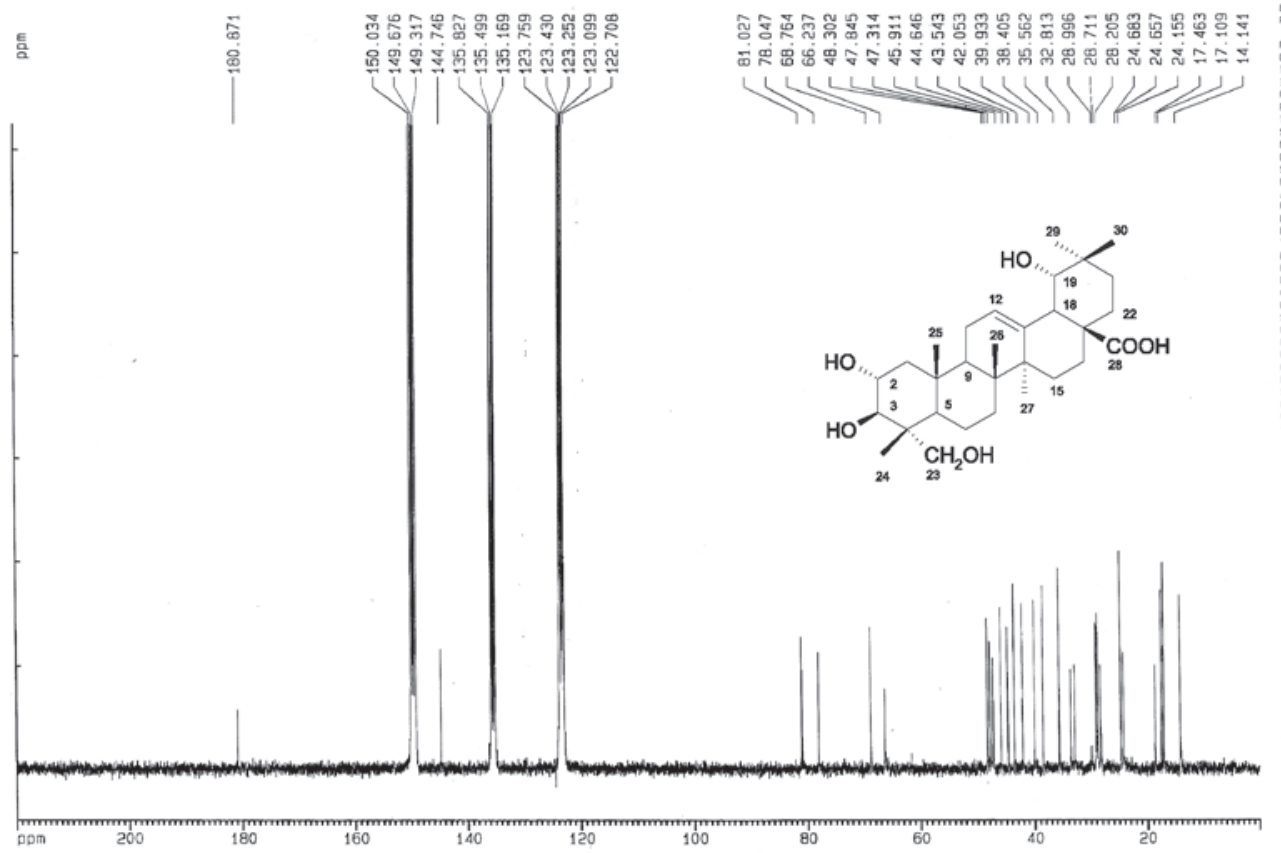

Figure S35. ${ }^{13} \mathrm{C}$ NMR spectrum of compound $15\left(75 \mathrm{MHz}, \mathrm{Py}-d_{5}\right)$. 


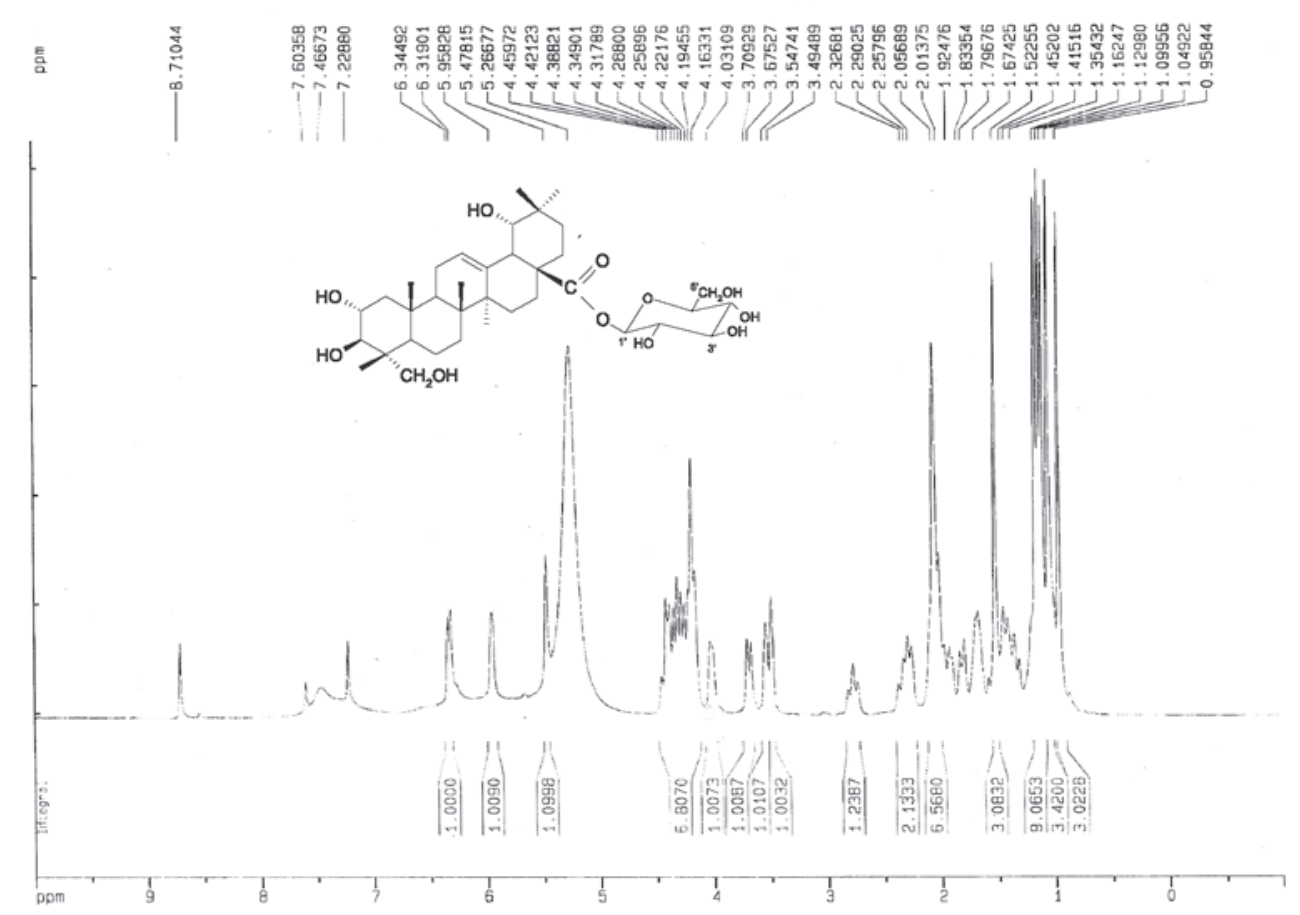

Figure S36. ${ }^{1} \mathrm{H}$ NMR spectrum of compound $16\left(300 \mathrm{MHz}, \mathrm{Py}-d_{5}\right)$.

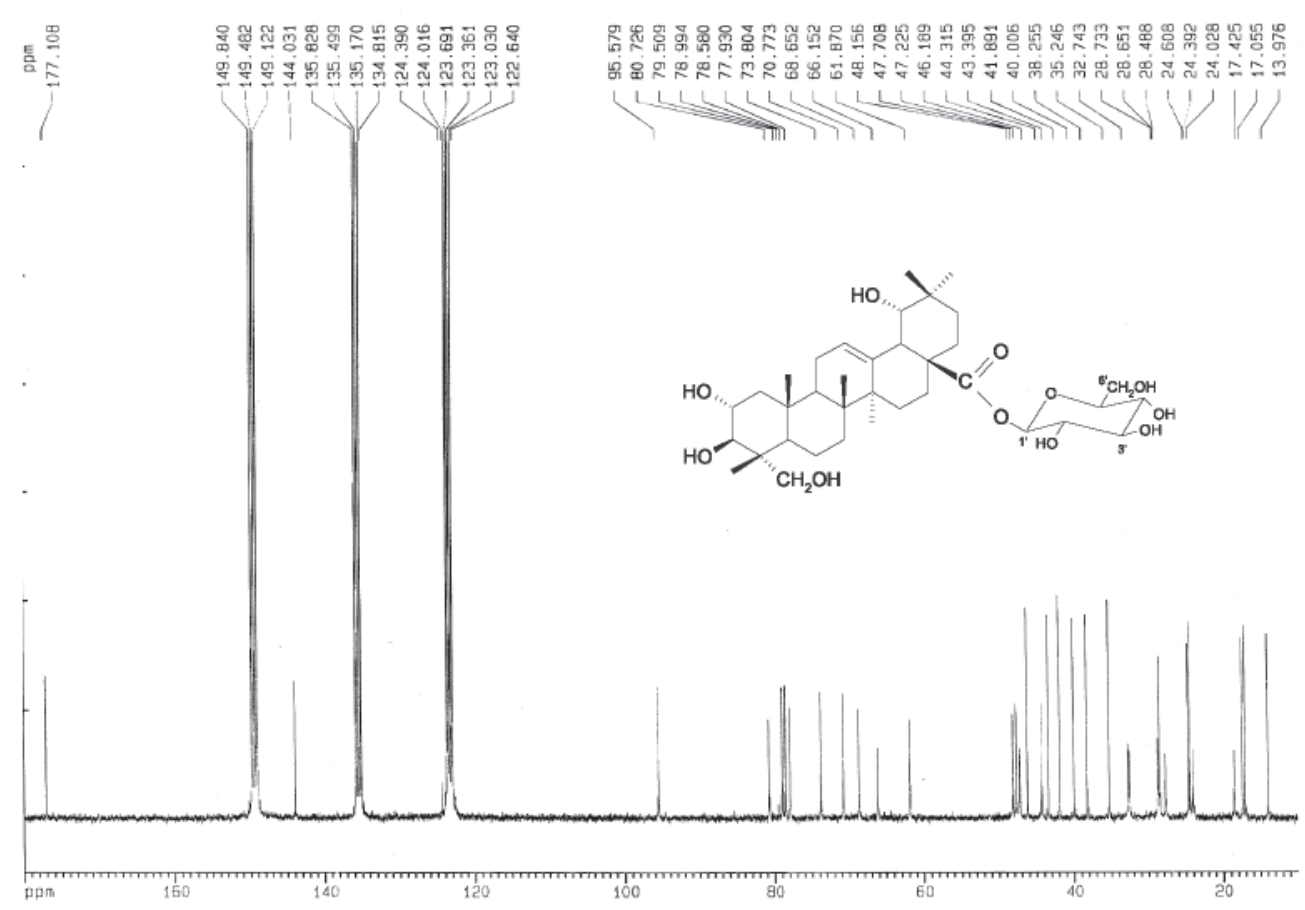

Figure S37. ${ }^{13} \mathrm{C}$ NMR spectrum of compound $16\left(75 \mathrm{MHz}\right.$, Py- $\left.d_{5}\right)$. 


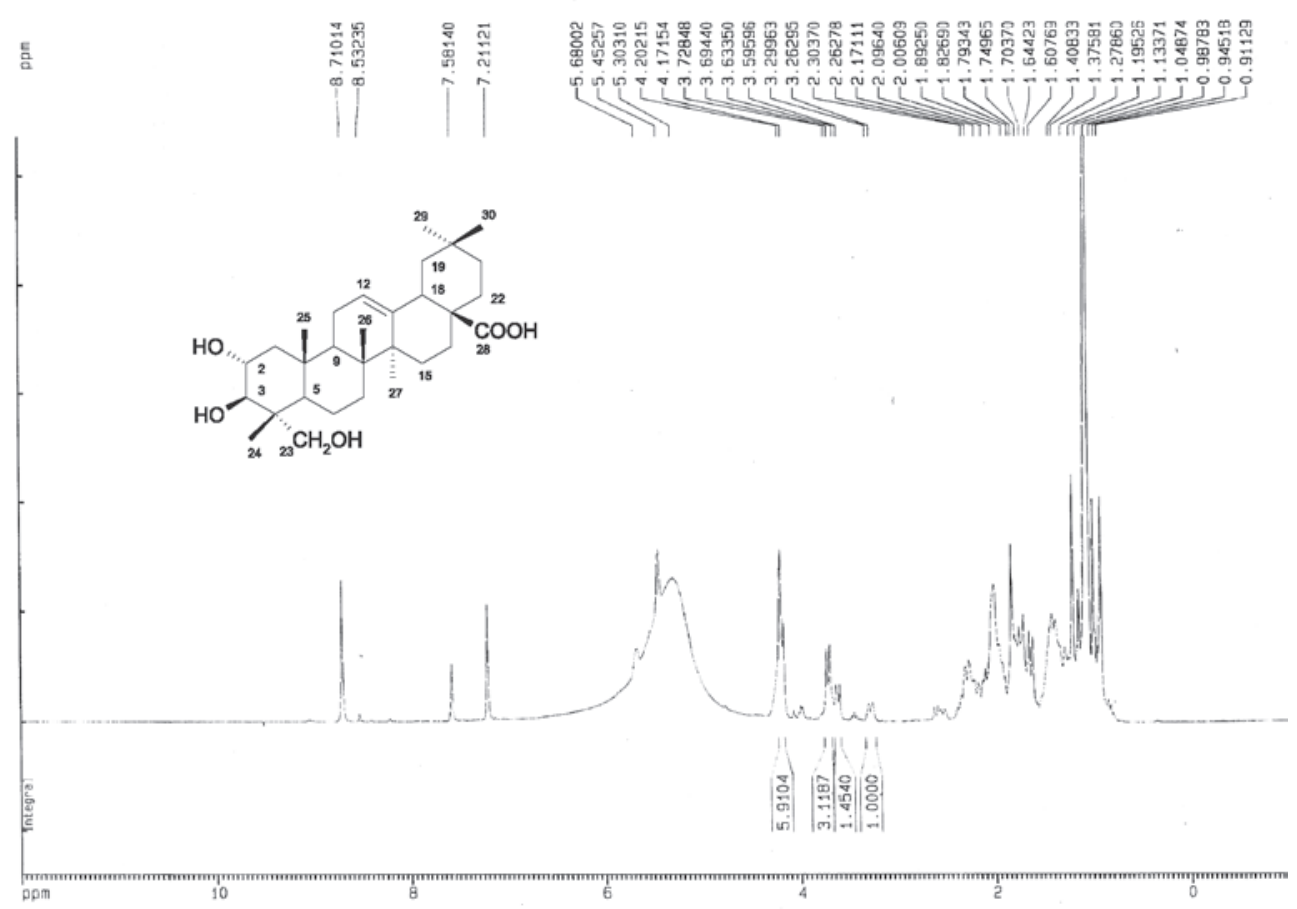

Figure S38. ${ }^{1} \mathrm{H}$ NMR spectrum of compound $17\left(300 \mathrm{MHz}, \mathrm{Py}-d_{5}\right)$.

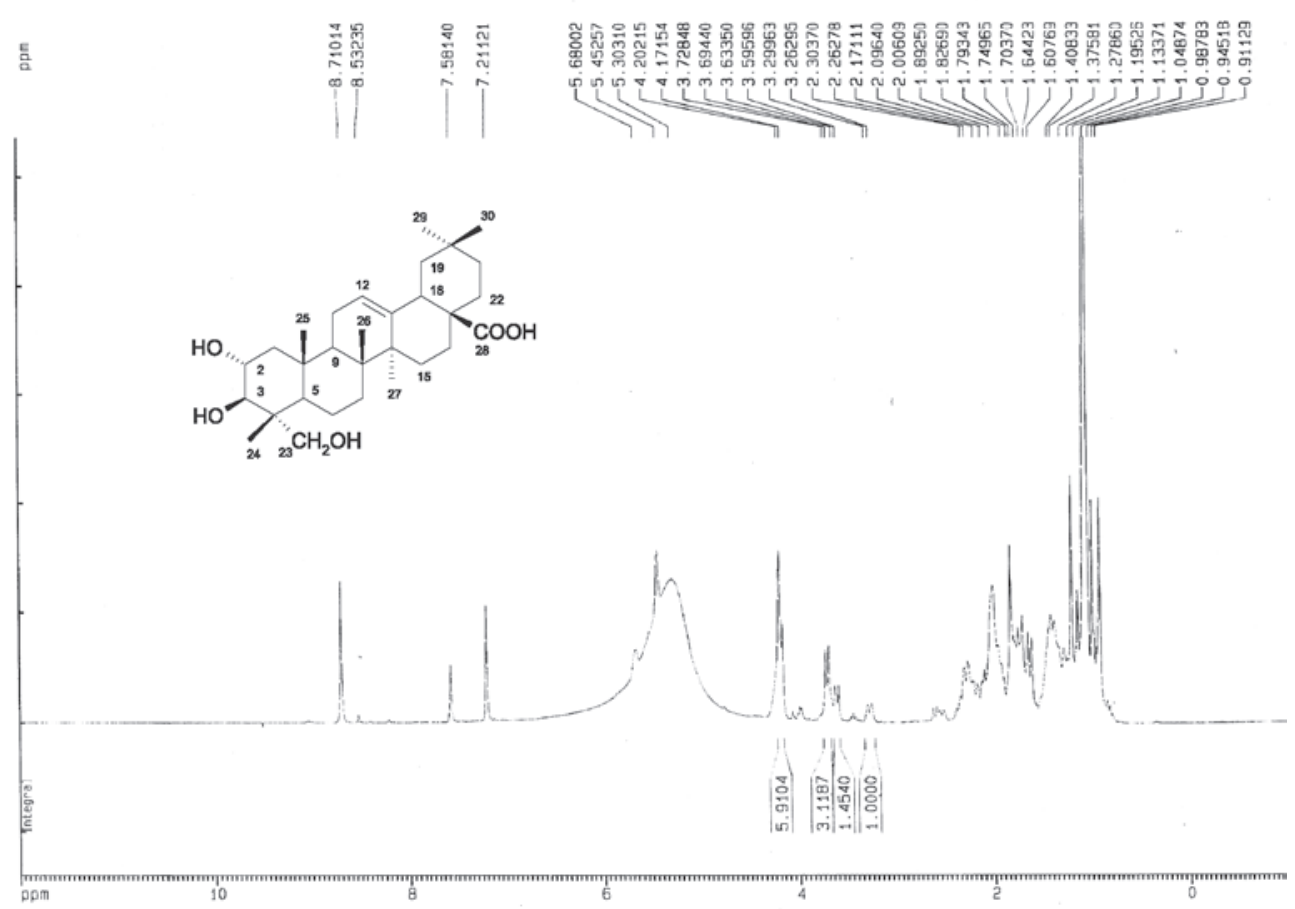

Figure S39. ${ }^{13} \mathrm{C}$ NMR spectrum of compound $17\left(75 \mathrm{MHz}, \mathrm{Py}-d_{5}\right)$. 


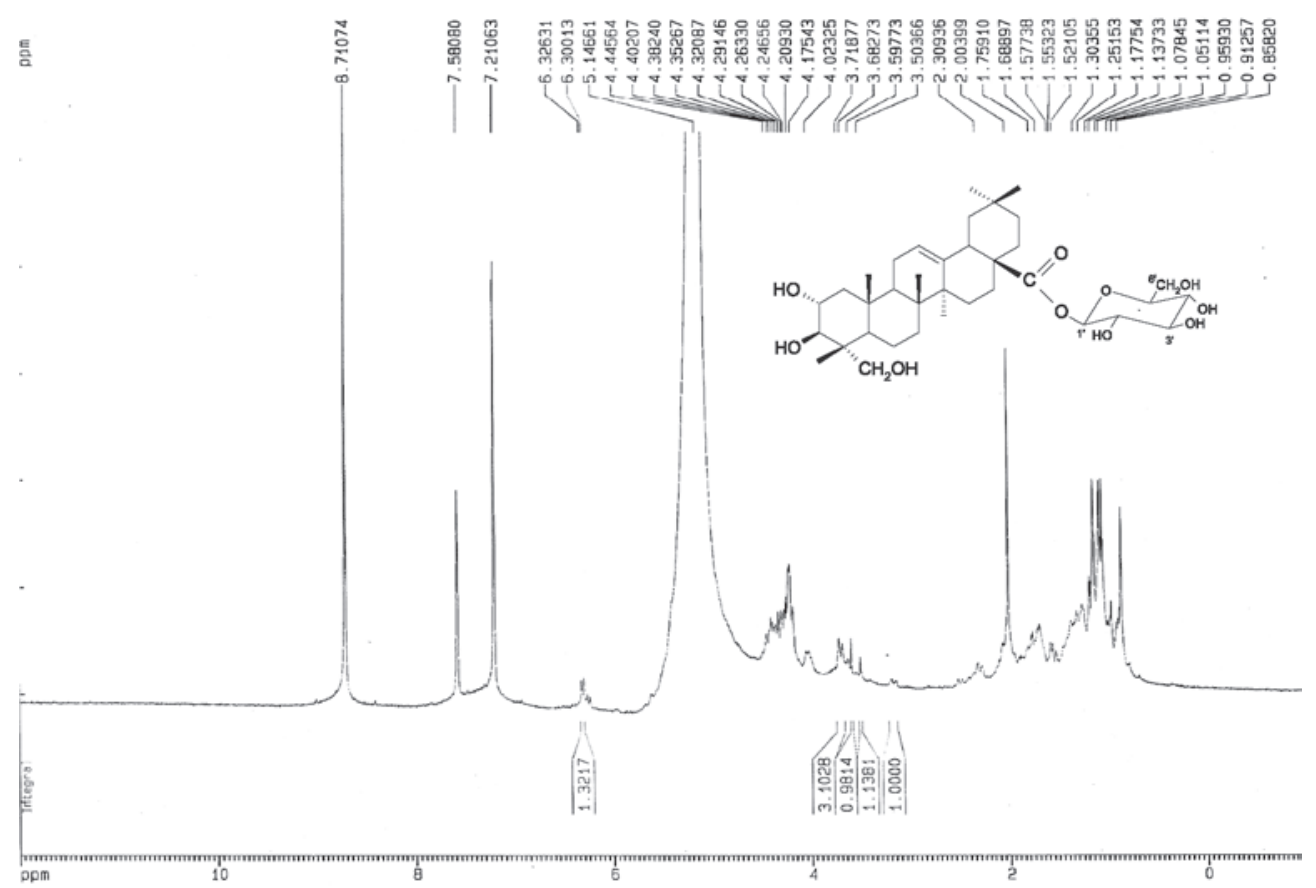

Figure S40. ${ }^{1} \mathrm{H}$ NMR spectrum of compound $18\left(300 \mathrm{MHz}\right.$, Py- $\left.d_{5}\right)$.

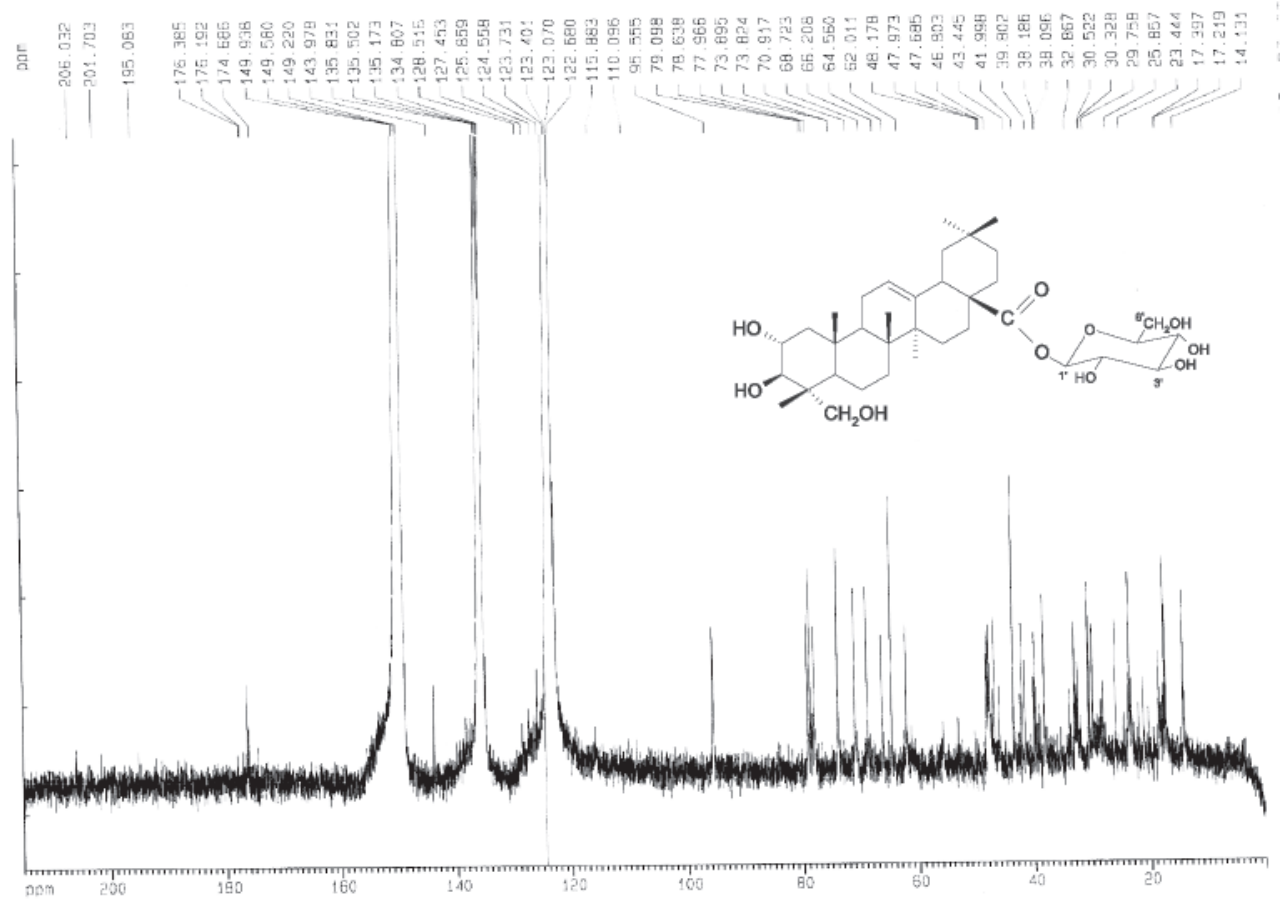

Figure S41. ${ }^{13} \mathrm{C}$ NMR spectrum of compound $18\left(75 \mathrm{MHz}, \mathrm{Py}-d_{5}\right)$. 


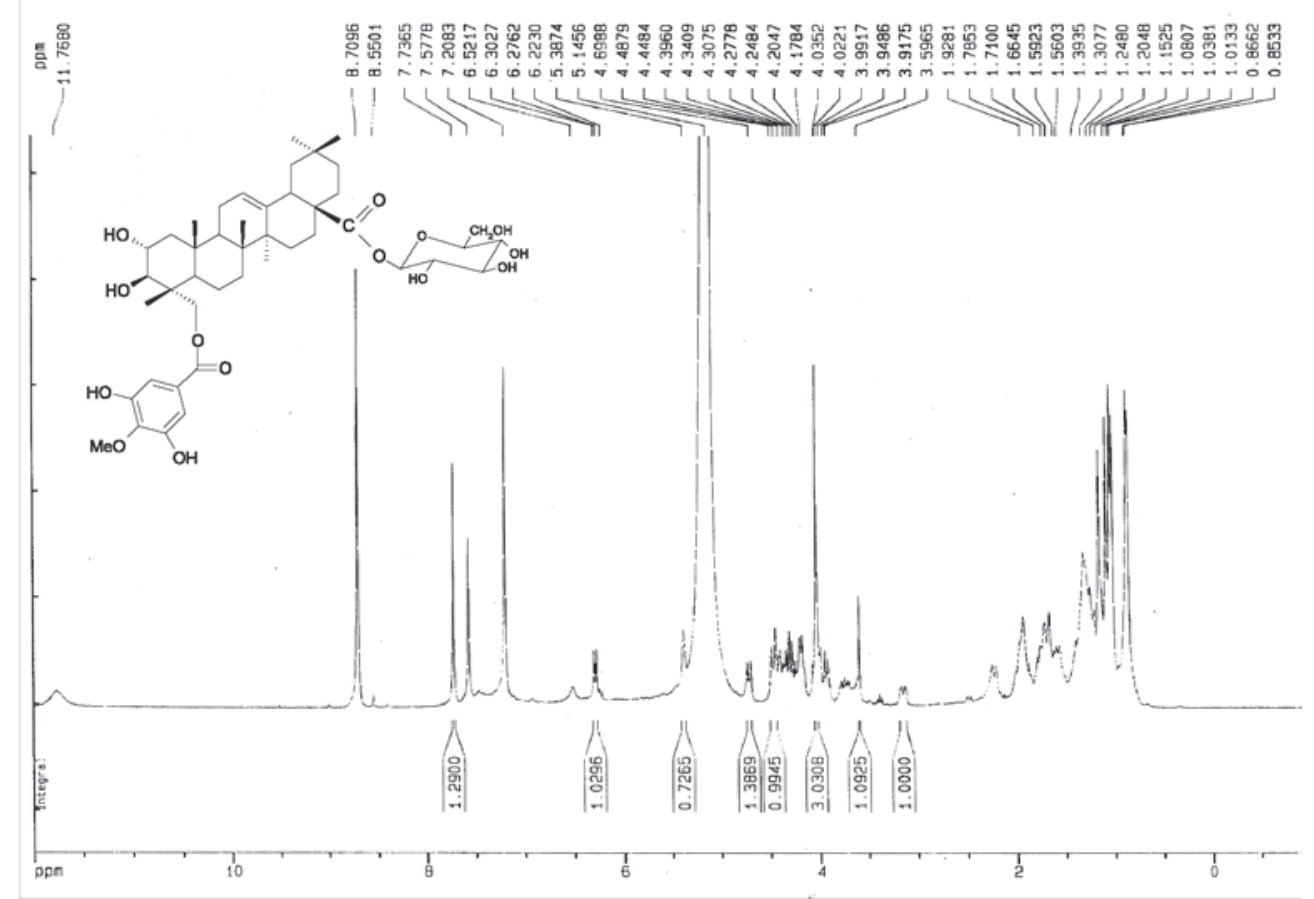

Figure S42. ${ }^{1} \mathrm{H}$ NMR spectrum of compound 19a (300 MHz, Py- $\left.d_{5}\right)$.

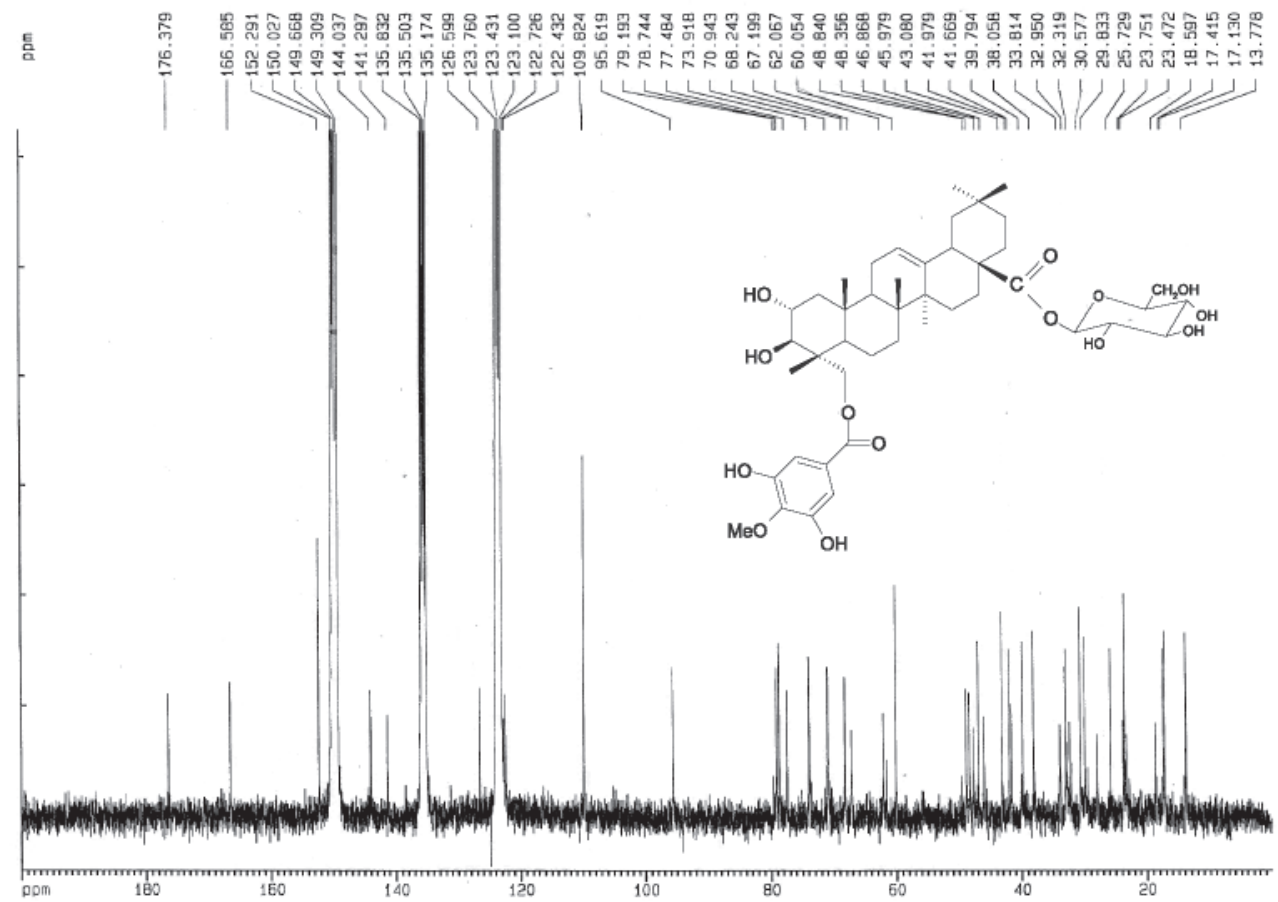

Figure S43. ${ }^{13} \mathrm{C}$ NMR spectrum of compound 19a $\left(75 \mathrm{MHz}, \mathrm{Py}-d_{5}\right)$. 


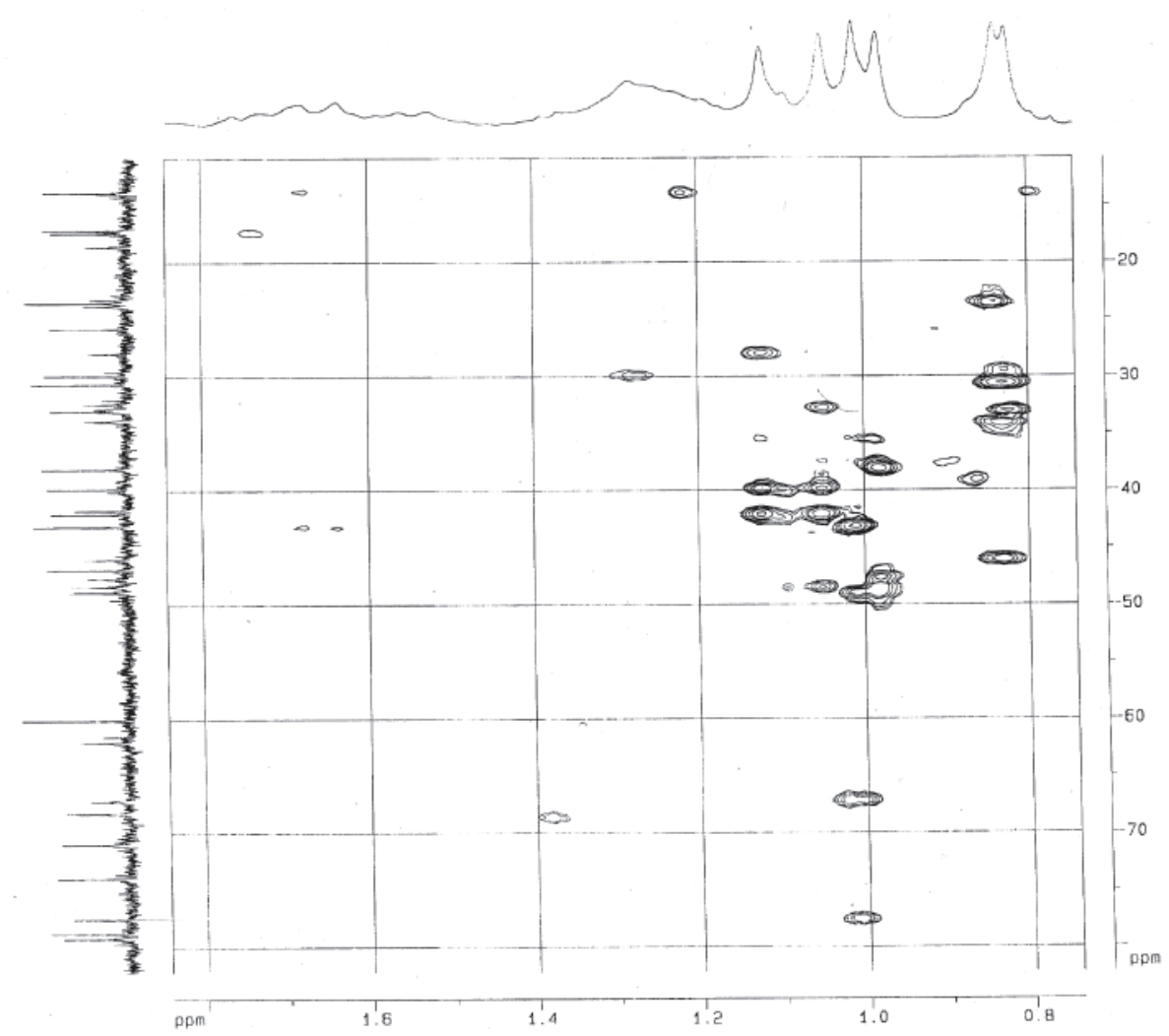

Figure S44. HMBC experiment of compound 19a.

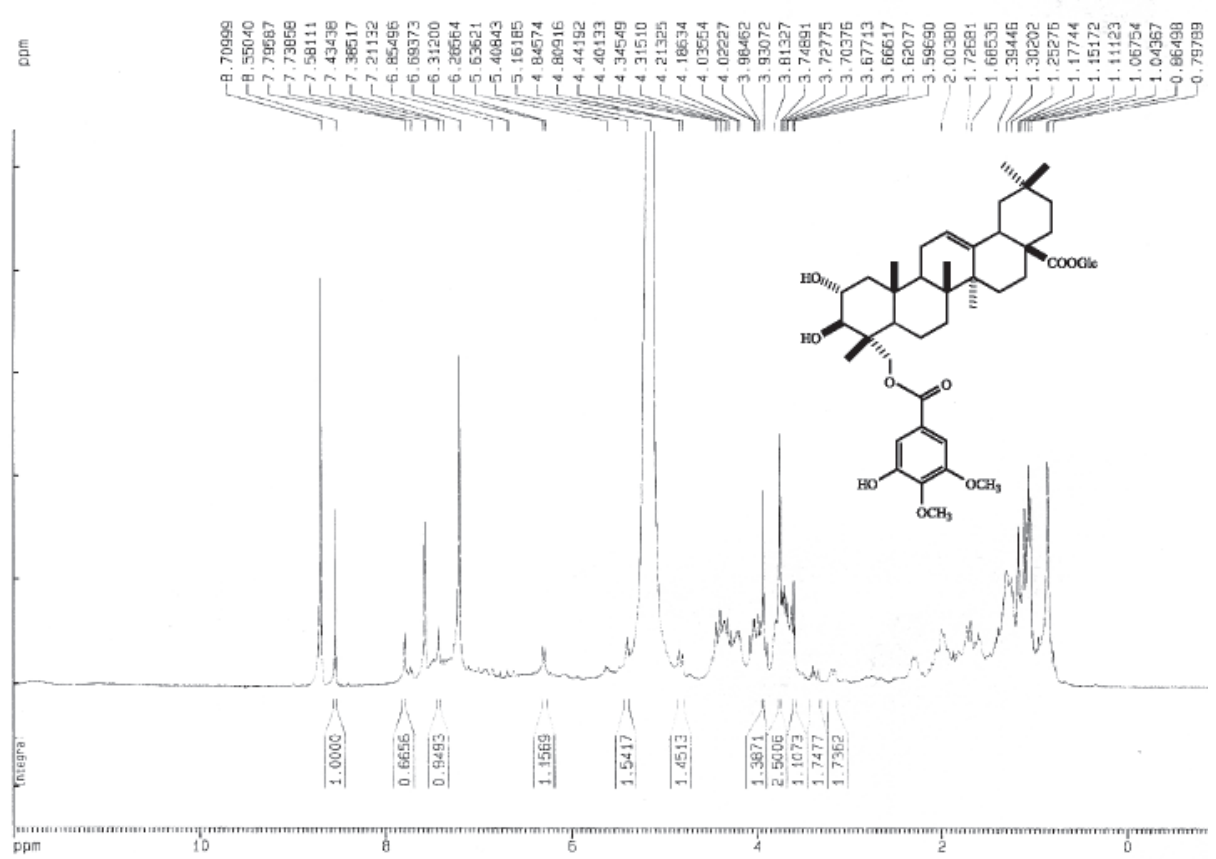

Figure S45. ${ }^{1} \mathrm{H}$ NMR spectrum of compound $19 b$ (300 MHz, Py- $\left.d_{5}\right)$. 


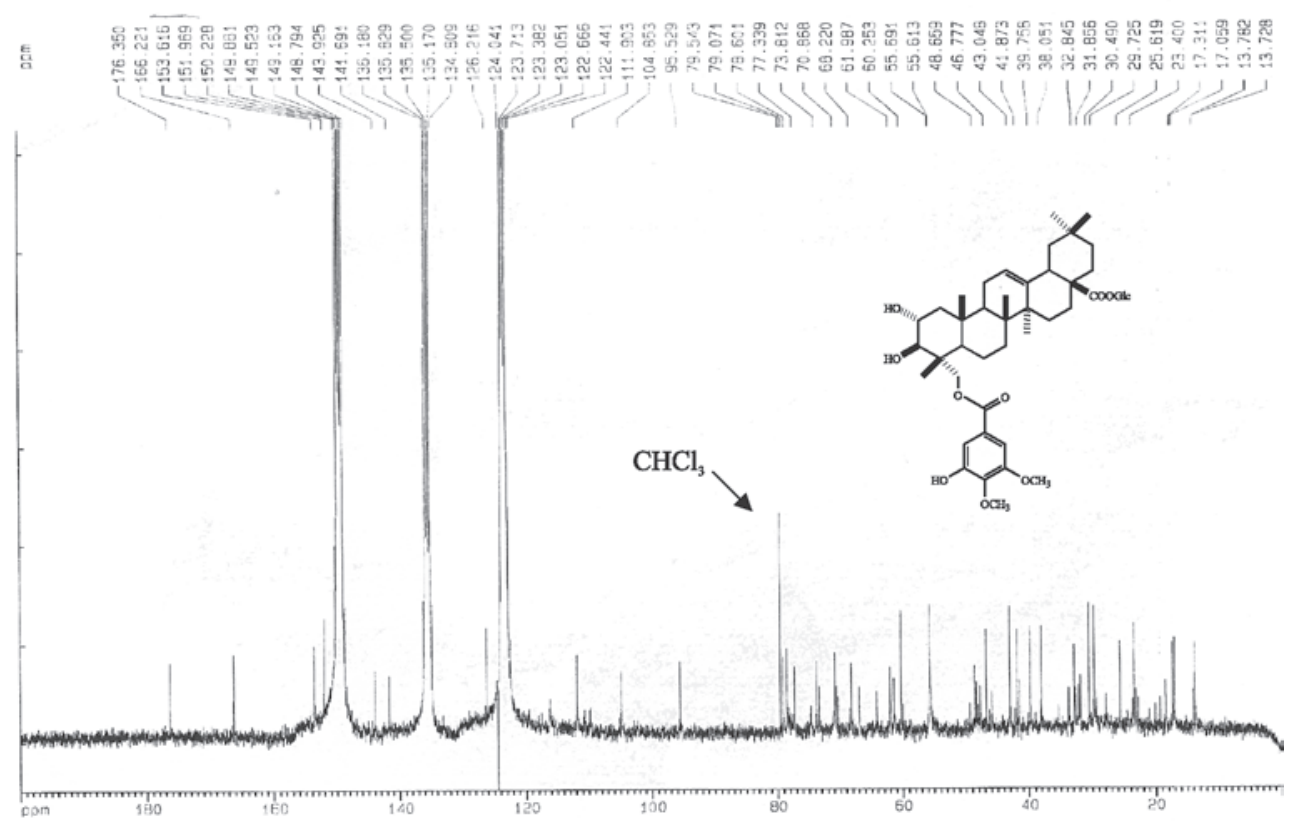

Figure S46. ${ }^{13} \mathrm{C}$ NMR spectrum of compound 19b $\left(75 \mathrm{MHz}, \mathrm{Py}-d_{5}\right)$.

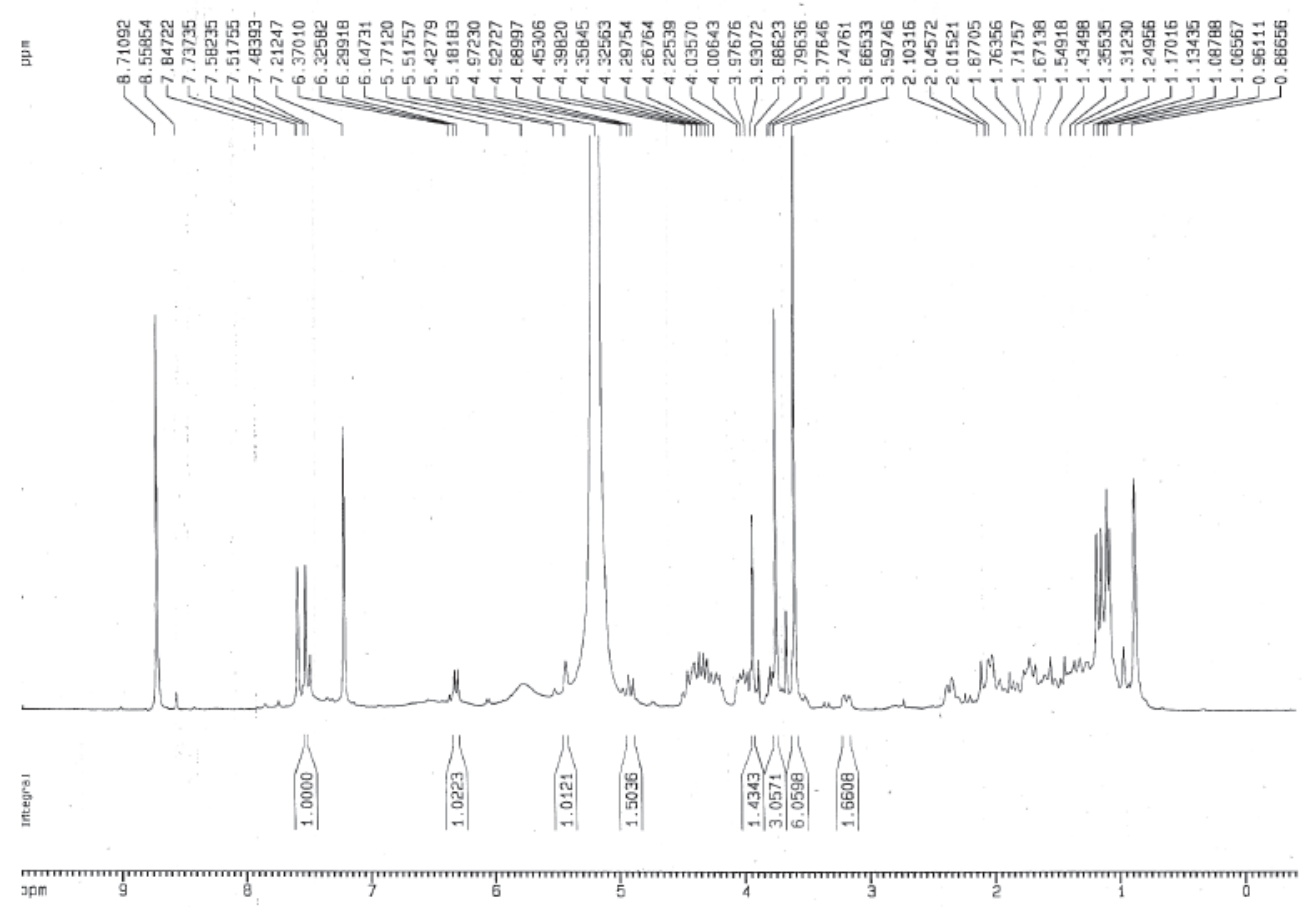

Figure S47. ${ }^{1} \mathrm{H}$ NMR spectrum of compound $19 \mathrm{c}\left(300 \mathrm{MHz}, \mathrm{Py}-d_{5}\right)$. 


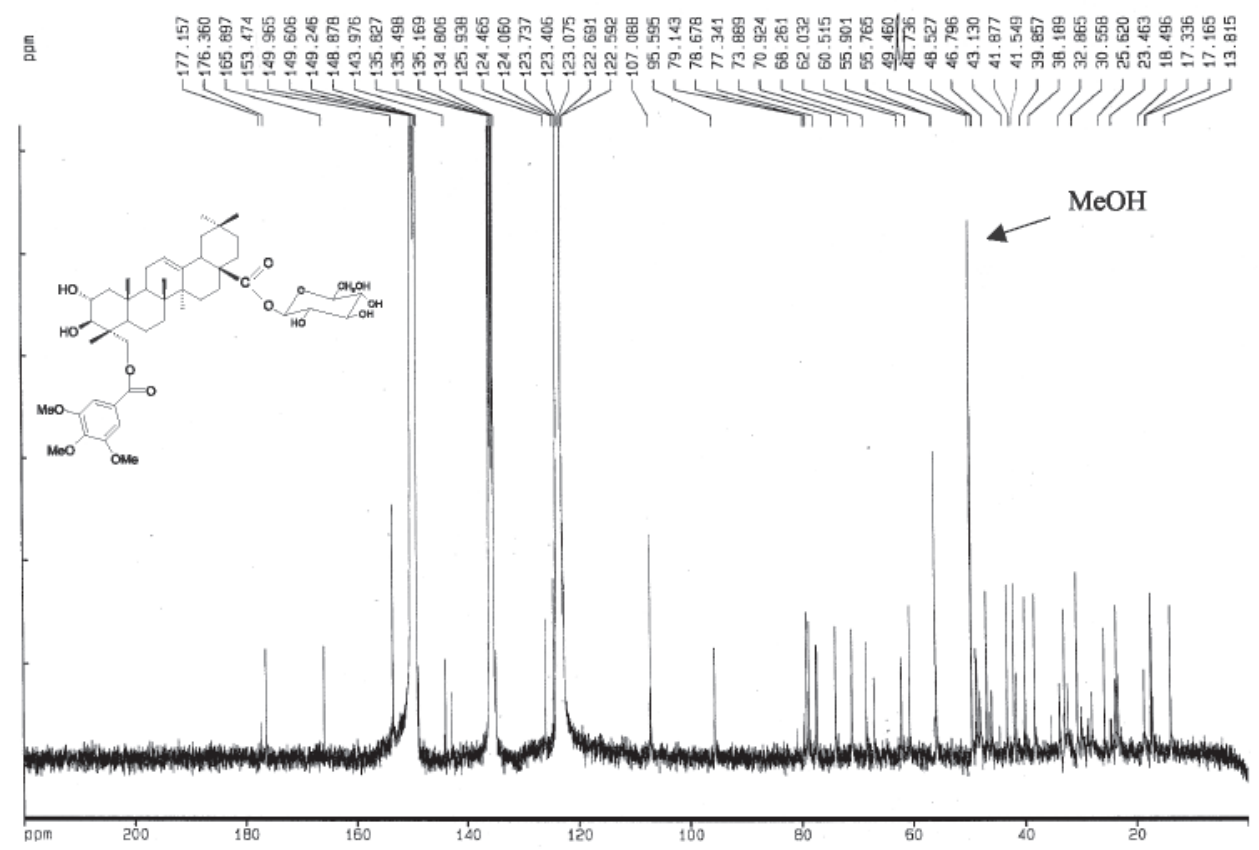

Figure S48. ${ }^{13} \mathrm{C}$ NMR spectrum of compound $19 \mathrm{c}\left(75 \mathrm{MHz}, \mathrm{Py}-d_{5}\right)$.

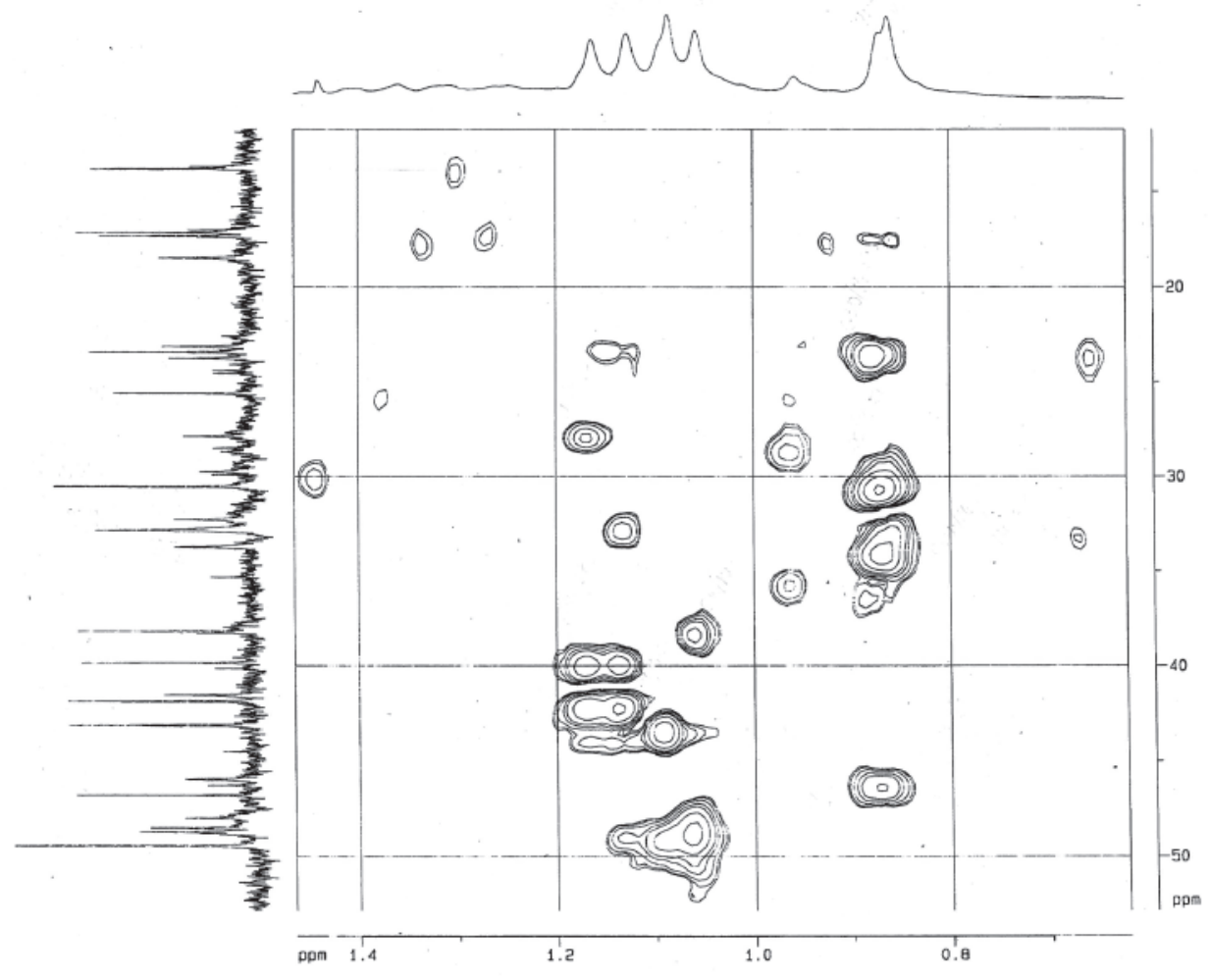

Figure S49. HMBC experiment of compound 19c. 


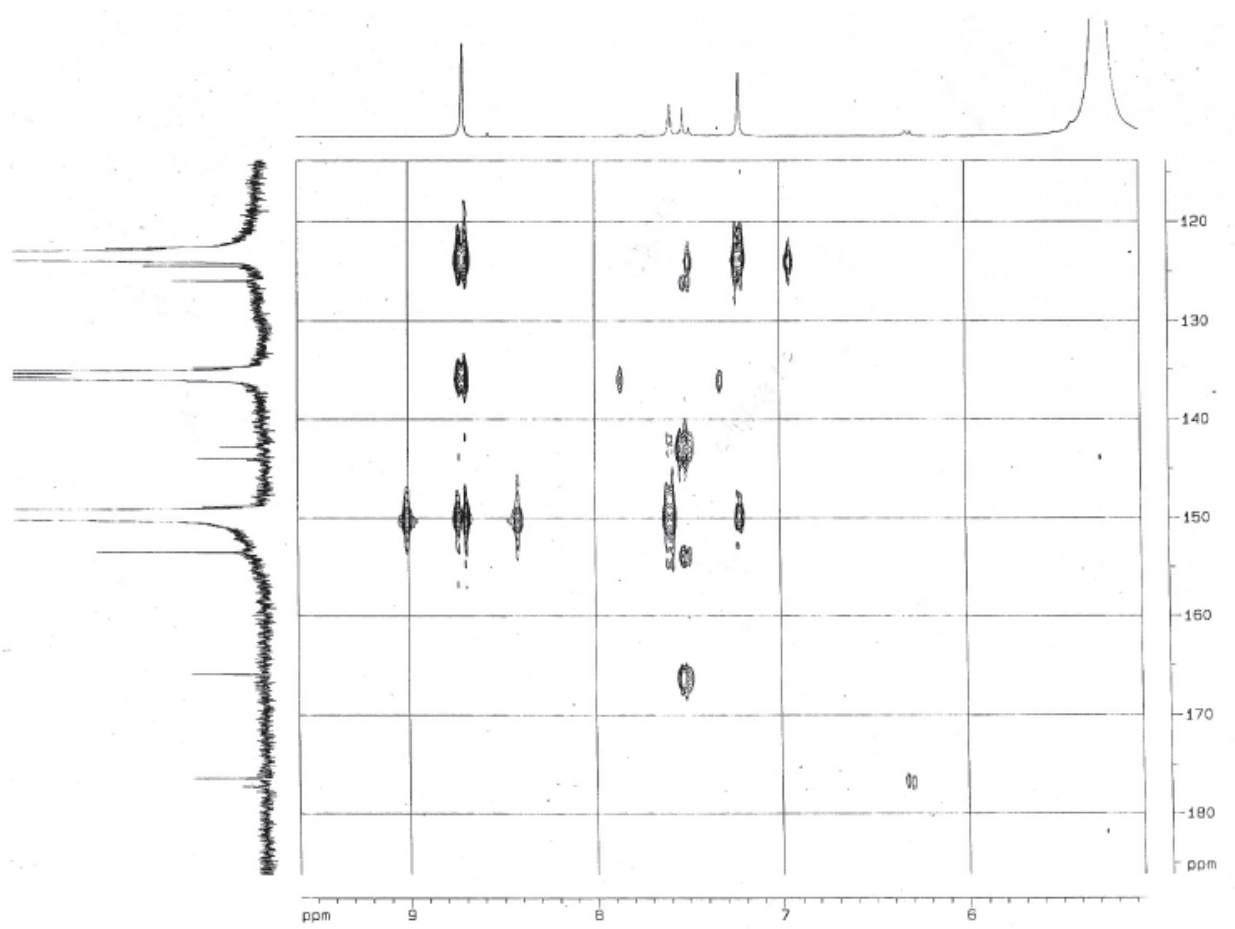

Figure S50. HMBC experiment of compound 19c.

Table S1. ${ }^{13} \mathrm{C}(75 \mathrm{MHz}) \mathrm{NMR}$ spectral data for $\mathbf{1}, \mathbf{2}\left(\mathrm{d}, \mathrm{CDCl}_{3}\right)$ and $\mathbf{3}$ (acetone- $d_{6}$ )

\begin{tabular}{lccc}
\hline C & $\mathbf{1}$ & $\mathbf{2}$ & $\mathbf{3}$ \\
\hline 2 & 79,0 & 79,0 & 79,8 \\
3 & 43,2 & 43,1 & 43,4 \\
4 & 196,0 & 196,0 & 197,1 \\
5 & 164,1 & 164,3 & 165,2 \\
6 & 95,1 & 96,7 & 96,8 \\
7 & 167,8 & 164,8 & 167,8 \\
8 & 94,2 & 95,5 & 95,9 \\
9 & 162,9 & 163,2 & 164,3 \\
10 & 103,1 & 103,1 & 103,0 \\
$1^{\prime}$ & 130,4 & 130,3 & 130,6 \\
2 ' e 6' & 127,7 & 127,7 & 128,9 \\
$3^{\prime}$ e 5' & 114,2 & 114,2 & 116,1 \\
4' & 160,0 & 160,0 & 158,8 \\
OMe & 55,$7 ; 55,4$ & 55,4 & - \\
\hline
\end{tabular}

Table S2. ${ }^{13} \mathrm{C}(75 \mathrm{MHz}) \mathrm{NMR}$ spectral data for $\mathbf{4}, \mathbf{5}$ and $\mathbf{6}\left(\mathrm{d}, \mathrm{CDCl}_{3}\right)$

\begin{tabular}{lccc}
\hline C & $\mathbf{4}$ & $\mathbf{5}$ & $\mathbf{6}$ \\
\hline 2 & 79,8 & 79,9 & 79,7 \\
3 & 44,1 & 44,1 & 44,1 \\
4 & 190,8 & 191,0 & 191,1 \\
5 & 128,7 & 129,4 & 128,8 \\
6 & 110,2 & 110,5 & 110,3 \\
7 & 166,2 & 164,0 & 166,3 \\
8 & 100,9 & 103,4 & 100,9 \\
9 & 163,6 & 162,5 & 163,7 \\
10 & 114,8 & 115,1 & 114,7 \\
1 ' & 130,8 & 130,7 & 130,8 \\
$2^{\prime}$ e 6' & 127,7 & 127,7 & 128,0 \\
3 ' e 5' & 114,2 & 114,2 & 115,7 \\
4, & 160,0 & 160,0 & 156,2 \\
OMe & 55,$7 ; 55,4$ & 55,4 & 55,6 \\
\hline
\end{tabular}


Table S3. ${ }^{13} \mathrm{C}(75 \mathrm{MHz})$ NMR spectral data for $\mathbf{8}\left(\mathrm{d}, \mathrm{CDCl}_{3}\right)$

\begin{tabular}{cccc}
\hline C & $\mathbf{8}$ & $\mathbf{C}$ & $\mathbf{8}$ \\
\hline 2 & 78,0 & 10 & 114,2 \\
3 & 24,6 & 1, & 133,6 \\
4 & 30,1 & 2, & 108,6 \\
5 & 130,2 & 3, & 146,6 \\
6 & 107,9 & 4, & 145,4 \\
7 & 154,8 & 5, & 114,2 \\
8 & 103,5 & 6, & 119,2 \\
9 & 155,9 & OMe-3 & 55,9 \\
\hline
\end{tabular}

Table S4. ${ }^{13} \mathrm{C}(75 \mathrm{MHz})$ NMR spectral data for $\mathbf{9}$ and $\mathbf{1 0}$ (d, acetone- $d_{6}$ )

\begin{tabular}{lcc}
\hline C & $\mathbf{9}$ & $\mathbf{1 0}$ \\
\hline a & 118,6 & 118,4 \\
b & 144,0 & 144,9 \\
b' & 192,0 & 192,4 \\
1 & 128,0 & 126,6 \\
2 e 6 & 130,9 & 131,2 \\
3 e 5 & 114,7 & 116,1 \\
4 & 162,3 & 160,7 \\
$1^{\prime}$ & 113,5 & 114,6 \\
$2^{\prime}$ & 166,1 & 166,4 \\
$3^{\prime}$ & 103,2 & 101,0 \\
$4^{\prime}$ & 167,1 & 166,8 \\
$5^{\prime}$ & 108,6 & 107,4 \\
6, & 132,7 & 132,1 \\
OMe & 55,3 & 55,4 \\
\hline
\end{tabular}

Table S5. ${ }^{13} \mathrm{C}(75 \mathrm{MHz})$ NMR spectral data for $\mathbf{1 3}$ and $\mathbf{1 4}\left(\mathrm{d}, \mathrm{Py}-d_{5}\right)$

\begin{tabular}{lccccc}
\hline C & $\mathbf{1 3}$ & $\mathbf{1 4}$ & $\mathbf{C}$ & $\mathbf{1 3}$ & $\mathbf{1 4}$ \\
\hline 1 & 45,9 & 47,4 & 19 & 81,3 & 80,9 \\
2 & 68,2 & 68,5 & 20 & 34,6 & 35,4 \\
3 & 83,3 & 83,7 & 21 & 27,5 & 28,8 \\
4 & 39,0 & 38,5 & 22 & 32,6 & 32,8 \\
5 & 55,2 & 55,9 & 23 & 28,4 & 29,2 \\
6 & 18,3 & 18,9 & 24 & 16,7 & 16,7 \\
7 & 32,3 & 33,0 & 25 & 16,2 & $17,4^{\mathrm{a}}$ \\
8 & 39,4 & 40,1 & 26 & 16,5 & $17,5^{\mathrm{a}}$ \\
9 & 47,7 & 48,3 & 27 & 24,3 & 24,7 \\
10 & 38,1 & 39,7 & 28 & 180,9 & 177,2 \\
11 & 23,5 & 24,1 & 29 & 27,9 & 28,6 \\
12 & 123,9 & 123,5 & 30 & 24,6 & 24,5 \\
13 & 143,4 & 144,2 & 1 & - & 95,7 \\
14 & 41,2 & 42,0 & 2 & - & 74,0 \\
15 & 28,1 & 28,9 & 3 & - & 78,7 \\
16 & 29,1 & 27,8 & 4 & - & 70,9 \\
17 & 44,9 & 46,3 & 5 & - & 79,1 \\
18 & 43,7 & 44,5 & 6 & - & 62,0 \\
\hline
\end{tabular}

Table S6. ${ }^{13} \mathrm{C}(75 \mathrm{MHz})$ NMR spectral data for $\mathbf{1 5}$ and $\mathbf{1 6}\left(\mathrm{d}, \mathrm{Py}-d_{5}\right)$

\begin{tabular}{lccccc}
\hline C & $\mathbf{1 5}$ & $\mathbf{1 6}$ & $\mathbf{C}$ & $\mathbf{1 5}$ & $\mathbf{1 6}$ \\
\hline 1 & 47,3 & 47,2 & 19 & 81,0 & 80,7 \\
2 & 68,8 & 68,7 & 20 & 35,6 & 35,2 \\
3 & 78,0 & 77,9 & 21 & 29,0 & 28,7 \\
4 & 43,5 & 43,4 & 22 & 32,8 & 32,7 \\
5 & 47,8 & 48,2 & 23 & 66,2 & 66,2 \\
6 & 18,5 & 18,5 & 24 & 14,1 & 14,0 \\
7 & 33,5 & 32,6 & 25 & $17,5^{\text {c }}$ & $17,4^{\text {c }}$ \\
8 & 39,9 & 40,0 & 26 & $17,1^{\text {c }}$ & $16,9^{\text {c }}$ \\
9 & 48,3 & 47,7 & 27 & 24,7 & 24,4 \\
10 & 38,4 & 38,3 & 28 & 180,9 & 177,1 \\
11 & 24,2 & 24,0 & 29 & 28,7 & 28,5 \\
12 & 123,3 & 123,4 & 30 & 24,7 & 24,6 \\
13 & 144,7 & 144,0 & 1 & - & 95,6 \\
14 & 42,1 & 41,9 & 2 & - & 73,8 \\
15 & 28,2 & 27,7 & 3 & - & 78,6 \\
16 & 29,0 & 28,7 & 4 & - & 70,8 \\
17 & 45,9 & 46,2 & 5 & - & 79,0 \\
18 & 44,6 & 44,3 & $6^{\prime}$ & - & 61,9 \\
\hline
\end{tabular}

Table S7. ${ }^{13} \mathrm{C}(75 \mathrm{MHz})$ NMR spectral data for $\mathbf{1 7}$ and $\mathbf{1 8}\left(\mathrm{d}, \mathrm{Py}-d_{5}\right)$

\begin{tabular}{lccccc}
\hline $\mathbf{C}$ & $\mathbf{1 7}$ & $\mathbf{1 8}$ & $\mathbf{C}$ & $\mathbf{1 7}$ & $\mathbf{1 8}$ \\
\hline 1 & 47,5 & 47,5 & 19 & 46,3 & 45,9 \\
2 & 68,7 & 68,7 & 20 & 30,8 & 30,5 \\
3 & 78,0 & 78,0 & 21 & 34,1 & 33,7 \\
4 & 43,5 & 43,4 & 22 & 32,7 & 32,3 \\
5 & 48,0 & 48,0 & 23 & 66,3 & 66,2 \\
6 & 18,4 & 18,3 & 24 & 14,2 & 14,1 \\
7 & 33,1 & 32,7 & 25 & 17,4 & 17,6 \\
8 & 39,7 & 39,8 & 26 & 17,2 & 17,4 \\
9 & 47,7 & 47,7 & 27 & 26,0 & 25,9 \\
10 & 38,2 & 38,2 & 28 & 180,3 & 176,4 \\
11 & 23,8 & 23,6 & 29 & 33,1 & 32,9 \\
12 & 122,3 & 123,9 & 30 & 23,6 & 23,4 \\
13 & 144,8 & 144,0 & 1 & - & 95,6 \\
14 & 42,1 & 42,0 & 2 & - & 73,8 \\
15 & 28,1 & 28,0 & 3, & - & 78,6 \\
16 & 23,8 & 23,2 & 4 & - & 70,9 \\
17 & 46,5 & 46,8 & 5, & - & 79,1 \\
18 & 41,8 & 41,5 & 6 & - & 62,0 \\
\hline
\end{tabular}

